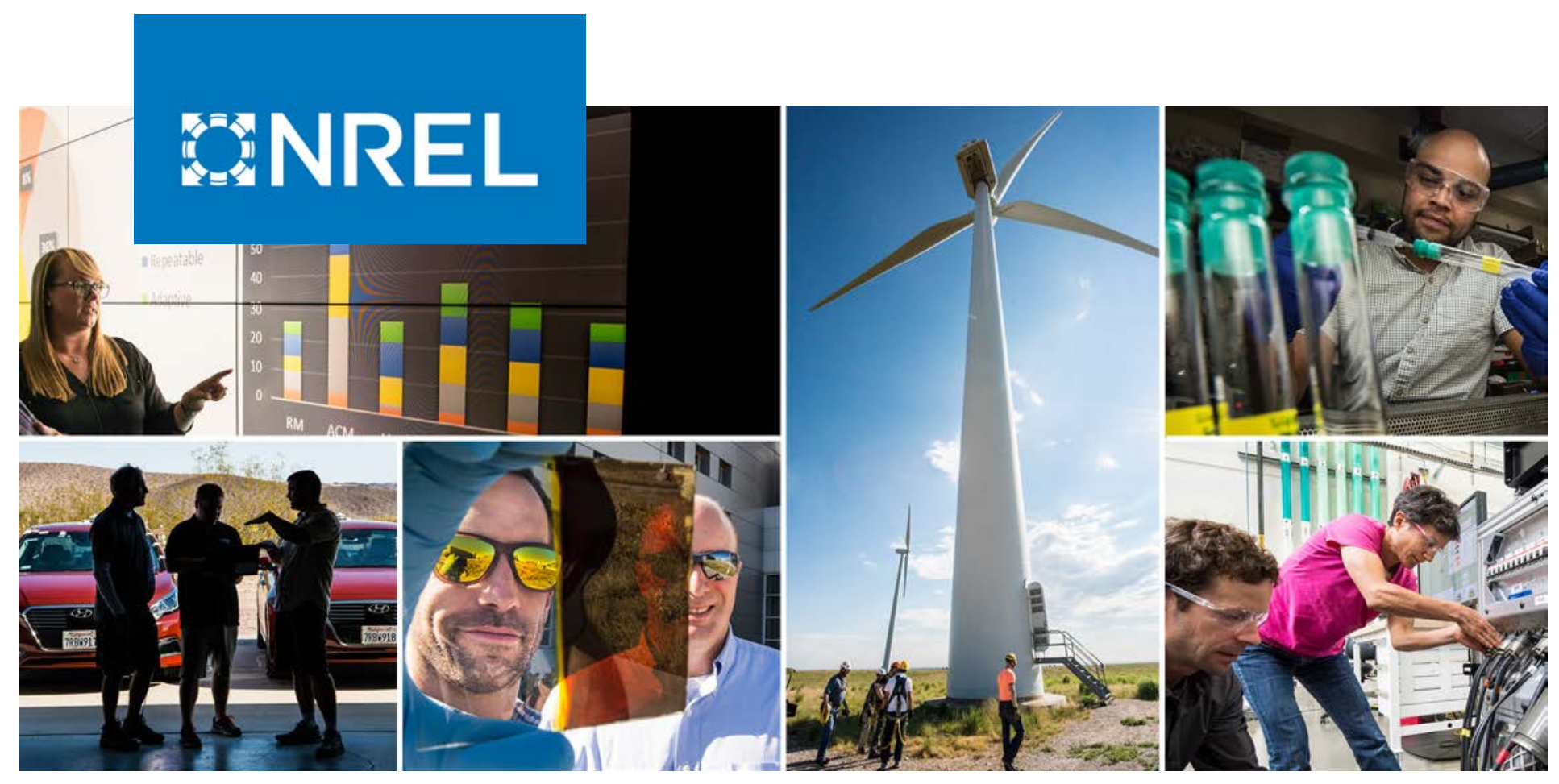

\title{
Phase I Microgrid Cost Study: Data Collection and Analysis of Microgrid Costs in the United States
}

\author{
Julieta Giraldez, ${ }^{1}$ Francisco Flores-Espino, ${ }^{1}$ \\ Sara MacAlpine, ${ }^{2}$ and Peter Asmus ${ }^{3}$ \\ ${ }^{1}$ National Renewable Energy Laboratory \\ 2 Juwi Americas \\ ${ }^{3}$ Navigant Consulting
}

NREL is a national laboratory of the U.S. Department of Energy Office of Energy Efficiency \& Renewable Energy

Operated by the Alliance for Sustainable Energy, LLC

This report is available at no cost from the National Renewable Energy Laboratory (NREL) at www.nrel.gov/publications.

\section{Technical Report}

NREL/TP-5D00-67821

October 2018 


\title{
GNREL
}

\section{Phase I Microgrid Cost Study: Data Collection and Analysis of Microgrid Costs in the United States}

\author{
Julieta Giraldez, ${ }^{1}$ Francisco Flores-Espino, ${ }^{1}$ \\ Sara MacAlpine, ${ }^{2}$ and Peter Asmus ${ }^{3}$ \\ ${ }^{1}$ National Renewable Energy Laboratory \\ 2 Juwi Americas \\ ${ }^{3}$ Navigant Consulting
}

\section{Suggested Citation}

Giraldez, Julieta, Francisco Flores-Espino, Sara MacAlpine, and Peter Asmus. 2018. Phase I Microgrid Cost Study: Data Collection and Analysis of Microgrid Costs in the United States. Golden, CO: National Renewable Energy Laboratory.

NREL/TP-5D00-67821. https://www.nrel.gov/docs/fy19osti/67821.pdf.

NREL is a national laboratory of the U.S. Department of Energy Office of Energy Efficiency \& Renewable Energy Operated by the Alliance for Sustainable Energy, LLC

This report is available at no cost from the National Renewable Energy Laboratory (NREL) at www.nrel.gov/publications.

Contract No. DE-AC36-08GO28308
Technical Report NREL/TP-5D00-67821

October 2018

National Renewable Energy Laboratory 15013 Denver West Parkway Golden, CO 80401

303-275-3000 • www.nrel.gov 


\section{NOTICE}

This work was authored in part by the National Renewable Energy Laboratory, operated by Alliance for Sustainable Energy, LLC, for the U.S. Department of Energy (DOE) under Contract No. DE-AC36-08G028308. Funding provided by U.S. Department of Energy, Office of Electricity Delivery and Energy Reliability. The views expressed herein do not necessarily represent the views of the DOE or the U.S. Government.

This report is available at no cost from the National Renewable Energy Laboratory (NREL) at www.nrel.gov/publications.

U.S. Department of Energy (DOE) reports produced after 1991 and a growing number of pre-1991 documents are available free via www.OSTI.gov.

Cover Photos by Dennis Schroeder: (clockwise, left to right) NREL 51934, NREL 45897, NREL 42160, NREL 45891, NREL 48097, NREL 46526.

NREL prints on paper that contains recycled content. 


\section{List of Acronyms}

CHP

DER

DOE

GTM

IQR

NREL

PV
Combined heat and power

Distributed energy resources

U.S. Department of Energy

Greentech Media

Interquartile range

National Renewable Energy Laboratory

Photovoltaic 


\section{Executive Summary}

Microgrids are gaining in popularity because of their adaptability and flexible expandability, the need for increased electricity reliability, the increased affordability of distributed energy resources (DERs) and grid intelligence devices, goals to reduce greenhouse gas emissions, and other factors. The U.S. Department of Energy commissioned the National Renewable Energy Laboratory to complete a microgrid cost study and develop a microgrid cost model. The goal is to elucidate the variables that have the highest impact on costs as well as potential areas for cost reduction. This study consists of two phases. Phase I comprises the collection and analysis of data from microgrid projects built in the United States and is the subject of this report. In Phase II, NREL will assess current barriers facing the industry and identify potential solutions with help from industry representatives.

Microgrid components are classified as follows in the form used to collect cost data from industry representatives for NREL's microgrid cost database:

- DERs: diesel, natural gas, combined heat and power (CHP), biofuel, solar photovoltaic (PV), wind, and fuel cell and energy storage

- Microgrid controller: primary, secondary, or tertiary

- Additional infrastructure: distribution system infrastructure, information technology communications upgrades, metering, etc.

- Soft costs: engineering, construction, commissioning, and regulatory.

The purposes of Phase I are to better determine the contribution of individual components to total project size and to identify cost differences in projects within the same market segment. Phase II will use the results of Phase I to have an initial indication of the costs that might be driving the cost of development the most.

Cost information for 80 microgrids was collected through a survey by directly contacting industry members and microgrid owners and from publicly available information. The cost data reflect a wide range of variability and regional distribution in microgrid design in the United States, in particular: (1) more than 50\% of operational microgrids are located in states in the East Coast and West Coast, and (2) regional hot spots include California, the Northeast, and Alaska. In terms of DER mix, the microgrid study database reflects the market trend dominated by CHP and natural gas, followed by traditional diesel generation. It also shows that PV and storage are being installed in microgrids in the United States. The main characteristics of each market segment by DER type are summarized as follows:

- The campus/institutional segment is dominated by new CHP generation capacity.

- Communities are leveraging existing standby diesel and natural gas generators into new microgrid projects.

- The commercial projects in the microgrid database show that the largest DER technology used is existing diesel generators, and the new technologies being installed in microgrids are energy storage, CHP, and solar PV. 
- For utility microgrids, existing PV projects are in the form of DERs with the highest capacity, followed by new natural gas, diesel generators, and energy storage. Note that this group has only five entries in the database, and one of them integrates an existing, large PV project under a power purchase agreement.

- In remote microgrids, the trend is in increasing the percentage share of renewable energy along with new energy storage capacity. Existing wind, diesel, and new storage are the most prevalent forms of DERs.

Other conclusions drawn from the data classification and analysis of the microgrid database are listed as follows:

- Often, microgrid projects are built in phases and leverage existing DER projects built throughout time. The percentage of existing generation varies widely among market segments, ranging from 3\% for commercial/industrial microgrids to $68 \%$ for utility microgrids. The weighted average of existing generation per market segment of the projects represented in the database is $10 \%$.

- Regarding the types of existing DER assets that are integrated into microgrids, campus microgrids primarily leverage natural gas generators and renewable energy, whereas the commercial and community segments leverage legacy standby diesel generators. Data for the utility segment were skewed by one project that has $26.5 \mathrm{MW}$ of solar PV capacity.

- To analyze the total costs of microgrids, the projects in the database were classified according to (1) market segment and (2) microgrid complexity level. Ranging from Level 1 to Level 6, with Level 1 being the least complex, complexity is described based on the number of DER assets, amount of renewable energy relative capacity, energy storage, control architecture, and enterprise-level capabilities.

- By market segment, the main conclusions are:

o The analysis of total microgrid costs per megawatt shows that the community microgrid market has the lowest mean, at \$2.1 million/MW of DERs installed; followed by the utility and campus markets, which have mean costs of $\$ 2.6$ million/MW and \$3.3 million/MW, respectively. Finally, the commercial market has the highest average cost, at $\$ 4$ million/MW. The interquartile ranges (IQR) and means are presented in Table ES- 1.

Table ES-1. Market Segment IQR and Mean Normalized Microgrid Costs in \$/MW

\begin{tabular}{l|l|l} 
Segment & IQR & Mean \\
\hline Campus/Institutional & $\$ 4,936,109-\$ 2,472,849$ & $\$ 3,338,666$ \\
\hline Commercial/Industrial & $\$ 5,353,825-\$ 3,399,162$ & $\$ 4,079,428$ \\
\hline Community & $\$ 3,334,788-\$ 1,430,805$ & $\$ 2,119,908$ \\
\hline Utility & $\$ 3,219,804-\$ 2,323,800$ & $\$ 2,548,080$
\end{tabular}

o Figure ES-1 shows the normalized costs of projects as a function of the capacity of the project. The results seem to indicate that there is some economy of scale for projects between $2 \mathrm{MW}$ and $10 \mathrm{MW}$ of installed generation capacity. The commercial microgrid projects in the database are all less than $3 \mathrm{MW}$, with the 
exception of one larger project, and they drive the higher costs reported for this market segment

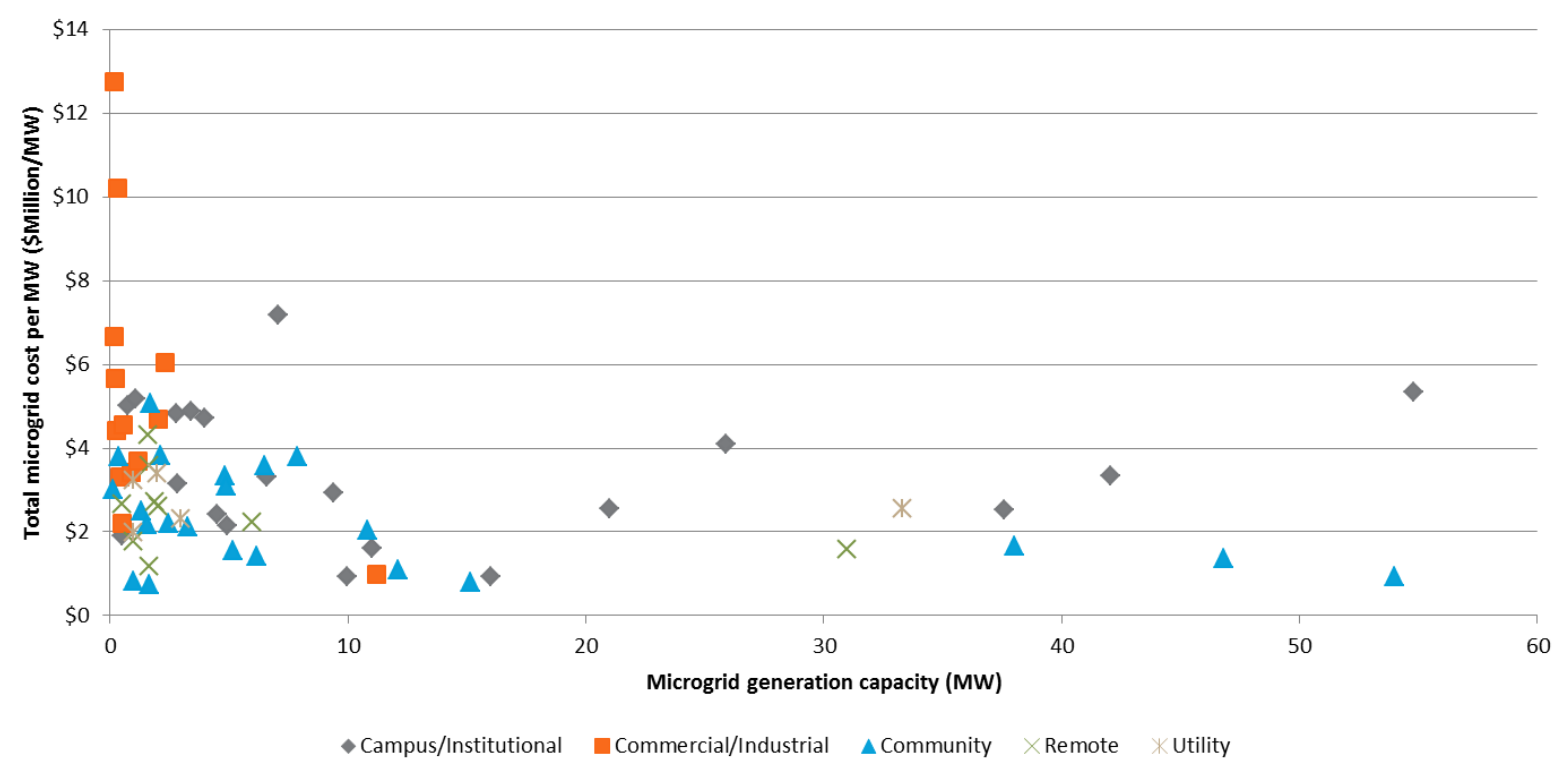

Figure ES-1. Normalized microgrid costs by size of the project in megawatts and by market segment

o Regarding the breakdown of component costs with respect to total system costs per megawatt, conventional and renewable generation represent the largest percentage in most segments. Conventional generation accounts for $76 \%$ of the total cost per megawatt in microgrids in the campus/institutional segment and $54 \%$ in the community segment. In commercial/industrial and utility microgrids, soft costs (43\% and $24 \%$, respectively) represent a significant portion of the total costs per megawatt. Finally, energy storage contributes significantly to the total cost of commercial and community microgrids, with percentages of $25 \%$ and $15 \%$ of the total costs per megawatt, respectively.

- By complexity level (increasing complexity from Level 1 to Level 4), the main conclusions are:

o Level 1 projects have the lowest mean, at $\$ 2$ million/MW (Table ES-2). The normalized costs in terms of IQR values and mean are very similar for levels 2 and 3, with average costs in the range from $\$ 3.5$ million/MW to $\$ 3.1$ million/MW. The IQR range and mean increase for Level 4, which has a mean of \$4.4 million/MW. 
Table ES-2. IQR and Mean Normalized Microgrid Costs in \$/MW by Levels of Microgrid Complexity

\begin{tabular}{lll}
\hline Level & IQR & Mean \\
\hline Level 1 & $\$ 2,856,775-\$ 931,485$ & $\$ 1,981,800$ \\
Level 2 & $\$ 4,870,648-\$ 2,178,975$ & $\$ 3,462,685$ \\
Level 3 & $\$ 3,820,975-\$ 1,940,507$ & $\$ 3,053,979$ \\
Level 4 & $\$ 5,142,510-\$ 3,727,321$ & $\$ 4,436,563$ \\
\hline
\end{tabular}

o Conventional generation costs represent the largest share of component costs in all levels, reaching $88 \%$ for Level 2 . Level 1 microgrids have a considerably higher portion of total cost per megawatt assigned to the controls and additional infrastructure components. This could be because microgrids at this level are represented by projects that consist of networked diesel generators, in which a larger portion of the project cost is commonly directed to retrofitting legacy generators (operating with an automatic transfer switch) to enable parallel operation. Level 3 microgrids show that renewable energy and storage costs become the most prominent contributors to the total costs of the projects. Finally, Level 4 microgrids show a considerable increase in soft costs.

- Microgrid controller costs reported in the database per megawatt range from \$6,200/MW to $\$ 470,000 / \mathrm{MW}$, with a mean of $\$ 155,000 / \mathrm{MW}$.

- The soft cost category exhibits a high degree of variability, ranging from $1 \%$ to $75 \%$. We believe this could be because some of the costs considered in this category might have been reported in other categories. For example, construction and engineering costs related to new generation plants might be reported as installed generation costs in some projects and as soft costs in others.

A series of hypotheses are made from the non-DER cost components collected in the microgrid database:

- Controller cost as a percentage of total microgrid costs-both by market segment and complexity level—show a decline generally as microgrids grow in size, suggesting that the fixed component of controller costs might be significant.

- $\quad$ Soft costs are higher for smaller projects (less than $1 \mathrm{MW}$ ).

- Community and utility market segments show the highest costs associated with the additional infrastructure cost category, and this could be because such market segments tend to involve islanding at the medium voltage level (when compared to smaller commercial microgrid projects), which involve more investments in additional infrastructure, such as medium-voltage switchgear and supervisory control and data acquisition systems. 


\section{Table of Contents}

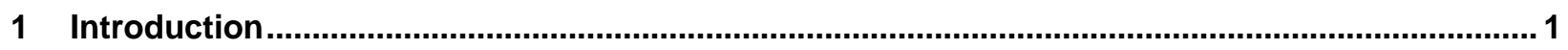

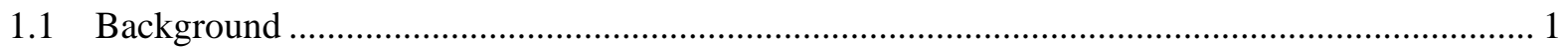

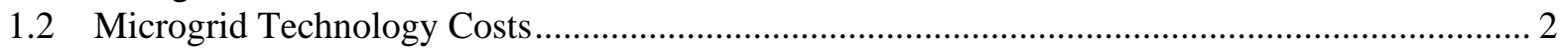

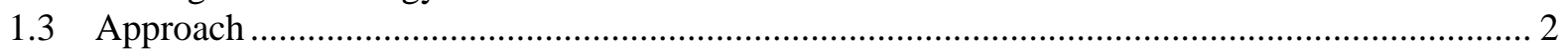

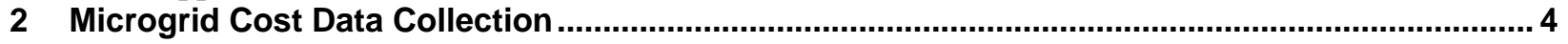

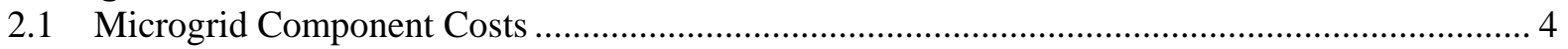

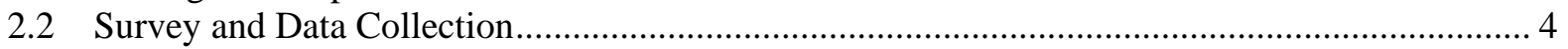

2.3 Microgrid Cost Study Database …........................................................................... 5

2.3.1 Microgrid Cost Database by Geography .................................................................. 5

2.3.2 Microgrid Cost Database by DER Capacity per Market Segment .................................. 6

2.3.3 Microgrid Cost Database by Number of Projects per Market Segment .......................... 8

2.3.4 Microgrid Cost Database by DER Technology Mix ................................................... 10

2.3.5 Existing and New DER Technology by Market Segment............................................ 11

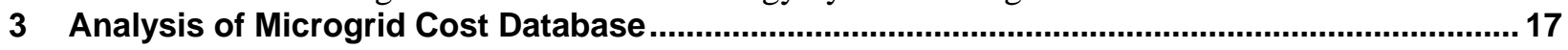

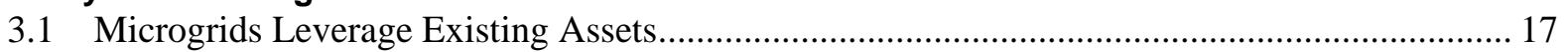

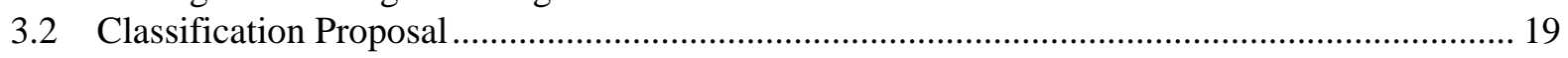

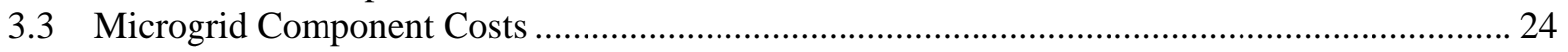

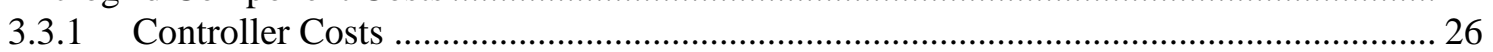

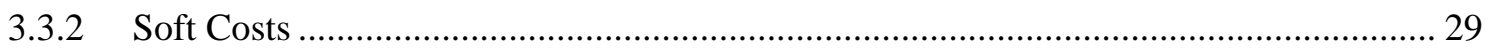

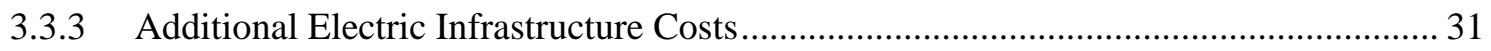

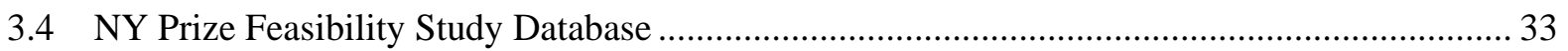

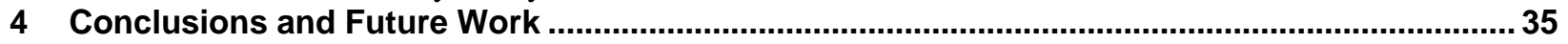

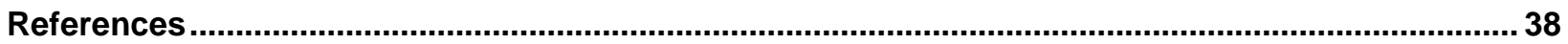

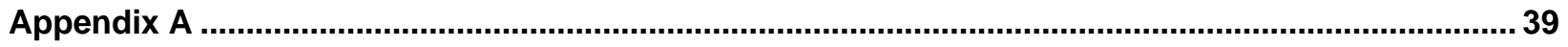

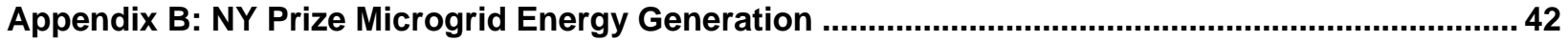

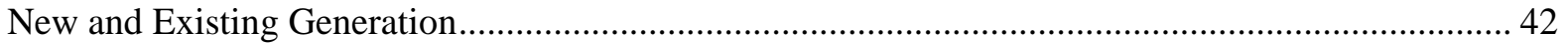

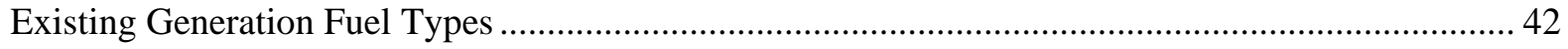

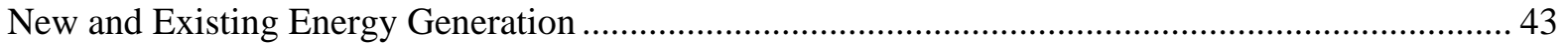

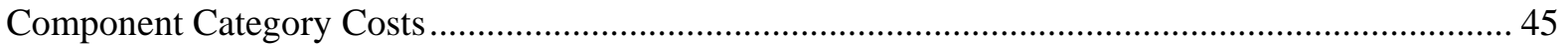

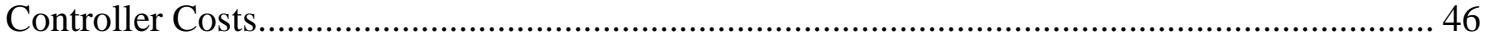

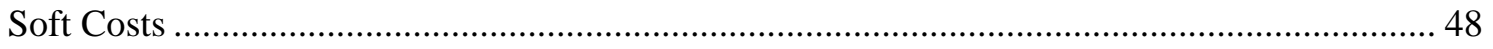

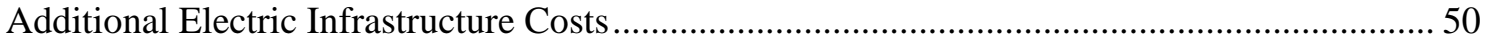




\section{List of Figures}

Figure ES-1. Normalized microgrid costs by size of the project in megawatts and by market segment.... vii Figure 1. U.S. map of NREL microgrid project database locations per market segment ............................ 6

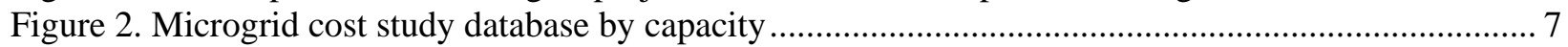

Figure 3. Navigant Research and GTM microgrid tracker projects by capacity........................................ 8

Figure 4. Microgrid cost study database by number of projects .............................................................. 9

Figure 5. Navigant Research and GTM's microgrid trackers by total number of projects ........................ 10

Figure 6. Microgrid cost study database by DER technology ................................................................. 11

Figure 7. New and existing distributed generation by technology for campus and institutional microgrids

Figure 8. New and existing distributed generation by technology for community microgrids.................. 13

Figure 9. New and existing distributed generation by technology for commercial and industrial microgrids

Figure 11. New and existing distributed generation by technology for remote microgrids........................ 16

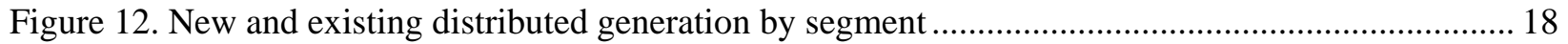

Figure 13. Existing distributed generation in commercial microgrid projects by technology .................... 19

Figure 14. Box plot of normalized microgrid costs by market segment .............................................. 20

Figure 15. Normalized microgrid costs by size of the projects in megawatts and market segment ............ 21

Figure 16. S\&C Electric's categorization based on microgrid complexity.............................................. 22

Figure 17. Box plot of normalized microgrid costs by microgrid levels ................................................ 23

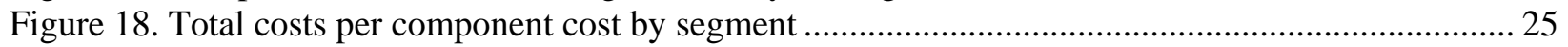

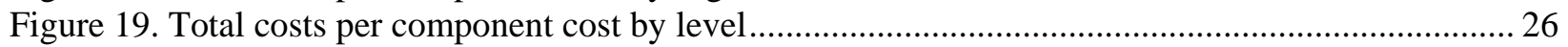

Figure 20. Controller cost data as a percentage of total microgrid costs per megawatt..............................2

Figure 21. Microgrid controller costs as a percentage of total project costs............................................ 28

Figure 22. Microgrid controller costs as a percentage of total microgrid costs .........................................29

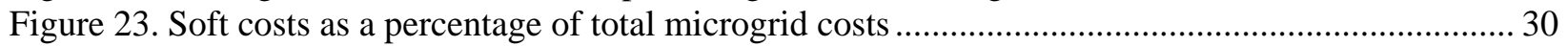

Figure 24. Soft cost subcategories as a percentage of total microgrid costs ........................................... 30

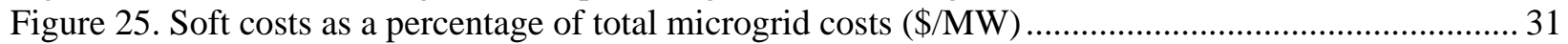

Figure 26. Additional electrical infrastructure costs as a percentage of total microgrid costs.................... 32

Figure 27. Additional electrical infrastructure costs per megawatt of capacity (\$thousand/MW) ............. 33

Figure A-1. New and existing generation for Stage 1 (left) and Stage 2 (right) of the NY Prize microgrids

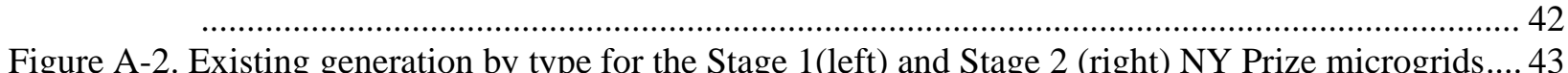

Figure A-3. New and existing generation for the Stage 1 (top) and Stage 2 (bottom) NY Prize microgrids

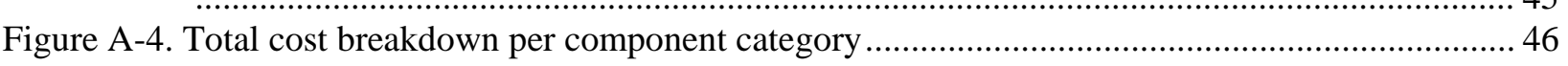

Figure A-5. Controller cost data as a percentage of total microgrid costs as dollars per megawatt of microgrid capacity (left) and per megawatt for the NY Prize Stage 1 feasibility studies (right) .....

Figure A-6. Microgrid controller costs as a percentage of total project costs for the NY Prize Stage 1

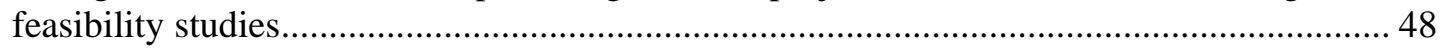

Figure A-7. Soft costs as a percentage of total microgrid costs for the NY Prize feasibility studies ......... 49

Figure A-8. Soft costs as a percentage of total microgrid cost compared to microgrid capacity for the NY

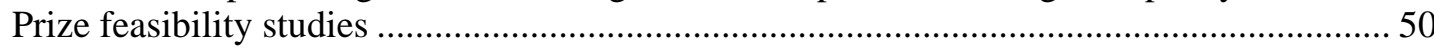

Figure A-9. Additional electric infrastructure costs as a percentage of total microgrid cost for the NY Prize feasibility study data .................................................................................................... 51

Figure A-10. Additional electric infrastructure costs as a percentage of total microgrid cost compared to microgrid capacity for the NY Prize feasibility studies ......................................................... 52 


\section{List of Tables}

Table ES-1. Market Segment IQR and Mean Normalized Microgrid Costs in \$/MW .. vi

Table ES-2. IQR and Mean Normalized Microgrid Costs in \$/MW by Levels of Microgrid Complexity viii

Table 1. IQR and Mean Normalized Microgrid Costs in \$/MW per Market Segment............................... 21

Table 2. IQR and Mean Normalized Microgrid Costs in \$/MW by Microgrid Levels............................... 23 


\section{Introduction}

The U.S. Department of Energy's (DOE’s) Office of Electricity Delivery and Energy Reliability microgrid cost study is identifying the costs of components, integration, and installation of U.S. microgrids; project cost improvements; and technical accelerators during the next 5 years and beyond. This information could then be used by DOE, among others, to develop research-anddevelopment agendas to advance the next generation of microgrids to provide cost-effective, reliable, and clean energy solutions.

The project scope includes two phases. Phase I focuses on collecting data and analyzing existing and planned microgrid projects in the United States in the following markets: (1) commercial, (2) community, (3) campus, (4) utility, and (5) remote.

\subsection{Background}

The most commonly used definition of a microgrid is that from DOE as "a group of interconnected loads and distributed energy resources within clearly defined electrical boundaries that acts as a single controllable entity with respect to the grid. A microgrid can connect and disconnect from the grid to enable it to operate in both grid-connected and islandmodel” (DOE 2011). Microgrids are composed of distributed energy resources (DERs) that can provide independent power to designated critical loads upon loss of the primary source of energy.

A microgrid is distinct from a standby backup system because it is capable of operating in both grid-connected and islanded modes. This distinction is important because it excludes backup generators and uninterrupted power supply systems that are not capable of operating in parallel with the grid and operate only if the main grid is disconnected via automatic transfer switch. A subset of microgrid projects involves upgrading a facility's backup generators with networked controls, which are considered a microgrid per the DOE definition because the network control operation to upgrade the generators enables them to operate in parallel with the grid.

Microgrids have different design and control architectures. Controls can be embedded in the DERs (primary control); centralized at a higher level to optimize for voltage and frequency stability by using primary local controls (secondary control); and, last, at the highest level, there can be centralized decision-making controls to incorporate enterprise-level economic dispatch optimization of DERs and load and manage the power flow with the main grid (tertiary control) in addition to achieving power system control (Hatziargyriou 2014; Bidram and Davoudi 2012, 1,963-1,976).

The scale and types of benefits created from microgrids vary depending on customer and location-specific circumstances, including the thermal and electric demands of interconnected loads, configuration of the local distribution system, ability of existing legacy grid infrastructure to meet load growth, local utility's generation mix, retail cost of energy, and energy market structure, among others.

Microgrid technology can provide economic and reliability benefits for a variety of stakeholders, but it requires additional investments for integration and components. In this project, the National Renewable Energy Laboratory (NREL) collected a substantial amount of data to 
identify the costs of microgrid components and integrated systems for installations in the United States during the past 10 years (up to 2016). For microgrid technology, it is particularly challenging to generalize costs because every installation has unique design and architecture characteristics that affect the overall cost of the individual microgrid components. For example, unit costs per capacity such as \$/MW peak or \$/MWh might vary from one design to another because of application requirements and site-specific differences.

Phase I of this study contributes to providing better insight, transparency, and standardization when reporting microgrid costs to:

- Better determine individual component contributions to total system price

- Identify large differences in system configurations depending on geography, market, etc.

- Identify differences and components in market segments.

\subsection{Microgrid Technology Costs}

This project is inspired by past studies on technology costs for solar photovoltaic (PV) and combined solar PV and storage systems. These studies have reported PV costs by component (e.g., engineering and equipment, soft costs, and modules) and projected costs during the next 5 years (Ardani et al. 2017; Chung et al. 2015; Fu et al. 2016; Feldman et al. 2015; Bolinger and Seel 2016). The added challenge of conducting a similar study on technology costs for microgrid technology is the difficulty in generalizing costs from one design and application to another.

Similar to microgrids, energy storage systems have a wide spectrum of applications and might use a wide variety of technologies; however, in terms of installed costs, the classification and linearity of costs by technology and size are more homogenous than microgrids.

In an April 2016 article published in Microgrid Knowledge, four microgrid developer companies were asked: "What does a microgrid cost?" The responses reflect the challenges previously described in conducting a microgrid cost study with regard to data variability and site-specific characteristics (Wood 2016). A respondent replied: “What does a house cost in the U.S?” As with houses, microgrids range in size and sophistication. Another respondent replied: "What do you already have?" The cost also depends on the energy infrastructure in place. Last, another respondent replied: “If you've seen one microgrid...you've seen one microgrid,” to highlight the uniqueness of each microgrid project.

Despite the relative novelty of the microgrid market and the challenges faced when discussing microgrid costs, it is a very useful exercise to collect cost information from the microgrid community and better understand component costs and differences from one project to another.

\subsection{Approach}

The principal goal in Phase I of the study was to collect data. Currently, market analysis companies track projects but do not necessarily have detailed cost information on a large number of them, and when they do, the information is at the level of aggregated total costs. Publicly available costs of microgrids are reported in ranges in \$/MW of DER capacity installed based on a limited amount of total project costs. 
NREL and key industry partners collected costs for existing and planned microgrid projects. Navigant Research is a key partner in the data collection effort and contributed existing and newly collected data to the microgrid cost database. NREL and Navigant Research designed a data-entry form and online survey to collect information on microgrid costs and sent it to microgrid owners, developers, and technology providers describing the project scope and inviting recipients to participate in the study. Once we received the data, we carefully processed it to adjust for inflation and homogenize project costs for brownfield and greenfield projects. In this case, greenfield projects refer to sites that did not leverage any existing DERs. Because many microgrid projects are built throughout time, this distinction is important to account for all costs and build a microgrid cost database with entries that can be compared.

As mentioned, NREL and Navigant Research compiled the microgrid cost database used in this study; however, in this report, we refer to the cost database as the NREL database for simplicity and to differentiate it from other microgrid databases, such as those belonging to Navigant Research and Greentech Media (GTM). 


\section{Microgrid Cost Data Collection}

A large number of microgrid customers, developers, and technology providers were contacted through an automatic survey and direct emails and phone calls. Those that agreed to participate in the study were sent a template to fill in cost information on existing or planned microgrid projects. Other sources of data that were used are publicly available information on microgrid project costs found in articles, on owner's and developer's websites, and in the NY Prize Phase I feasibility studies that are publicly available online.

This section describes the microgrid components and template as well as the general statistics of the microgrid cost database.

\subsection{Microgrid Component Costs}

In the template used to collect costs for the microgrid cost database, the microgrid components are classified as follows:

- DERs: diesel, natural gas, combined heat and power (CHP), biofuel, solar PV, wind, fuel cell and energy storage

- $\quad$ Microgrid controller: primary, secondary, or tertiary ${ }^{1}$

- Additional infrastructure: distribution system infrastructure, information technology communications upgrades, metering, etc.

- Soft costs: engineering, construction, commissioning, and regulatory.

Additionally, information on project characteristics were collected when available, such as location, customer and companies involved, year of operation, financing, and islanding type.

In collaboration with Navigant Research, we designed a template to send to microgrid customers, developers, and technology providers. The template is included in Appendix A.

\subsection{Survey and Data Collection}

A survey was sent to contacts included on Navigant Research's Microgrid Deployment Tracker list for the United States. Navigant Research maintains a worldwide microgrid database that is updated semiannually and including 1,568 project entries representing 15,600 MW of operating, under development, and proposed microgrid capacity and 147 new projects as of mid-2016. A total of 48 recipients completed the survey, and 12 of responded to the request for cost data. The survey letter is included in Appendix A.

\footnotetext{
${ }^{1}$ The primary control provides the set points for the voltage and current control loops of DER. Secondary control typically has a sampling time from seconds to minutes sampling (i.e.., slower than the primary control) and determines in a centralized manner the set points of the primary control for DER. Finally, tertiary control is the last (and slowest) control level, which considers economic constraints in the optimal operation of the microgrid (the sampling time is from minutes to hours), and manages the power flow between the microgrid and the main grid. The tertiary level, also referred to as the enterprise control level, often involves predicting weather, grid tariffs, and loads in the next hours or day to design a generator dispatch plan that achieves economic savings (Bidram and Davoudi 2012).
} 
Other industry members and microgrid owners were contacted directly via email and phone calls. Finally, cost information at an aggregate level on an additional 36 projects was found in articles and from industry and customer websites.

Collecting data for microgrid costs at the component level has been a challenging process. Microgrid developers and technology providers do not have the data readily available, and as such it takes a significant amount of effort and time to compile the research. Microgrid projects are often developed by multiple companies, and clear documentation of total project costs is not available from the general contractor, engineering services company, or smaller subcontractors. Finally, a few companies were not comfortable sharing detailed component costs because of concerns about competition.

\subsection{Microgrid Cost Study Database}

The final microgrid study cost study database contains 80 entries and is described in terms of geographical location of the entries, DER capacity, number of projects, and DER technology mix. The entries are compared to microgrid market reporting by Navigant Research and GTM. The objective of this comparison is to show that the microgrid cost database appears to be a fair representation of the current U.S. microgrid market. Total project costs were adjusted for inflation with respect to the year 2016.

\subsubsection{Microgrid Cost Database by Geography}

The geographical locations of the project entries in the microgrid cost study database are shown in Figure 1 by market segment. The database reflects the regional distribution described by Navigant Research and GTM: (1) more than 50\% of operational microgrids are located in states in the East Coast and West Coast, and (2) regional hot spots include California, the Northeast, and Alaska. 


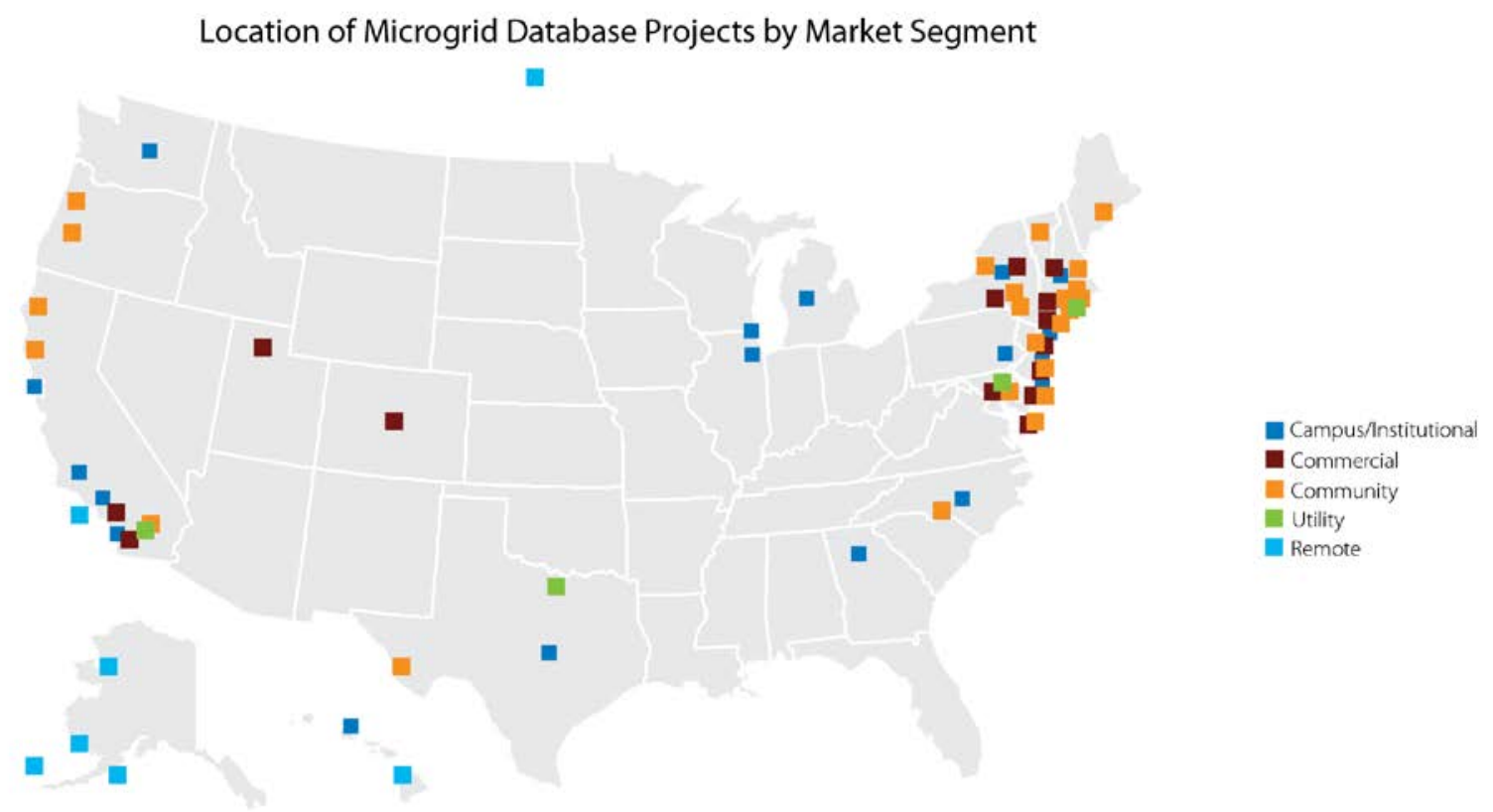

Figure 1. U.S. map of NREL microgrid project database locations per market segment

\subsubsection{Microgrid Cost Database by DER Capacity per Market Segment}

The microgrid database is compared to the 2016 reported capacity in megawatts published by Navigant Research and GTM, as shown in Figure 2 and Figure 3. The NREL microgrid cost database contains $40 \%-50 \%$ of the capacity reported in the databases by Navigant Research and GTM. In this report, energy storage capacity is included in quantities of generation capacity. To mirror the categories from Navigant Research and GTM, the utility category in NREL's database was combined with the community category. 


\section{NREL Study Capacity by Segment}

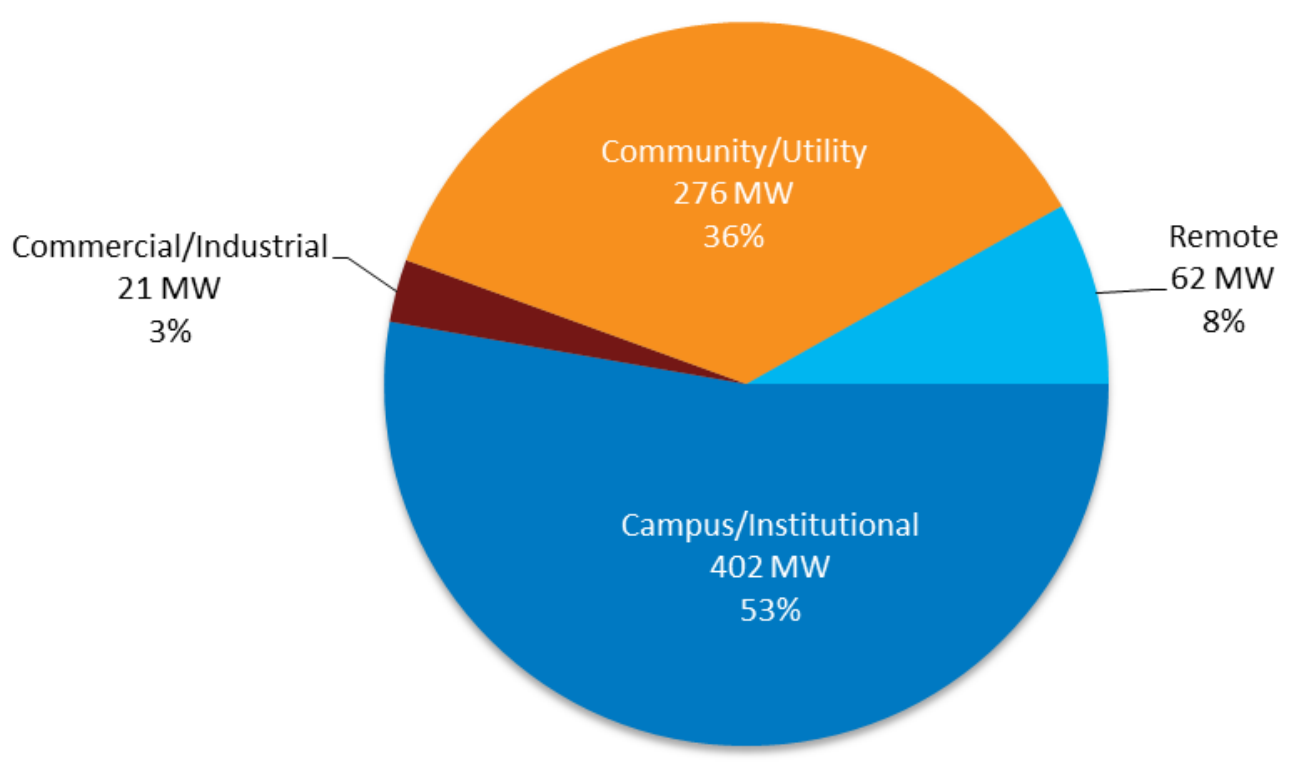

Figure 2. Microgrid cost study database by capacity 

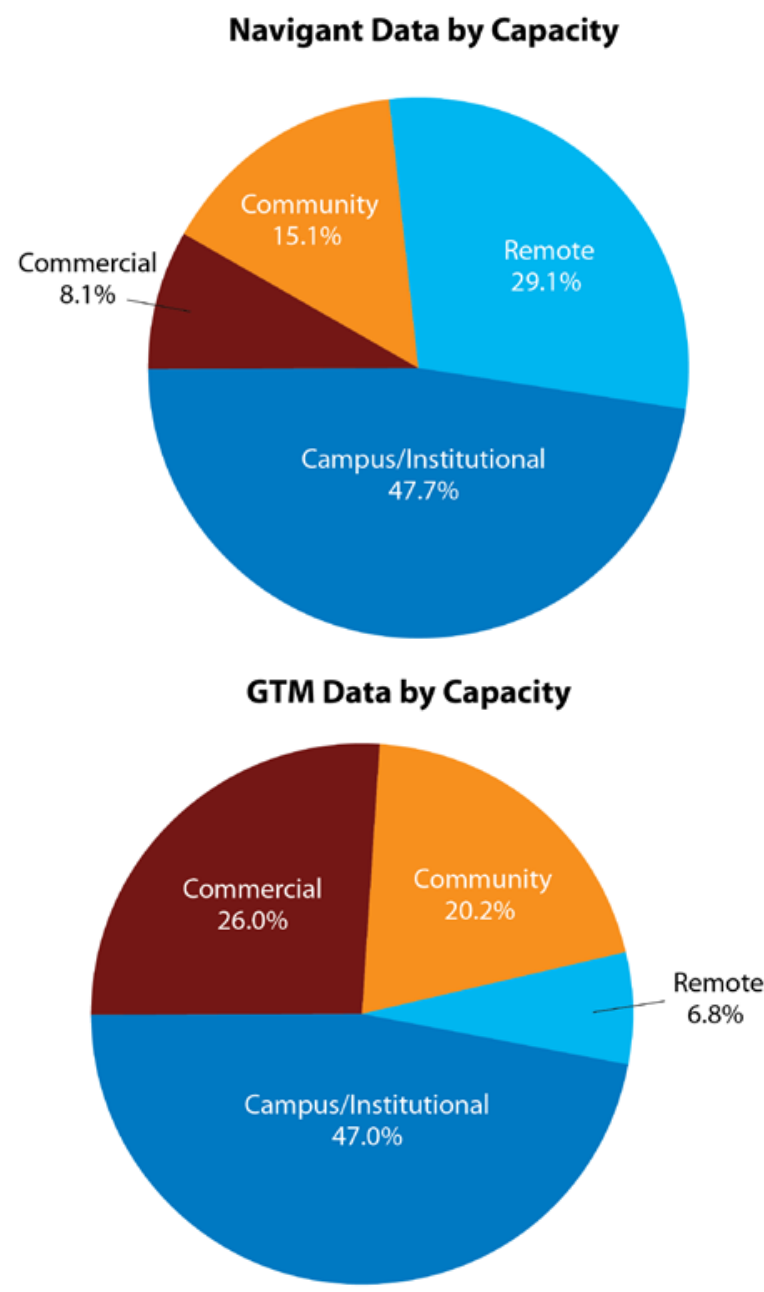

Figure 3. Navigant Research and GTM microgrid tracker projects by capacity

\subsubsection{Microgrid Cost Database by Number of Projects per Market Segment}

The microgrid database is compared to the 2016 reported number of projects published by Navigant Research and GTM, as shown in Figure 4 and Figure 5. In terms of the number of projects featured in each database, NREL's microgrid cost database is $13 \%$ the size of Navigant Research's database and 40\% of the GTM's database. GTM's and Navigant Research's databases vary significantly in the number of projects mainly because Navigant Research's database includes twice as many remote microgrid projects as GTM's. 


\section{NREL Study Number of Projects by Segment}

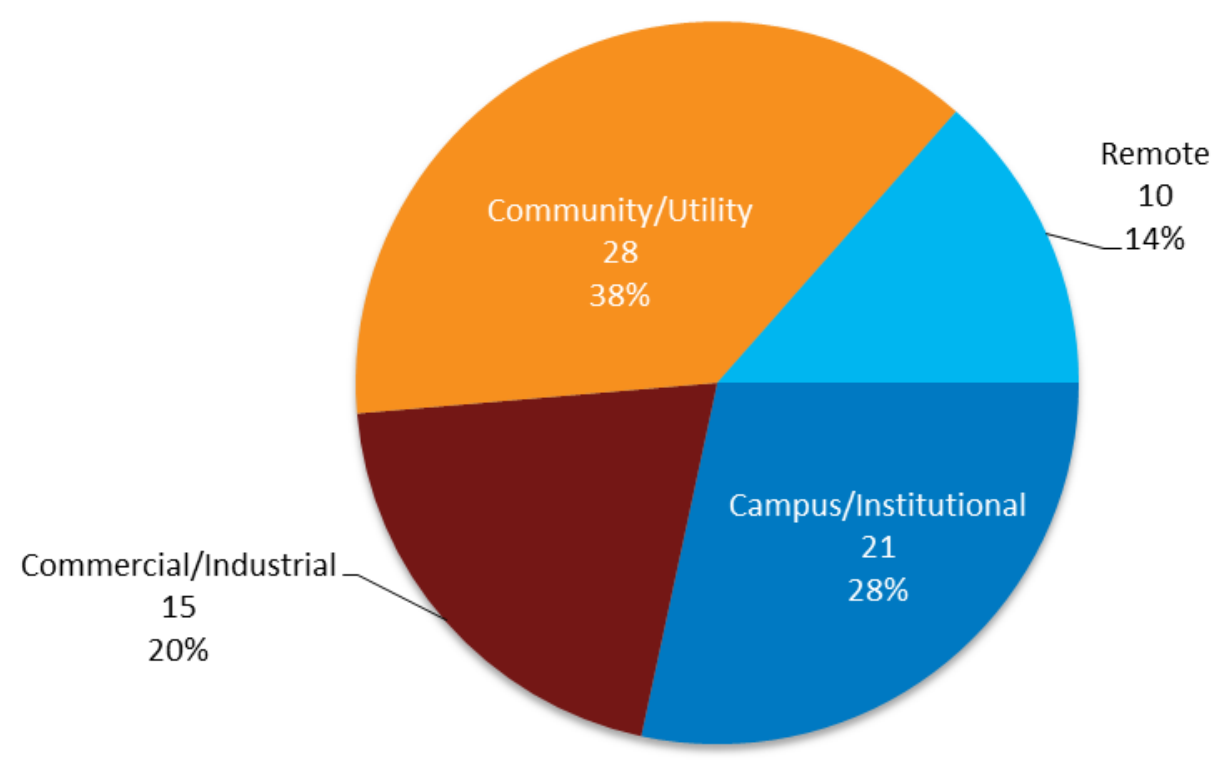

Figure 4. Microgrid cost study database by number of projects 


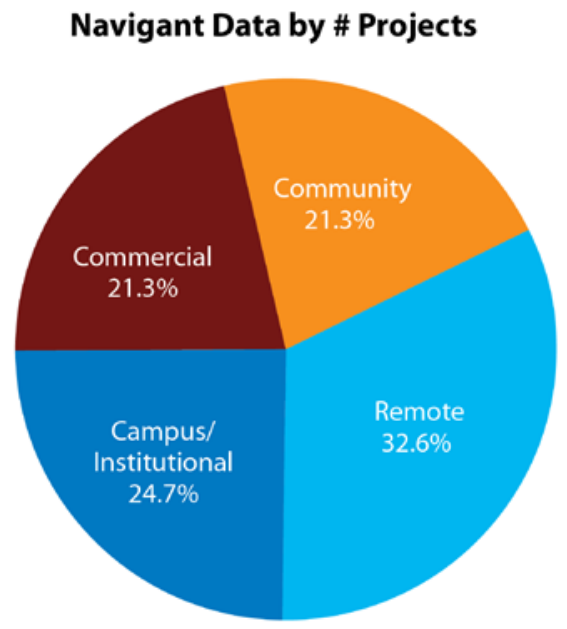

GTM Data by \# Projects

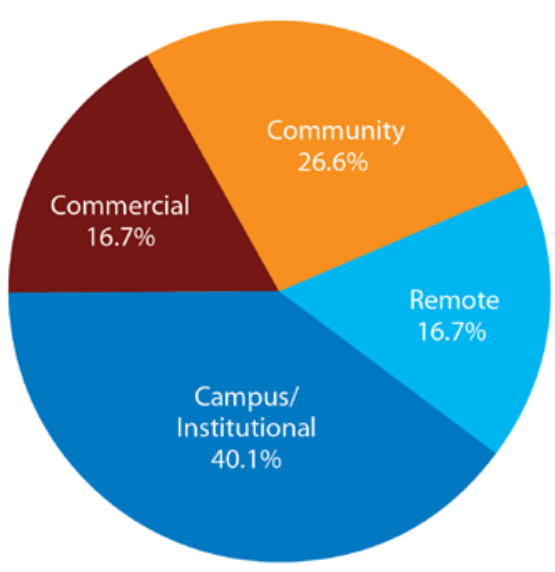

Figure 5. Navigant Research and GTM's microgrid trackers by total number of projects

\subsubsection{Microgrid Cost Database by DER Technology Mix}

In terms of DER mix, the microgrid study database reflects the market trend dominated by CHP and natural gas, followed by traditional diesel generation. Figure 6 shows that PV and storage are also being integrated into microgrid installations in the United States. The small amount of wind generation is mainly from the remote Alaska wind-diesel projects in the microgrid market. 


\section{NREL Study Capacity by Fuel/Technology (MW)}

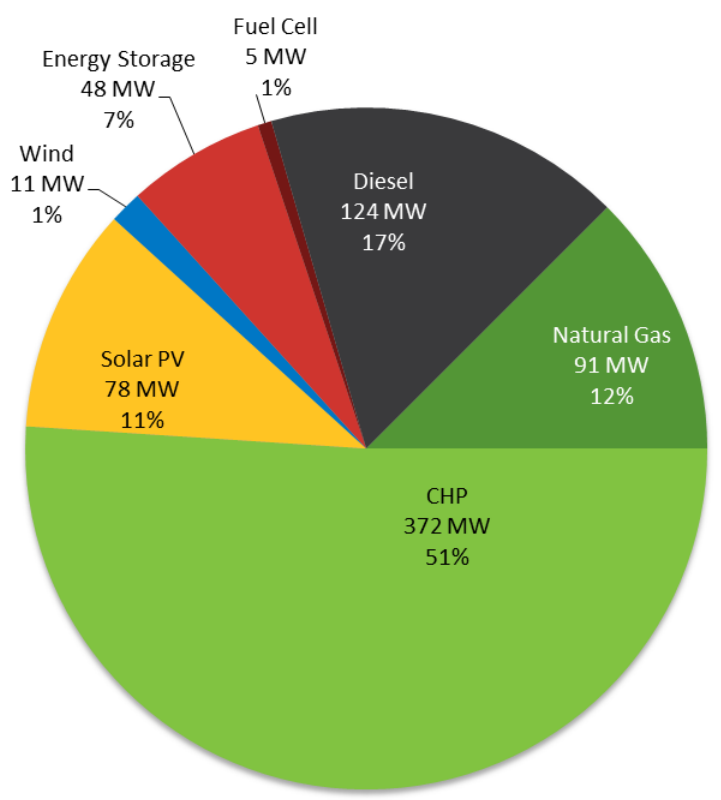

Figure 6. Microgrid cost study database by DER technology

\subsubsection{Existing and New DER Technology by Market Segment}

In this section, we show the DER technology mix by market segment. We include the costs of DER technology that predated the construction of some of the microgrids in this study by the sum of total microgrid costs. The intention is to homogenize costs between the projects that leveraged preexisting infrastructure and the ones that did not. For the analysis of new and existing generation, we used a subset of 21 projects for which we had information about new and existing generation technologies used.

The campus/institutional segment is dominated by new CHP generation capacity, as shown in Figure 7. Campuses typically have large a thermal demand that makes large CHP projects economically viable. The two most common new generation technologies used in this segment are natural gas and diesel.

The community market segment projects in the database include CHP and natural gas as the primary new technologies being installed, followed by solar and diesel, as shown in Figure 8. Communities are also leveraging existing standby diesel and natural gas generators into new microgrid projects. Finally, new energy storage is also being incorporated into new microgrids. 


\section{Campus/Institutional - New and Existing Generation by Technology}

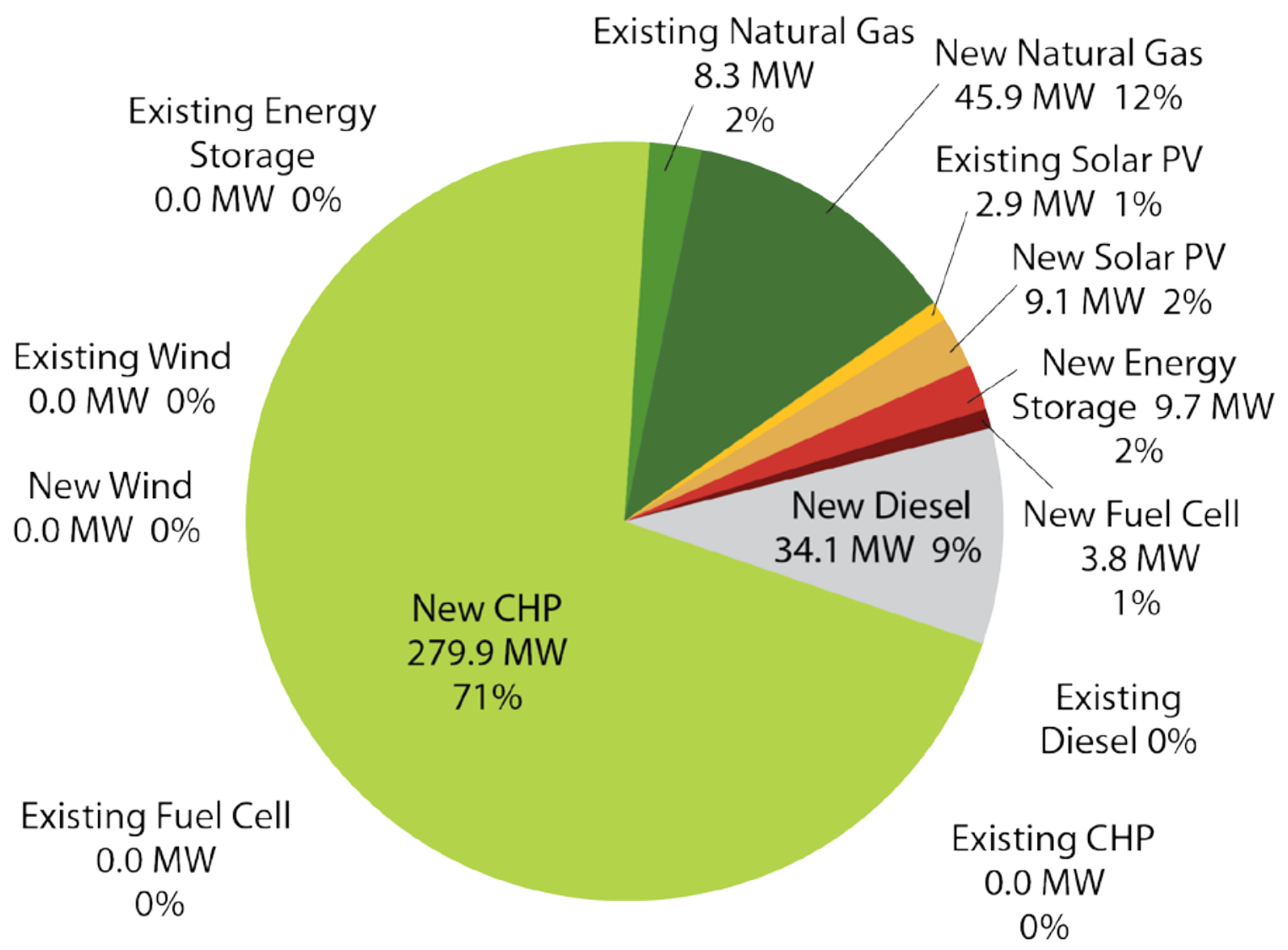

Figure 7. New and existing distributed generation by technology for campus and institutional microgrids 


\section{Community - New and Existing Generation by Technology}

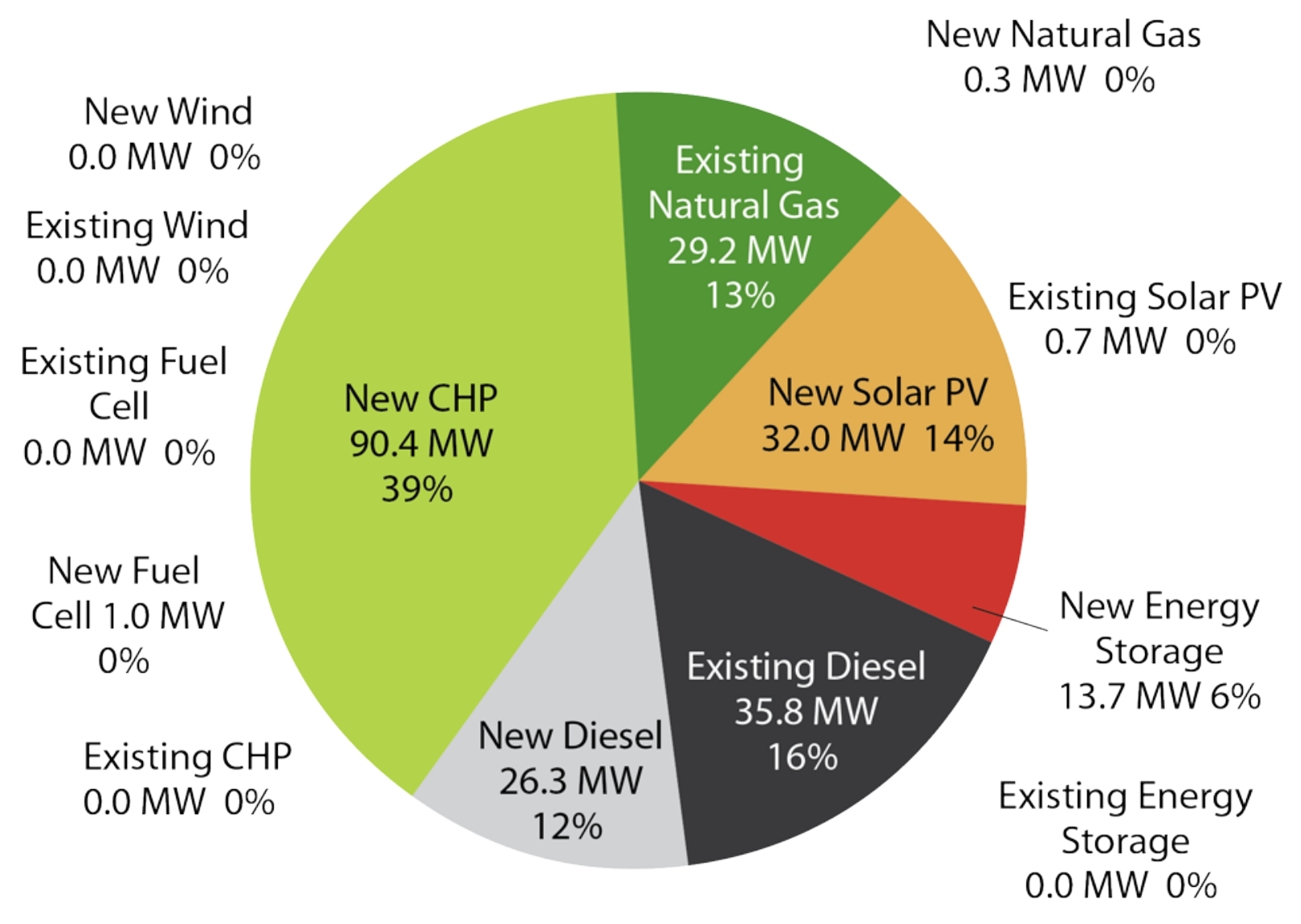

Figure 8. New and existing distributed generation by technology for community microgrids

The commercial projects in the microgrid database show that the largest DER technology used is existing diesel generators, and the new technologies being installed in microgrids are energy storage, CHP, and solar; see Figure 9. Existing natural gas and solar PV are also being incorporated into new microgrid projects. 


\section{Commercial/Industrial - New and Existing Generation by Technology}

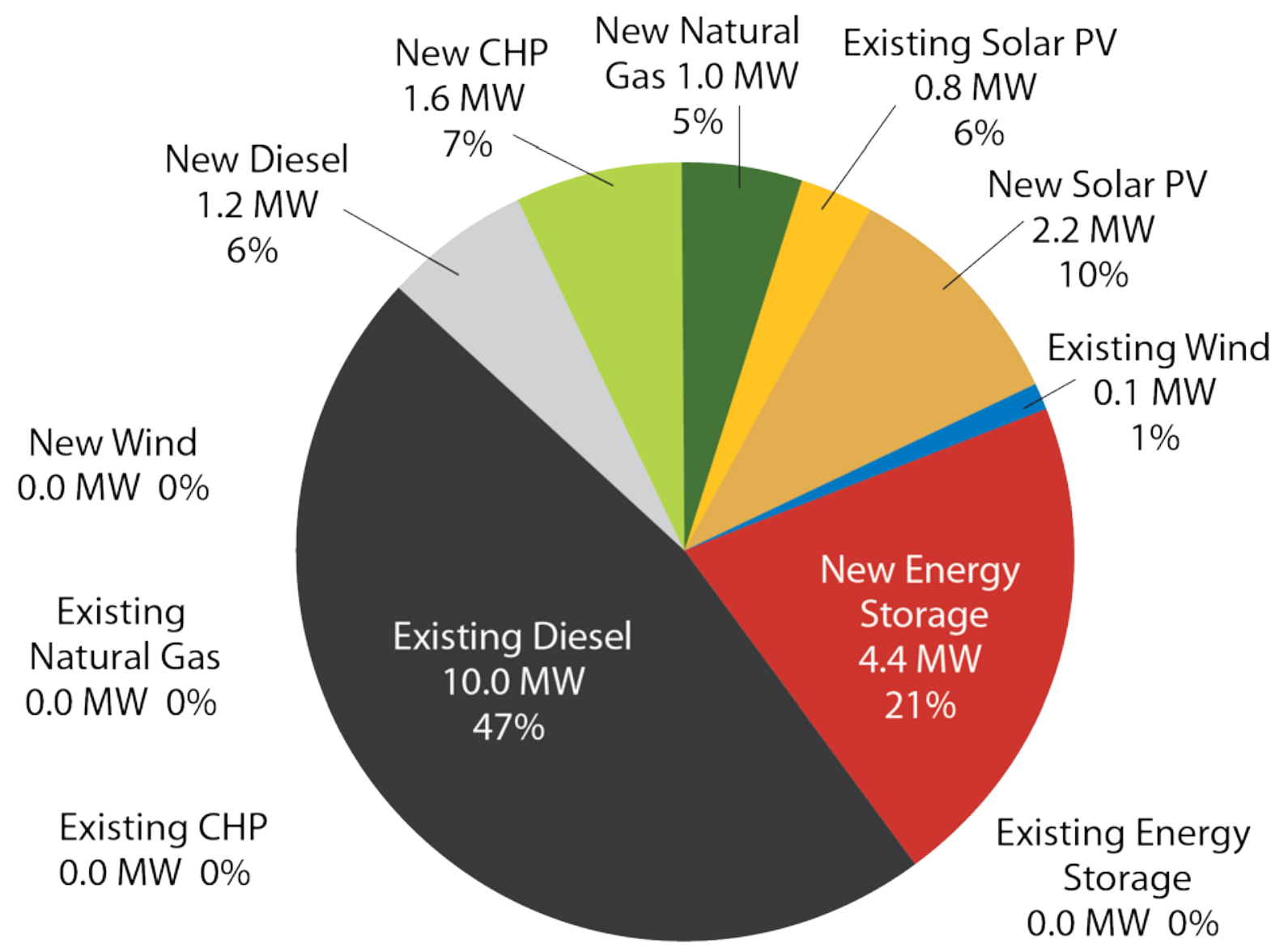

Figure 9. New and existing distributed generation by technology for commercial and industrial microgrids

In utility microgrids, existing solar projects are in the form of DERs, which have the highest capacity in our database, followed by new natural gas, diesel generators, and energy storage, as shown in Figure 10. Note that this group has only five entries in the database, and one of the projects integrates an existing, large PV project under a power purchase agreement. 


\section{Utility - New and Existing Generation by Technology}

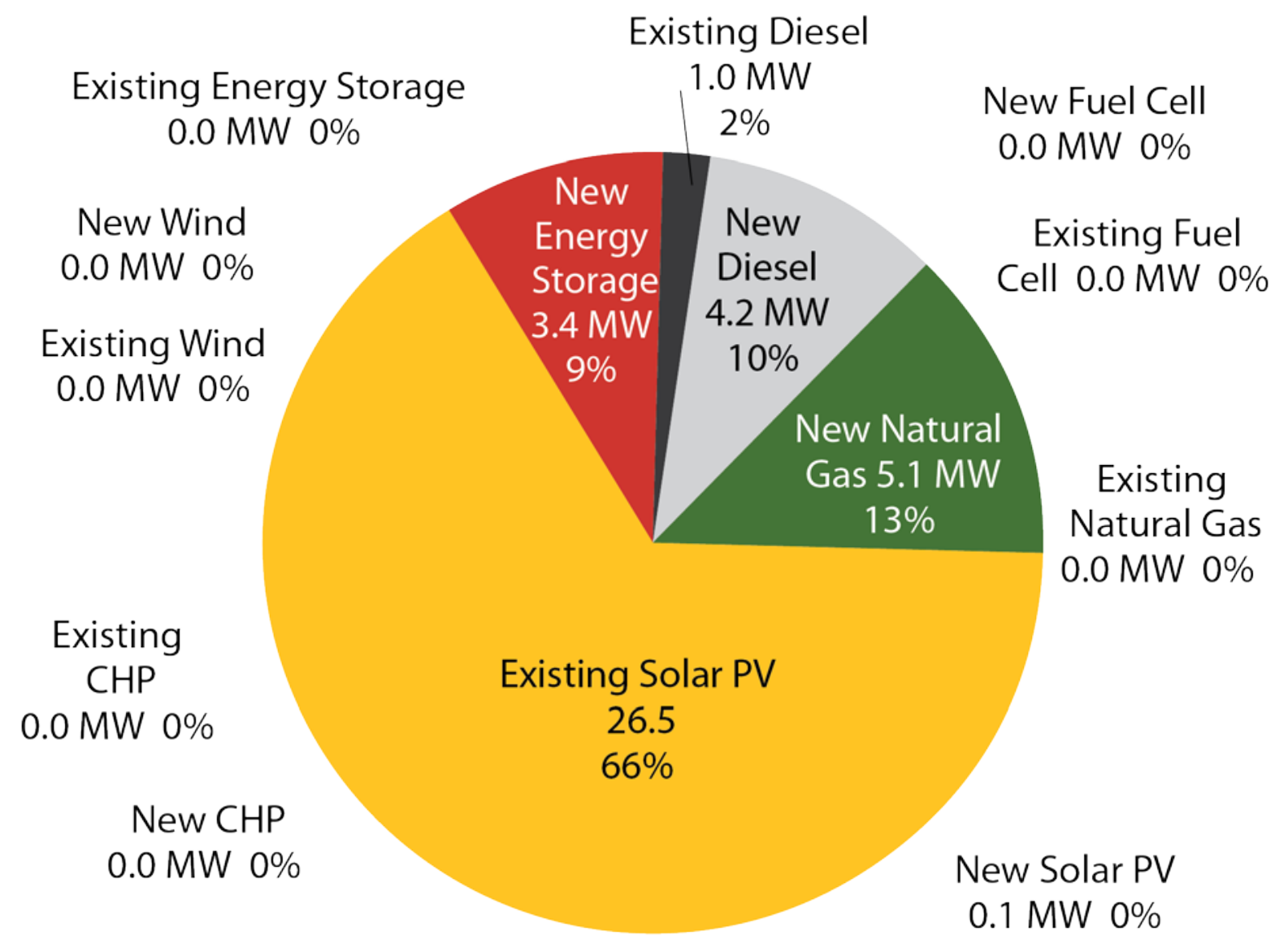

Figure 10. New and existing distributed generation by technology for utility microgrids

Finally, in remote microgrids, energy storage is being used increasingly in new microgrids, as shown in Figure 11. Existing wind, diesel, and new storage are the most prevalent forms of DERs. This segment reflects new projects in which renewable energy is being added to offset existing diesel-based energy in remote areas to reduce energy costs. To accomplish high penetration levels in remote power systems, energy storage is a key technology being deployed to ensure stable operation of smaller grids. 


\section{Remote - New and Existing Generation by Technology}

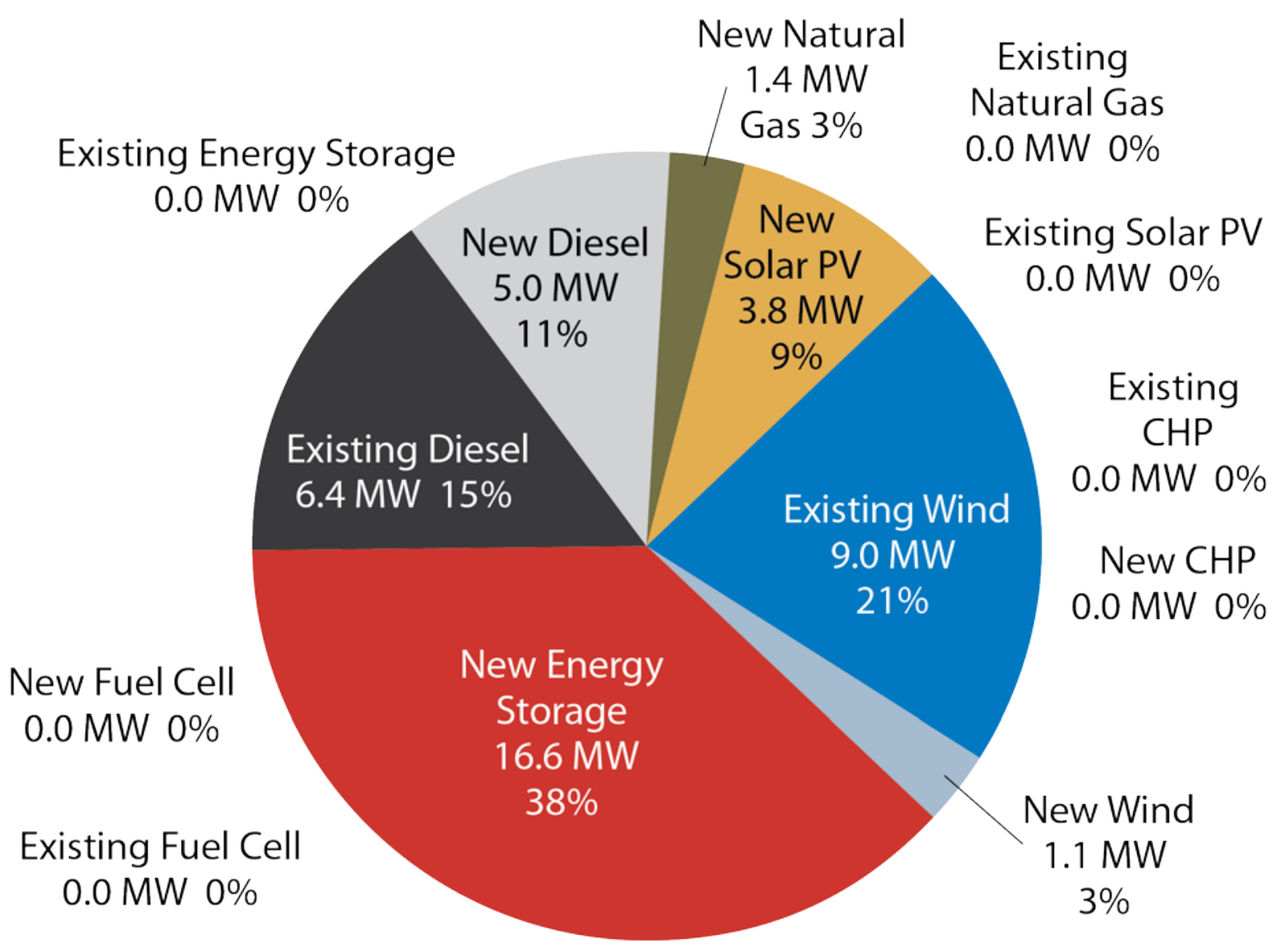

Figure 11. New and existing distributed generation by technology for remote microgrids 


\section{Analysis of Microgrid Cost Database}

In this section, we analyze the amount of existing generation and types of assets leveraged in new microgrids. This information helps quantify how much generation is typically already installed at a site prior to becoming a microgrid with islanding capabilities. We also calculate the total project costs per megawatt of generation capacity and group the costs according to market segments and microgrid complexity. Finally, for each market segment and complexity level, we disaggregate microgrid costs per megawatt in six components: conventional generation, renewable generation, energy storage, controls, soft costs, and additional infrastructure.

Note that the remote microgrid market segment is not included in this discussion because most sites leverage existing generation from legacy remote grids in the area, and the data collected pertain to new projects that focus on reducing the cost of electricity in remote areas.

\subsection{Microgrids Leverage Existing Assets}

As previously mentioned, some projects become microgrids after leveraging infrastructure and DERs from previous installations. In the database, projects that leverage existing generation resources were easily identified; however, projects that leverage other infrastructure - such as distribution automation, building management systems for load control, or advanced metering infrastructure for gathering consumption data-were not easily identified from the data collection template and responses, and when they were, there was not enough information on the project and system leveraged to estimate the costs.

Figure 13 shows the percentage in capacity of existing generation compared to new generation among the projects that leverage existing assets per market segment. These charts reflect the projects that are built in phases and leverage existing DER projects built throughout time, and they become microgrids by adding the necessary controls and electrical infrastructure to island. The percentage of existing generation varies widely from one segment to another, ranging from $3 \%$ for campus/institutional microgrids to $68 \%$ for utility microgrids. 


\section{Campus/Institutional}

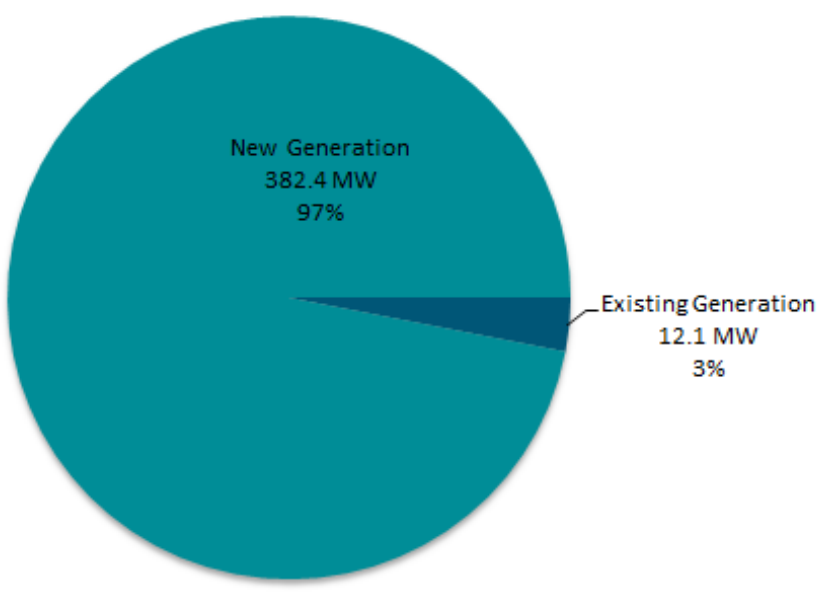

Commercial/Industrial

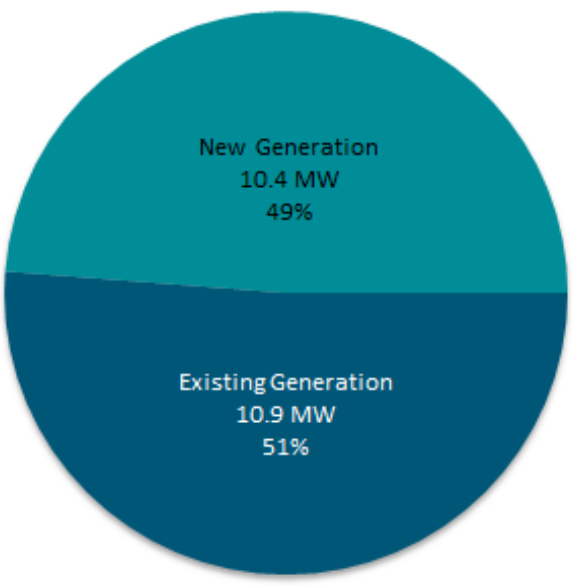

\section{Community}

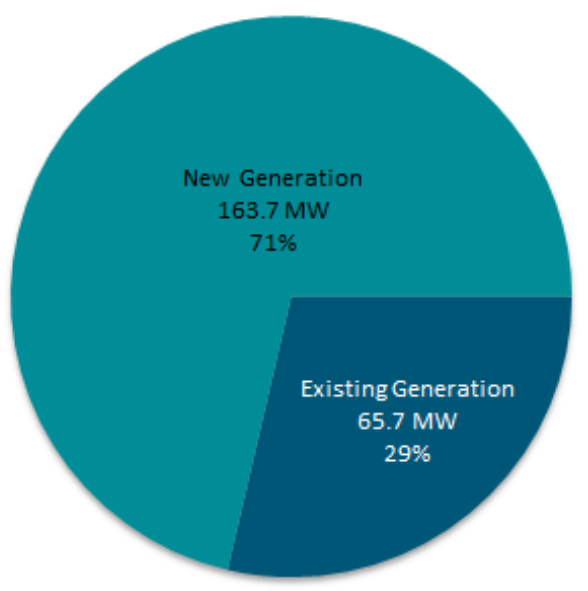

Utility

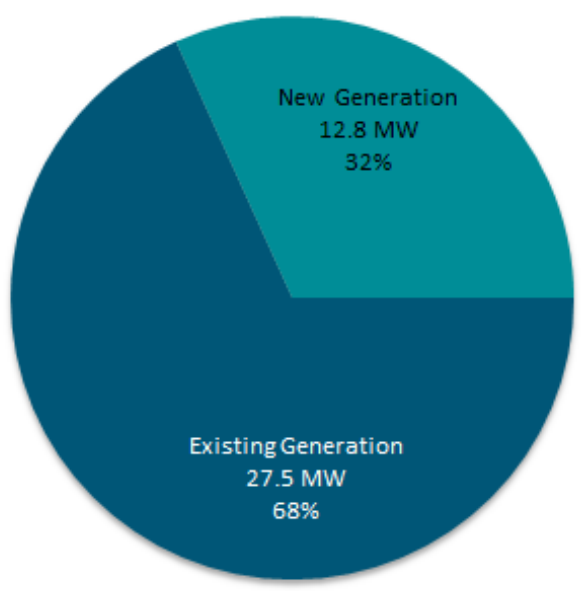

Figure 12. New and existing distributed generation by segment

The pie charts in Figure 13 show the mix of existing DER technologies by segment. The data collected show that campus microgrids leverage primarily natural gas generators and renewable energy projects, whereas the commercial and community segments leverage legacy standby diesel generators. The utility segment data were skewed by one project that has $26.5 \mathrm{MW}$ of solar capacity. 


\section{Campus/Institutional}

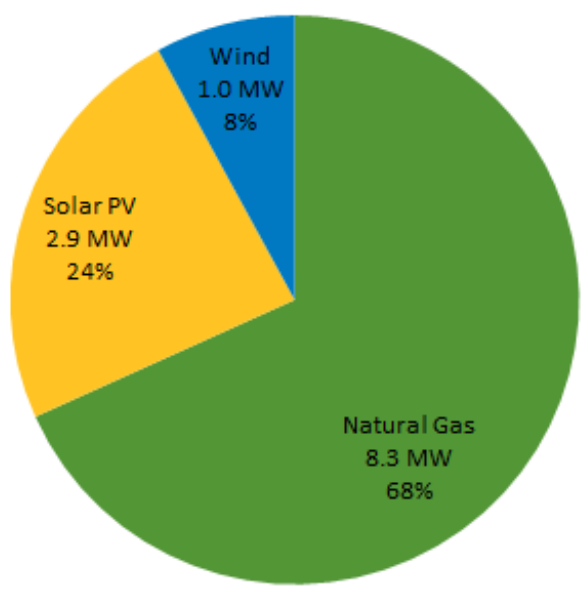

Commercial/Industrial

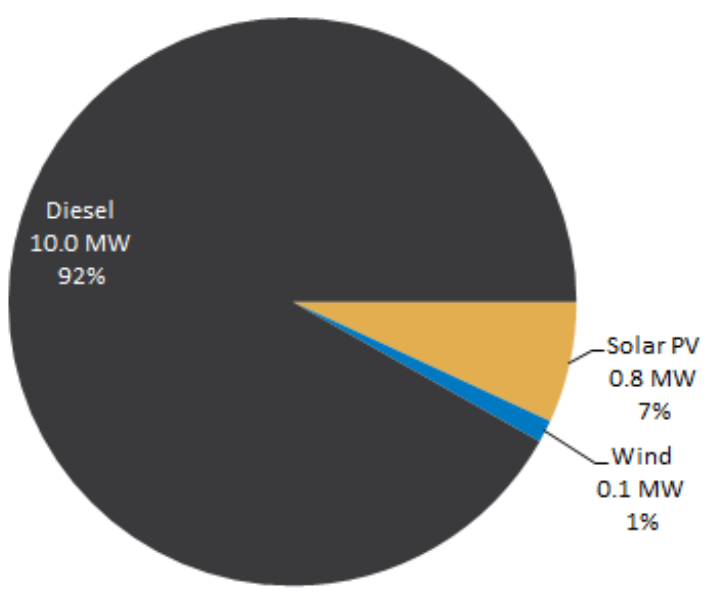

\section{Community}

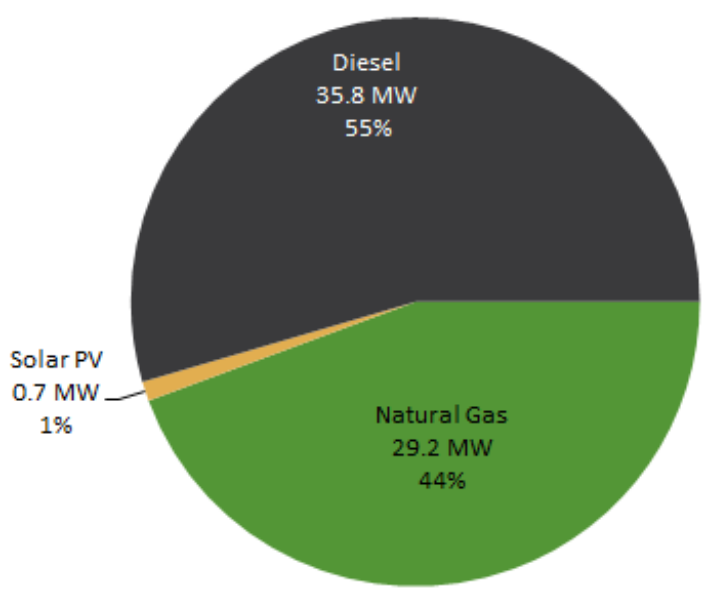

\section{Utility}

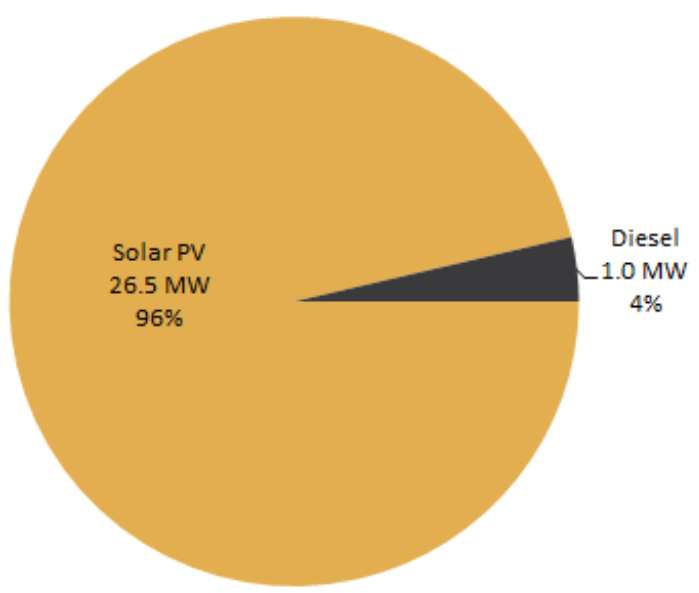

Figure 13. Existing distributed generation in commercial microgrid projects by technology

\subsection{Classification Proposal}

The total cost for each microgrid was adjusted for inflation in 2016 dollars and then divided by the project's total capacity to obtain each project's cost per megawatt. The total project costs per megawatt were analyzed by market segment to identify the mean and outliers for each category. The goal was to normalize costs among projects of different sizes.

We used quartiles to analyze the data to avoid making distribution assumptions or depending on a mean or standard deviation. The lower quartile (Q1) is the 25th percentile, and the upper quartile (Q3) is the 75th percentile of the data. The interquartile range (IQR) is defined as the interval between Q1 and Q3. Outliers are as defined as the values that fall outside the lower inner fence, calculated as Q1-(1.5*IQR), or the upper inner fence, Q3+(1.5*IQR) (Abebe et al. 2001). 
The cost ranges are wide for all market segments except for the utility microgrid, but the number of projects in the latter group is also low; however, the IQR range is less wide than the overall range of reported costs and can be used to provide a narrow range of costs per market segment, as included in Table 1. The whiskers in the box plots show lower and upper inner fences in each segment in Figure 14 and each level in Figure 18. Individual project costs are represented with diamonds.

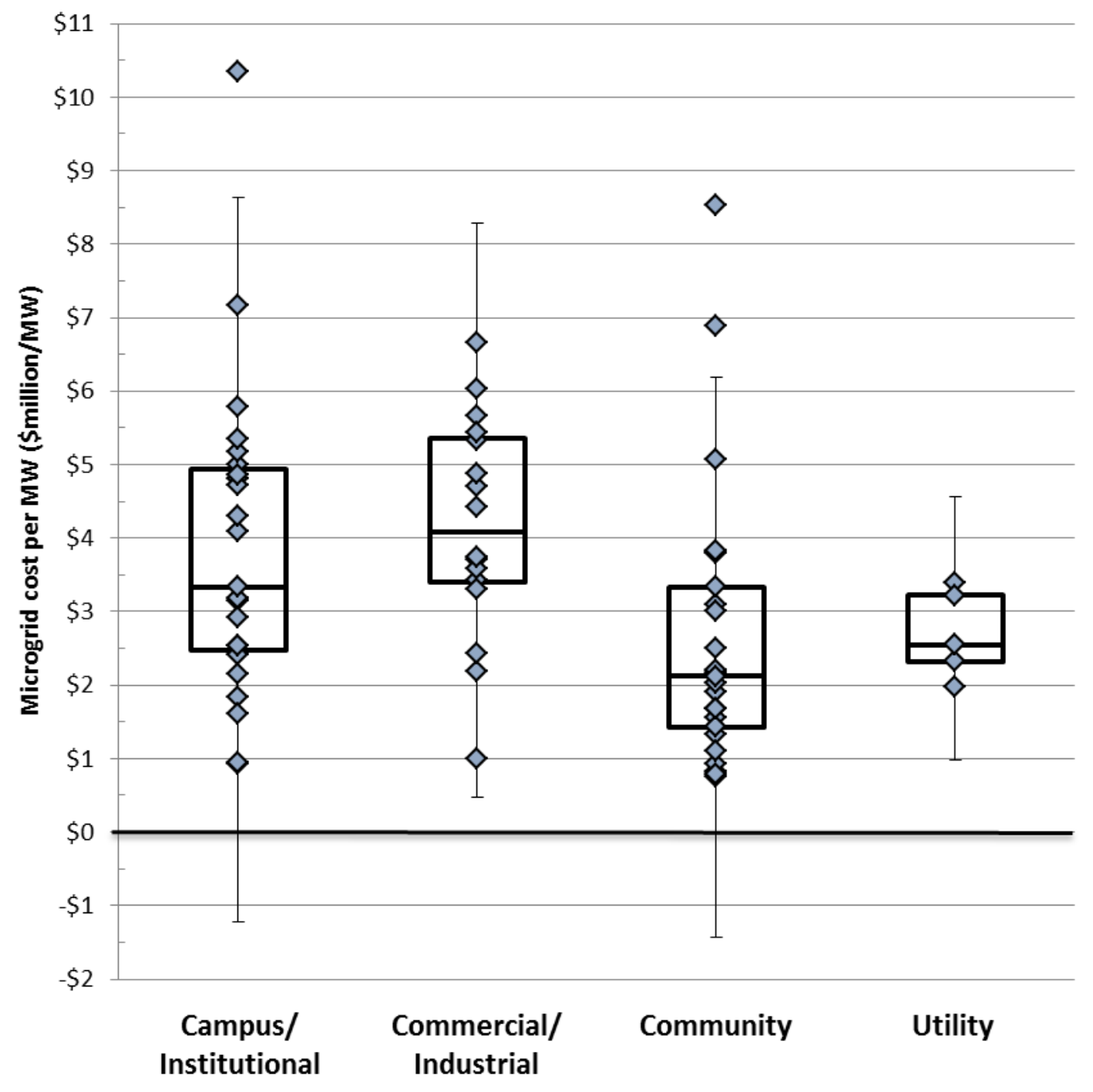

Figure 14. Box plot of normalized microgrid costs by market segment

The community microgrid market has the lowest mean, at $\$ 2.1$ million/MW of DERs installed; followed by the utility and campus markets, which have mean costs of $\$ 2.6$ million/MW and $\$ 3.3$ million/MW, respectively. Finally, the commercial market has the highest average cost, at $\$ 4$ million/MW. 
Table 1. IQR and Mean Normalized Microgrid Costs in \$/MW per Market Segment

\begin{tabular}{lll}
\hline Segment & IQR & Mean \\
\hline Campus/Institutional & $\$ 4,936,109-\$ 2,472,849$ & $\$ 3,338,666$ \\
Commercial/Industrial & $\$ 5,353,825-\$ 3,399,162$ & $\$ 4,079,428$ \\
Community & $\$ 3,334,788-\$ 1,430,805$ & $\$ 2,119,908$ \\
Utility & $\$ 3,219,804-\$ 2,323,800$ & $\$ 2,548,080$ \\
\hline
\end{tabular}

Figure 15 shows the normalized costs of projects according to function and capacity of the project. The results seem to indicate that there is some economy of scale in projects with installed generation capacity between $2 \mathrm{MW}-10 \mathrm{MW}$. The commercial microgrid projects in the database are all less than $3 \mathrm{MW}$, with the exception of one larger project, and they drive the higher costs reported for this market segment. Figure 16 excludes a 135-MW project from the graph to improve the visualization of the rest of the projects.

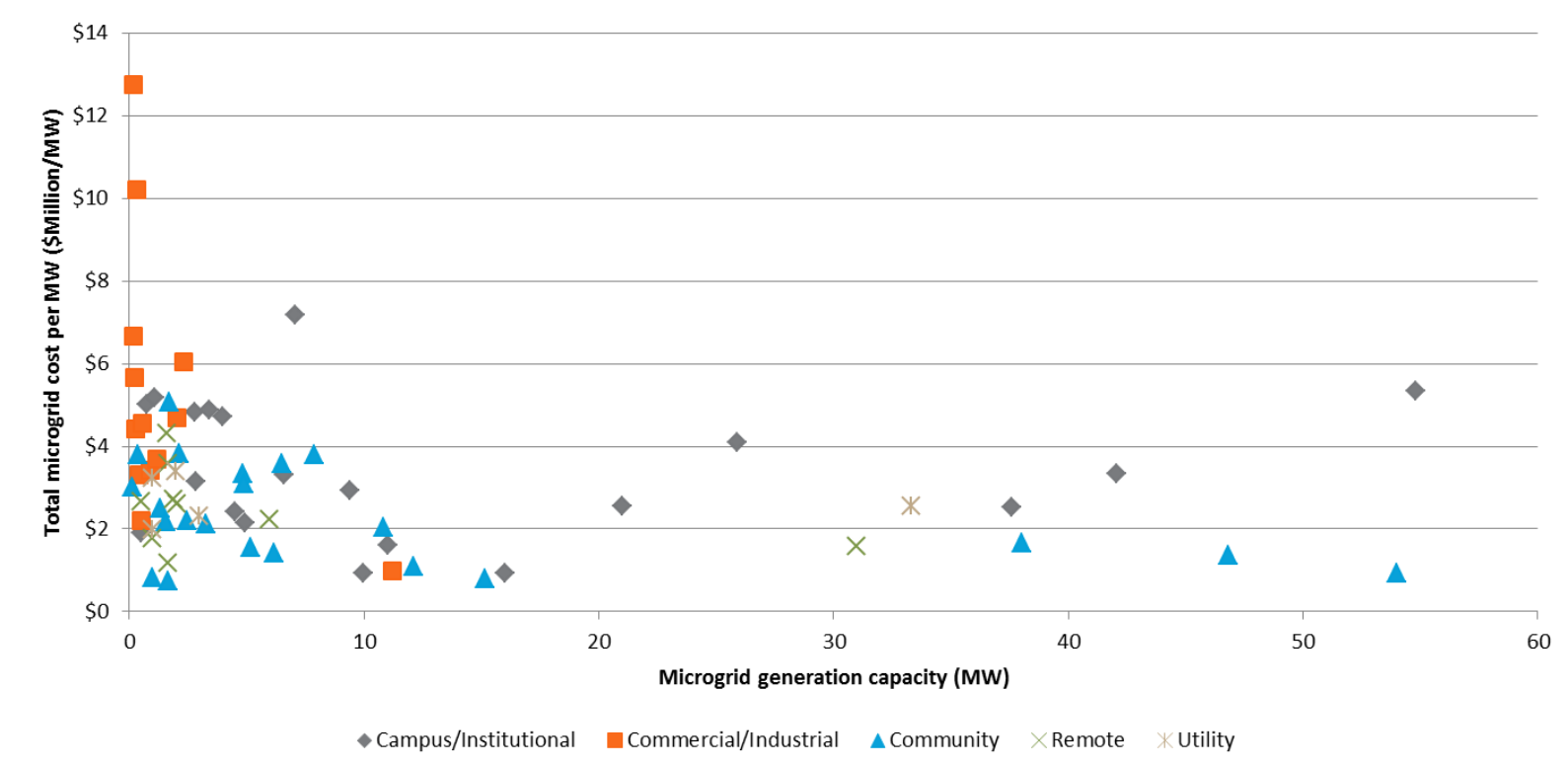

Figure 15. Normalized microgrid costs by size of the projects in megawatts and market segment

Another categorization methodology was used according to S\&C Electric’s microgrid levels, which classifies projects depending on their complexity, as shown in Figure 16. Complexity is described as a function of the number of DER assets, level of renewable energy penetration, energy storage, and level of control architecture and enterprise capabilities.

The microgrid projects in NREL's database were classified using S\&C Electric's microgrid complexity levels, and the normalized costs per level are shown in a box plot with outliers in Figure 18. NREL classified microgrids according to their respective levels based on the numbers and types of resources and publicly available information on the projects with regard to additional levels of control and enterprise capabilities. This is because classifying microgrids in the database according to complexity level was considered after industry and microgrid owners had been contacted. 


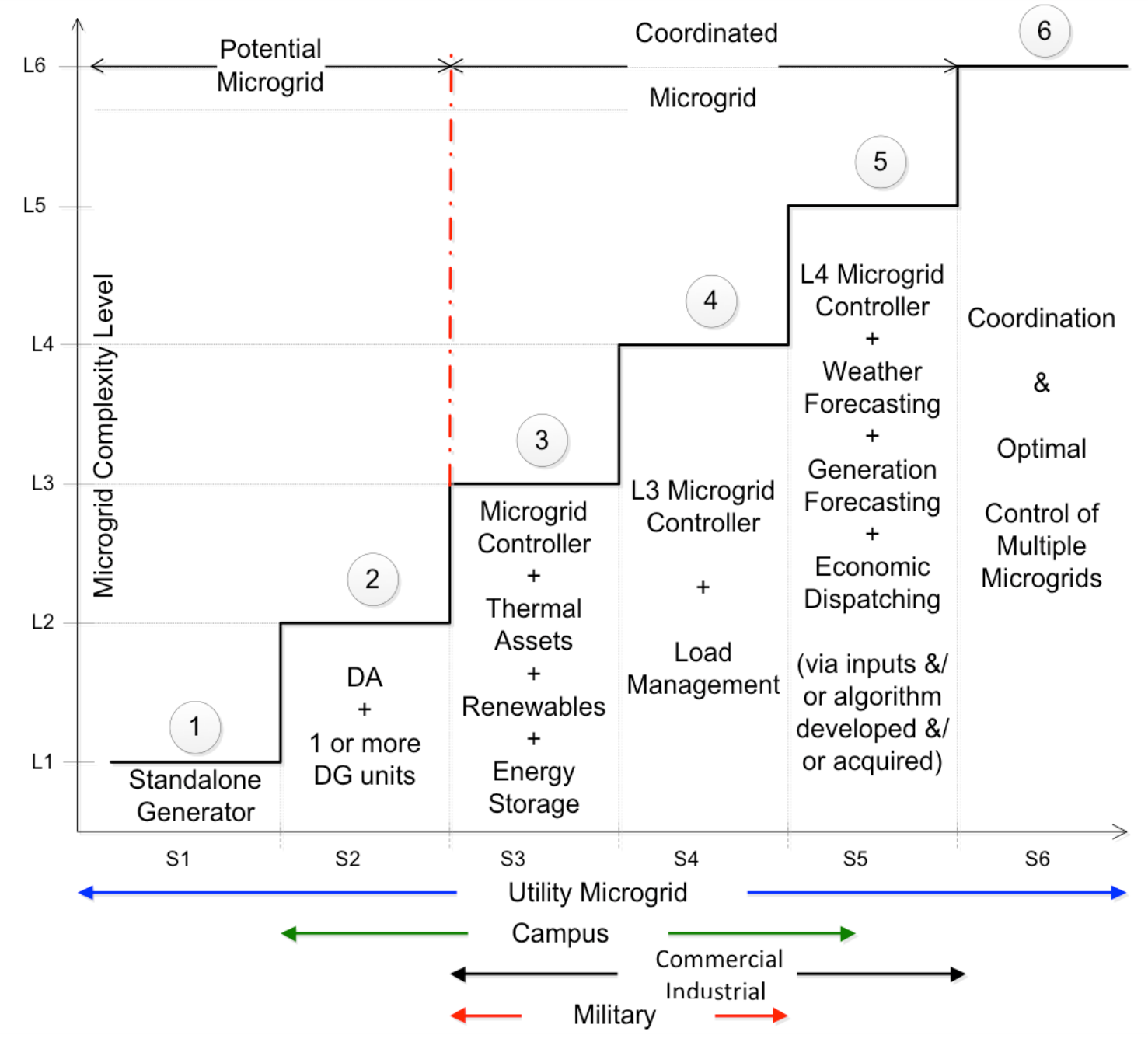

Figure 16. S\&C Electric's categorization based on microgrid complexity ${ }^{2}$

The classification by microgrid complexity shows that costs for Level 1 projects have the lowest mean, at \$2 million/MW (Table 2). The normalized costs in terms of IQR values and mean are very similar for Level 2 and Level 3, with average costs in the range from \$3.1-\$3.5 million/MW. The IQR range and mean increase for Level 4, which has a mean of $\$ 4.4$ million/MW. Finally, Level 5 contains only two projects in the database, which makes the statistical analysis insignificant. Level 5 data are not included in Figure 17 for this reason. The two Level 5 projects do not seem to reflect any increase in normalized costs.

Further research is required to refine the classification by market level and to confirm which costs are included. It could be possible that when there is load management or other refined enterprise-level controls in Level 3 or higher, the required software and hardware are not accounted for in the collected costs or were already there and integrated into the microgrid.

\footnotetext{
${ }^{2}$ DA: distribution automation; DG: distributed generation
} 


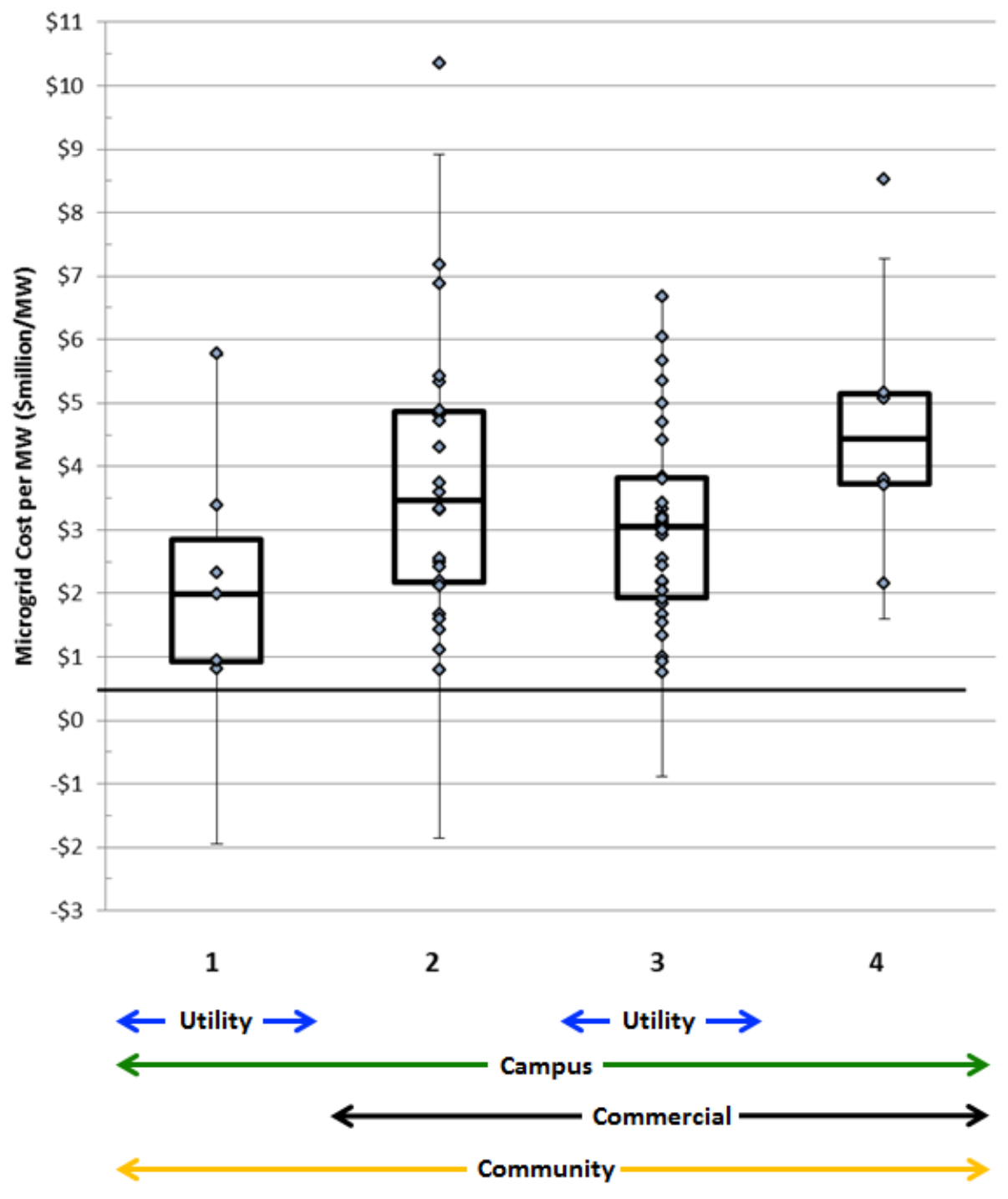

Figure 17. Box plot of normalized microgrid costs by microgrid levels

Table 2. IQR and Mean Normalized Microgrid Costs in \$/MW by Microgrid Levels

\begin{tabular}{lll}
\hline Level & IQR & Mean \\
\hline Level 1 & $\$ 2,856,775-\$ 931,485$ & $\$ 1,981,800$ \\
Level 2 & $\$ 4,870,648-\$ 2,178,975$ & $\$ 3,462,685$ \\
Level 3 & $\$ 3,820,975-\$ 1,940,507$ & $\$ 3,053,979$ \\
Level 4 & $\$ 5,142,510-\$ 3,727,321$ & $\$ 4,436,563$ \\
Level 5 & $\$ 3,700,938-\$ 2,920,014$ & $\$ 3,310,476$ \\
\hline
\end{tabular}




\subsection{Microgrid Component Costs}

This section presents the breakdown of costs by microgrid components and market segment. The cost per megawatt for each component was obtained by adding the cost of all the projects for which we have cost data for specific components and dividing the result by the sum of the total capacity (in megawatts) of the projects for which we have data for that specific component. This avoids reporting costs per megawatt that could be distorted with projects for which a specific component cost was not reported but might not necessarily be zero. The results varied widely from one segment to another.

Figure 18 shows the costs per megawatt by component for microgrids in each segment. There is a high degree of variability in the data, which might be an artifact of the limited information we collected on component costs. Conventional and renewable generation represent the largest percentage in most segments. Conventional generation accounts for $76 \%$ of the total cost per megawatt in microgrids in the campus/institutional segment and 54\% in the community segment. In commercial/industrial and utility microgrids, soft costs (43\% and $24 \%$, respectively) represent a significant portion of the total costs per megawatt. Finally, energy storage contributes significantly to the total cost of commercial and community microgrids, which have percentages of $25 \%$ and $15 \%$, respectively, of the total costs per megawatt. 


\section{Campus/Institutional - Cost per MW by Component}

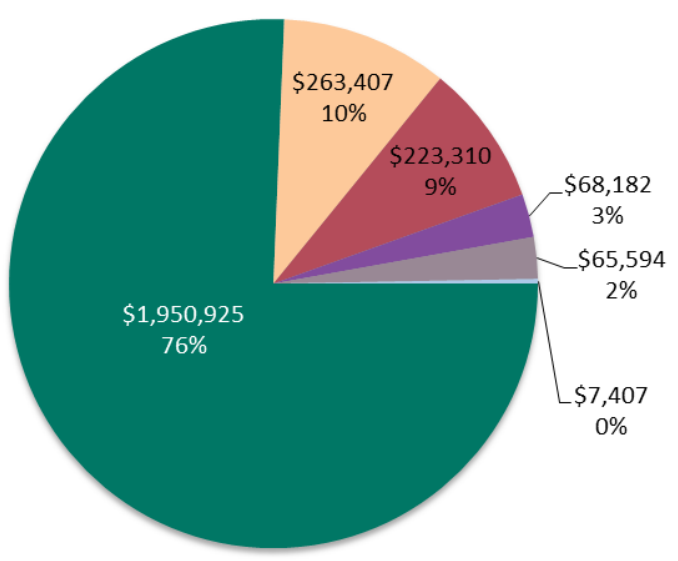

\section{Community - Cost per MW by Component}

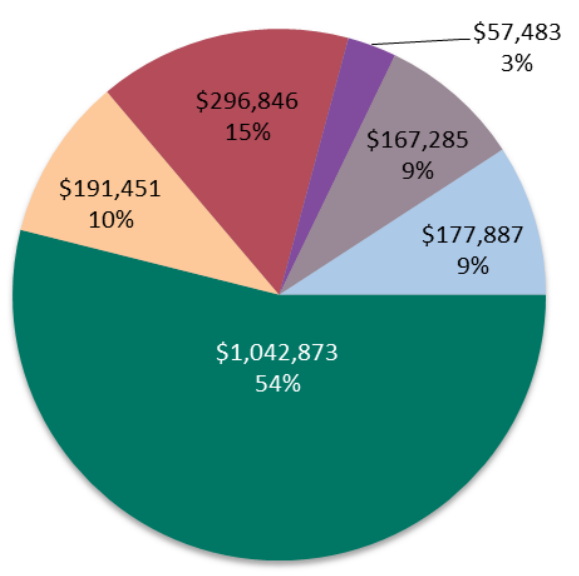

\section{Commercial/Industrial - Cost per MW by Component}

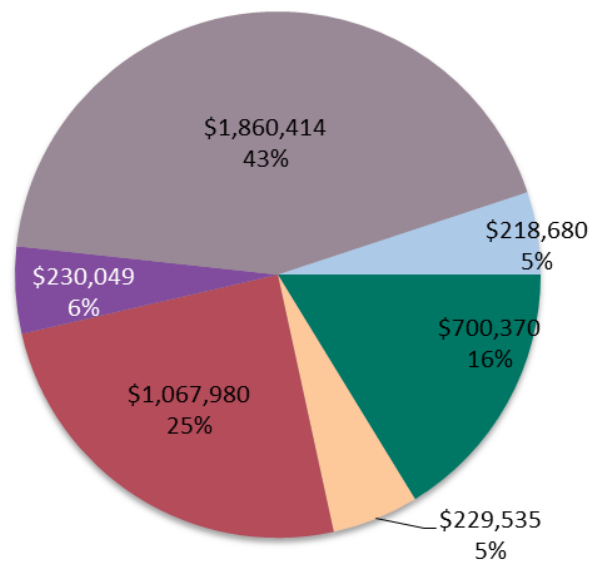

\section{Utility - Cost per MW by Component}

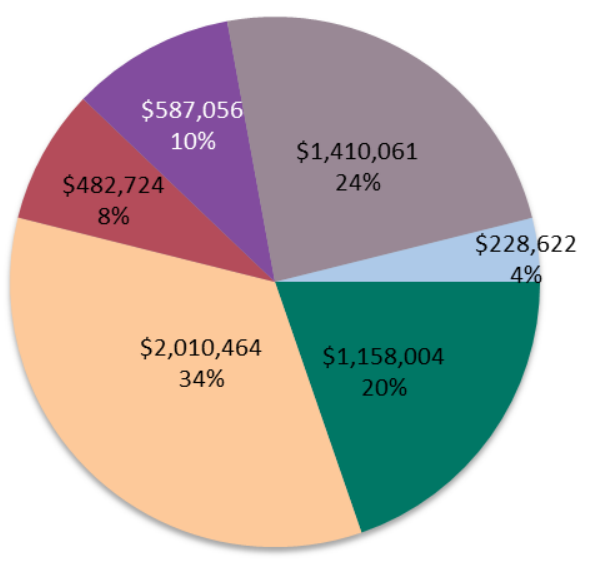

Energy Storage

Additional Infrastructure

Figure 18. Total costs per component cost by segment

Figure 19 shows the same analysis for microgrid component costs categorized by level of complexity. We have limited information in our database about both microgrid complexity level and component costs; the result is that data for this analysis by complexity level are even sparser. Conventional generation costs represent the largest share of component costs in all levels, reaching 88\% for Level 2 and Level 5. Level 1 microgrids have a considerably higher portion of total costs per megawatt assigned to the controls and additional infrastructure components. This could be because this level of microgrids is represented by networked diesel generator projects, in which a larger portion of the total project cost is most commonly used to retrofit legacy 
generators (operating with an automatic transfer switch) to enable parallel operation. Level 3 projects show that renewable energy and storage costs become the most prominent contributor to the total cost of the projects. Finally, Level 4 microgrids show a considerable increase in soft costs.

\section{Level 1 - Cost per MW by Component Level 2 - Cost per MW by Component}
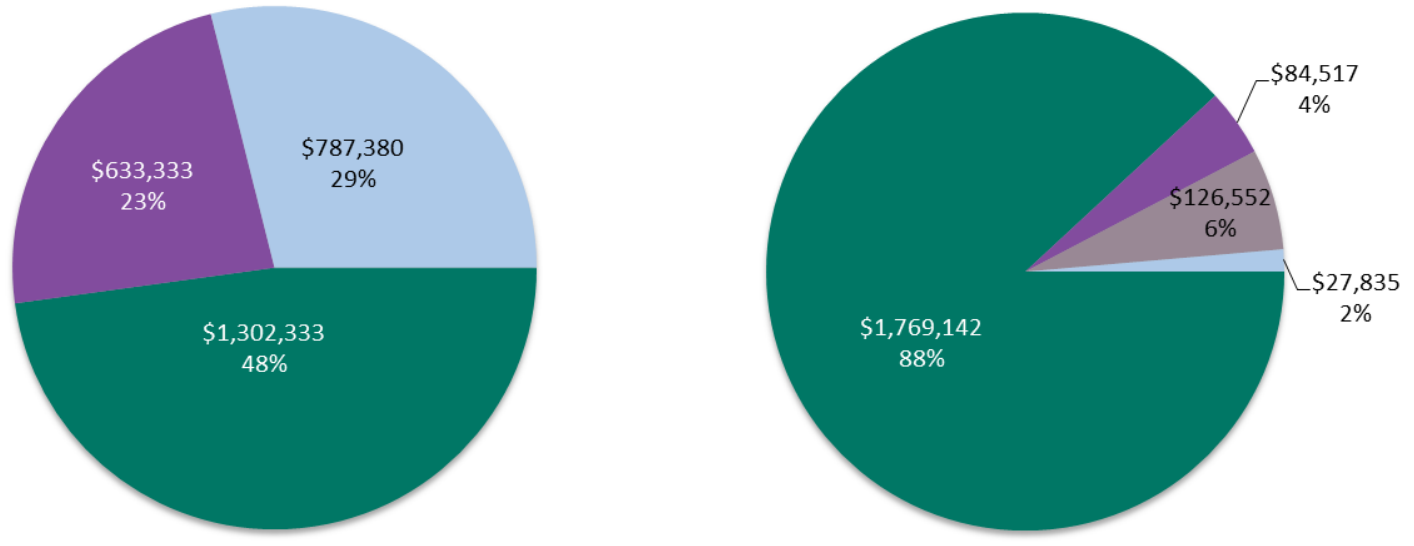

\section{Level 3 - Cost per MW by Component}

\section{Level 4 - Cost per MW by Component}

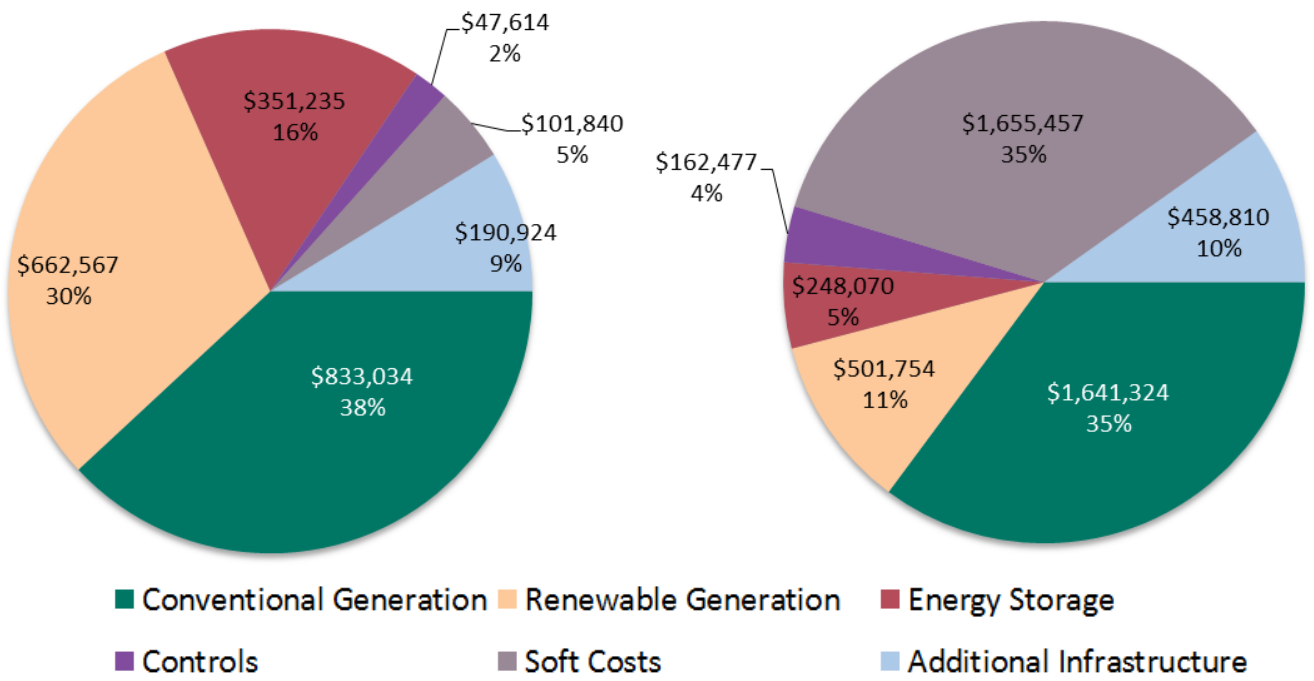

Figure 19. Total costs per component cost by level

\subsubsection{Controller Costs}

We analyzed the distribution of controller costs as a percentage of total microgrid costs per megawatt among all segments and levels, excluding outliers in terms of total costs (see Section 3.2). Controller costs as a percentage of total costs range from $0.5 \%-21 \%$, a median of $7 \%$, and one outlier with a value of 56\% (Figure 20.). The analysis shows that controller cost data as a percentage of total microgrid costs have a wide range of costs among the projects in our database. In total, we had controller cost data for 21 microgrids out of a total of 80 projects. 
Controller costs per megawatt range from \$6,200/MW-\$470,000/MW, excluding outliers, with a mean of $\$ 155,000 / \mathrm{MW}$.
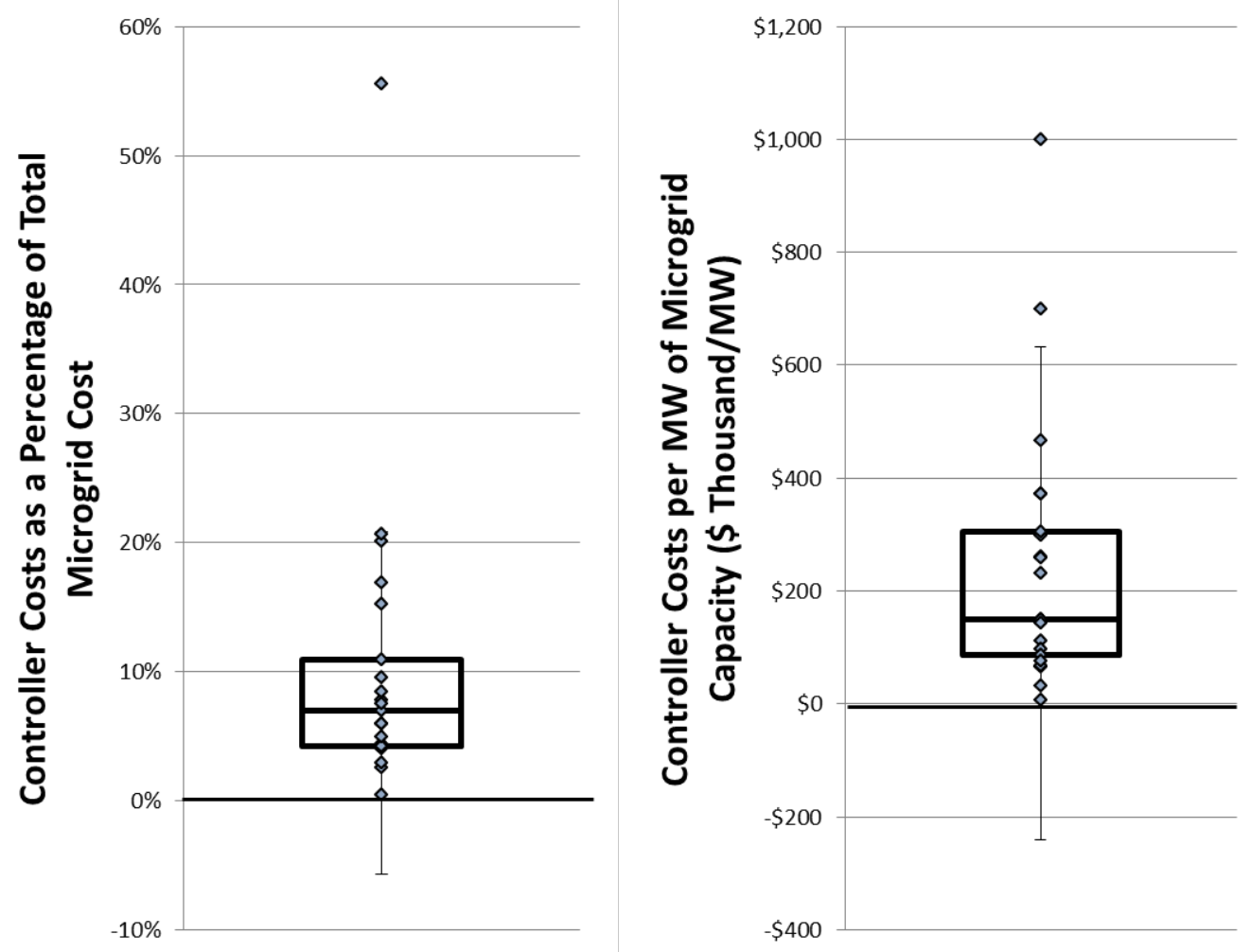

Figure 20. Controller cost data as a percentage of total microgrid costs per megawatt

Figure 21 shows microgrid controller costs as a percentage of total project costs sorted by generation capacity in megawatts. Controller costs show a generally downward trend as capacity increases for projects with capacities of $2 \mathrm{MW}$ or more (shown in light blue in the graph). 


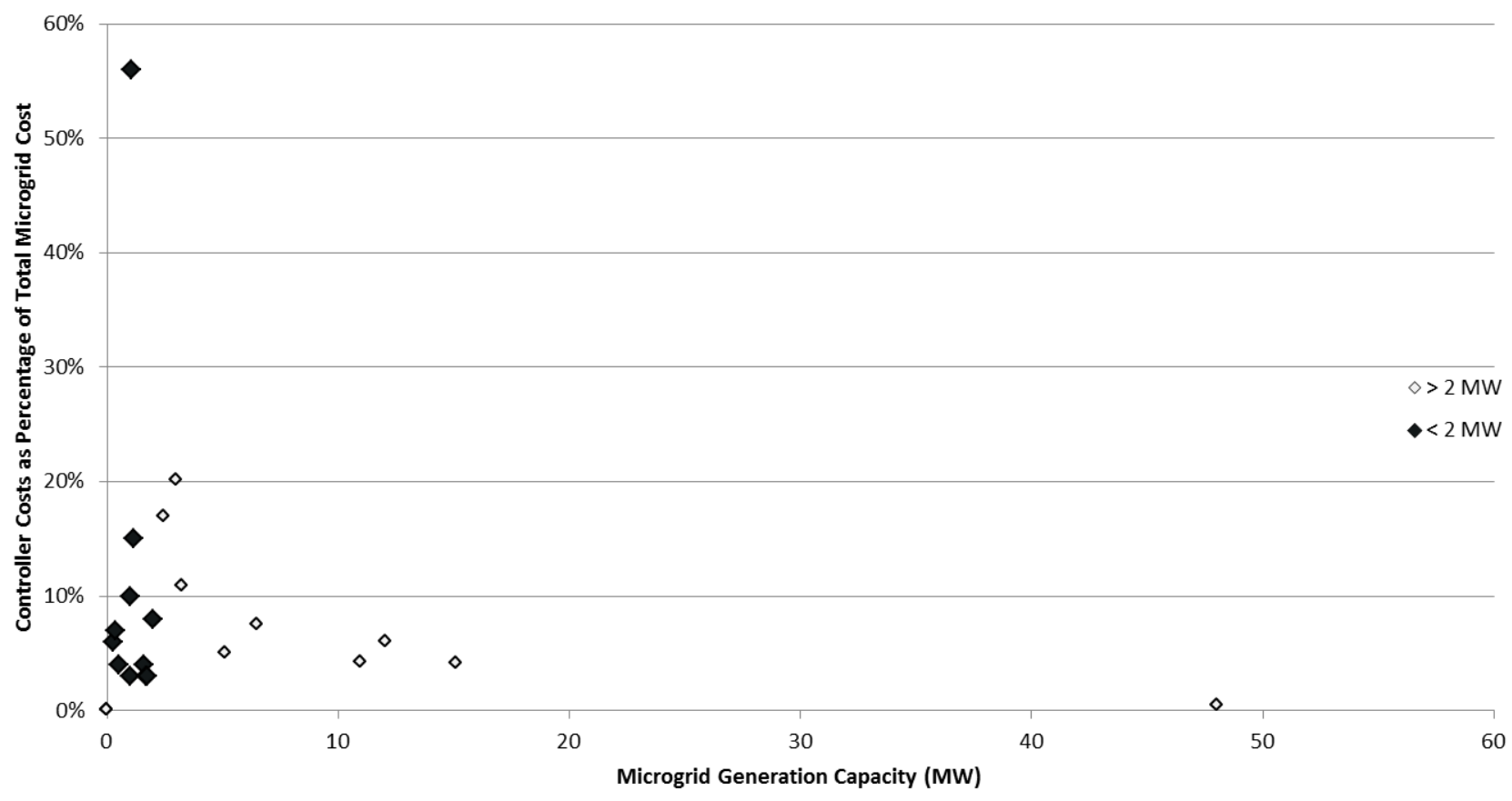

Figure 21. Microgrid controller costs as a percentage of total project costs

Figure 22 shows controller costs as a percentage of total microgrid costs by complexity level. The percentage declines generally as microgrids grow in size, suggesting that the fixed component of controller costs might be significant. 


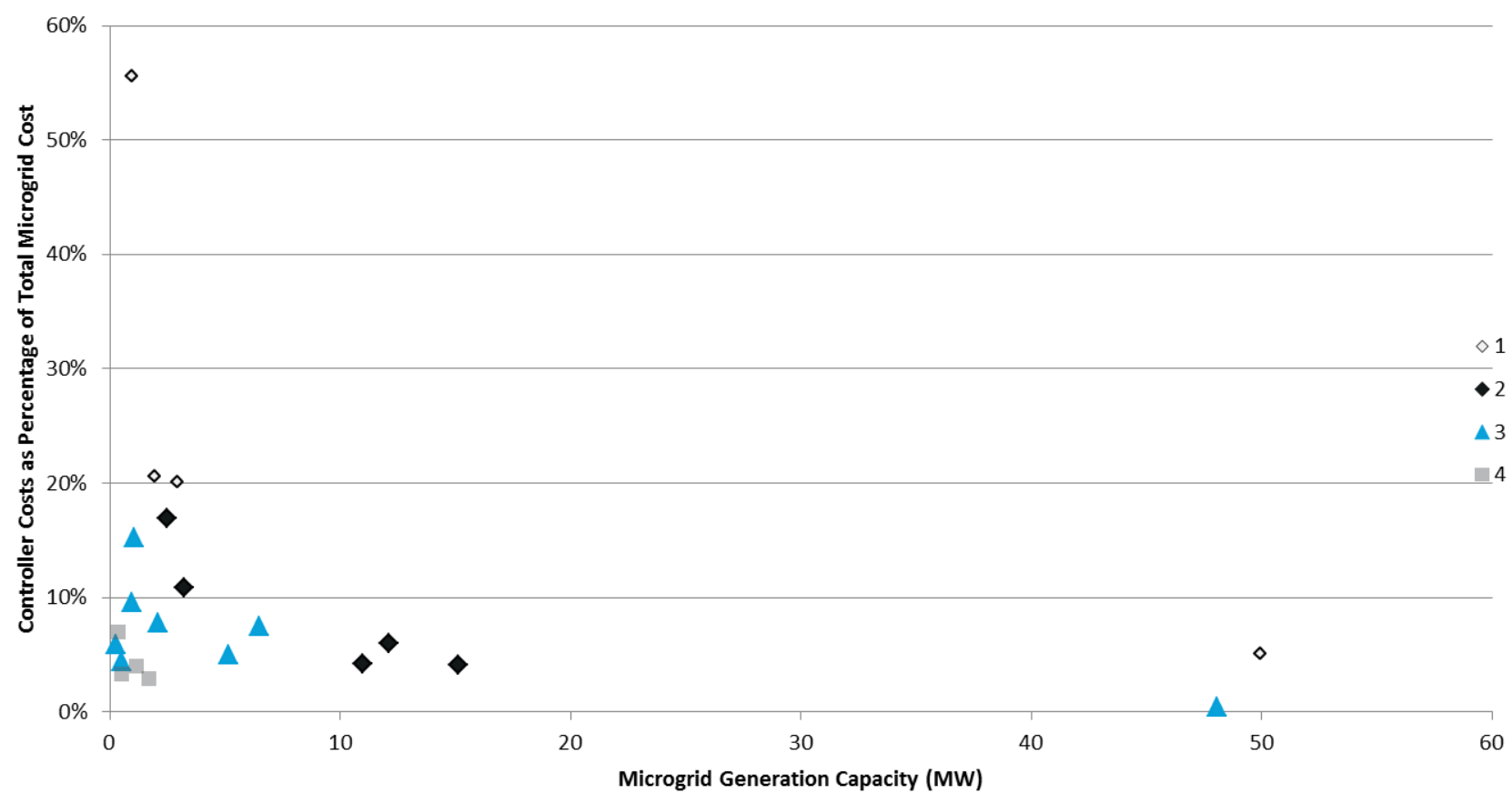

Figure 22. Microgrid controller costs as a percentage of total microgrid costs

A similar analysis of the controller costs for the NY Prize Stage 1 feasibility studies (community microgrids only) is included in Appendix B. The NY Prize data show trends that are similar to the microgrids in the NREL database despite the differences in system size, type, and intended use.

\subsubsection{Soft Costs}

Soft costs include engineering, construction, commissioning, and regulatory costs. Soft costs were calculated as the sum of these four cost subcategories, even for projects that did not include information about each of the four subcategories. Twenty-three projects had information about at least one cost subcategory within the soft cost category. Figure 23 shows a box plot of soft costs as a percentage of total microgrid costs. This cost category exhibits a high degree of variability, ranging from $1 \%-75 \%$. We believe this could be because some of the costs considered in this category might have been reported in other categories. For example, construction and engineering costs related to new generation plants might be reported as installed generation costs in some projects and as soft costs in others. 


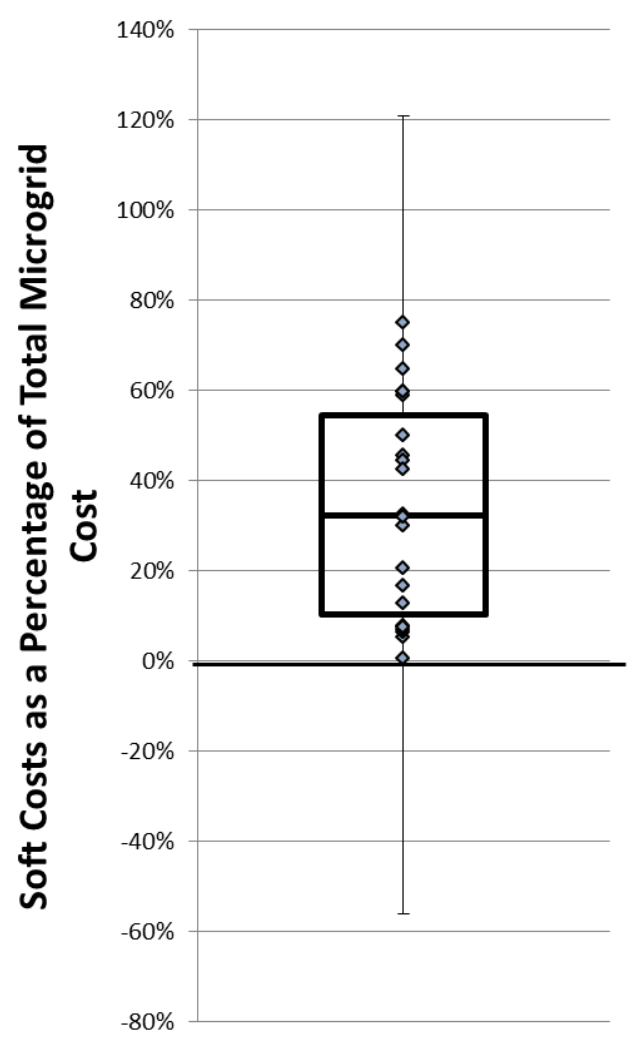

Figure 23. Soft costs as a percentage of total microgrid costs

Figure 24 shows box plots for each soft cost subcategory. Construction shows the highest degree of variability, ranging from $2 \%-75 \%$, and regulatory costs range from $0.4 \%-1.6 \%$.

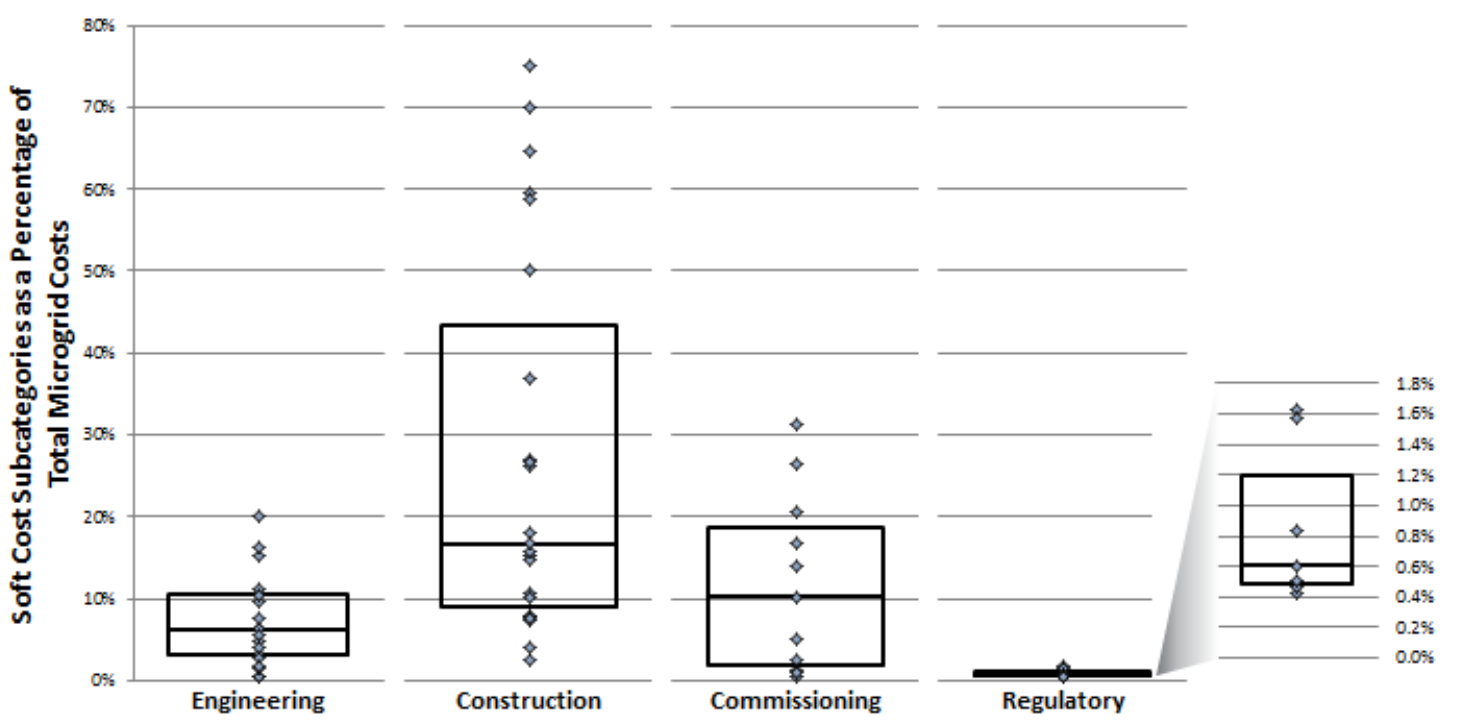

Figure 24. Soft cost subcategories as a percentage of total microgrid costs 
Figure 25 shows total soft costs as a percentage of total microgrid costs. We looked at the data divided by levels and segments, but they did not contain any discernable trend. The data could imply that soft costs are higher for smaller projects (less than $1 \mathrm{MW}$ ) and that there is some economy of scale with soft costs.

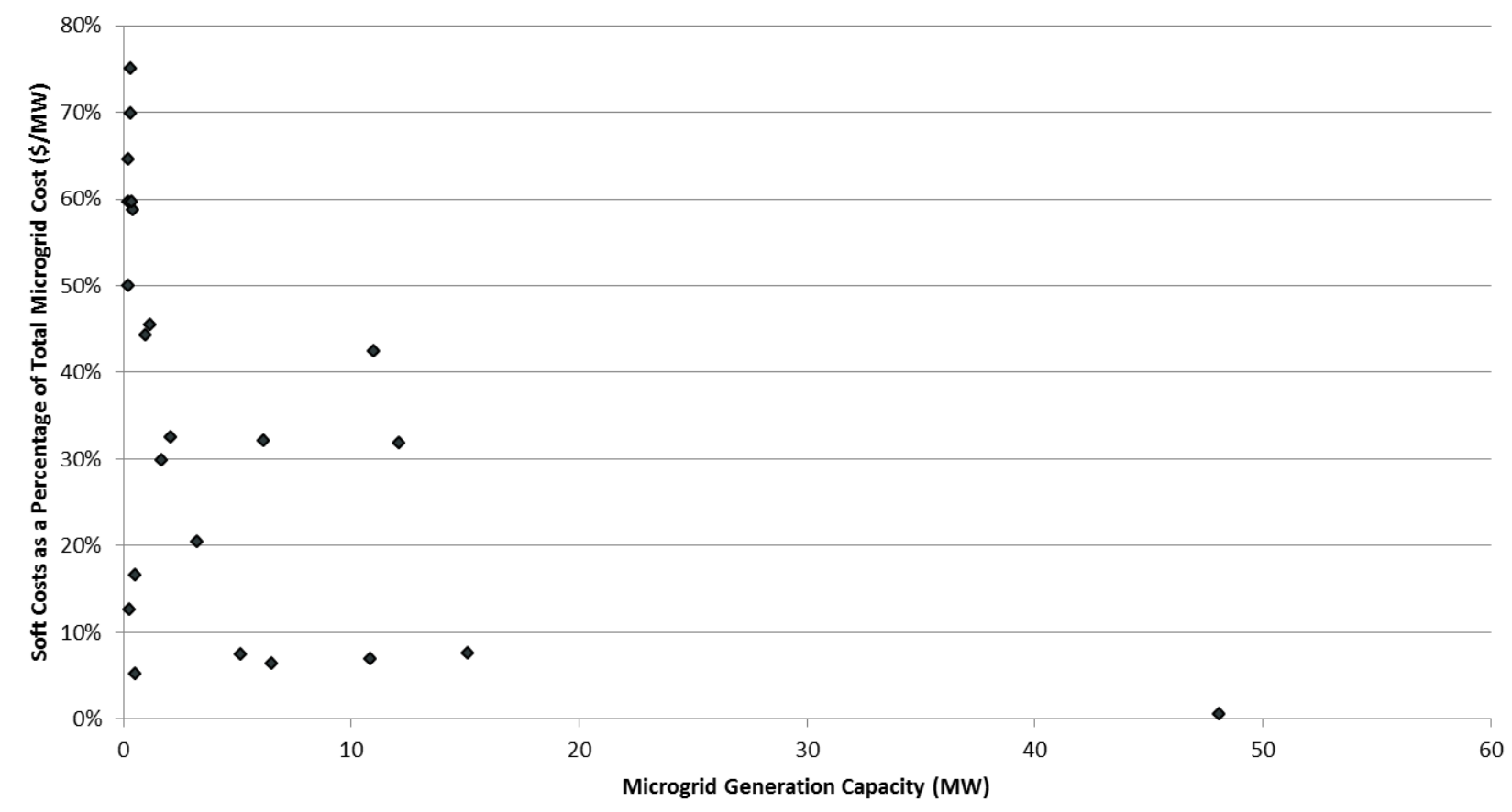

Figure 25. Soft costs as a percentage of total microgrid costs (\$/MW)

\subsubsection{Additional Electric Infrastructure Costs}

Additional electric infrastructure costs include all the expenses on tangible assets, excluding generation equipment. Figure 26 shows additional electrical infrastructure costs as a percentage of total microgrid costs, which range from 1\%-38\%, excluding one outlier with a value of $47 \%$. 


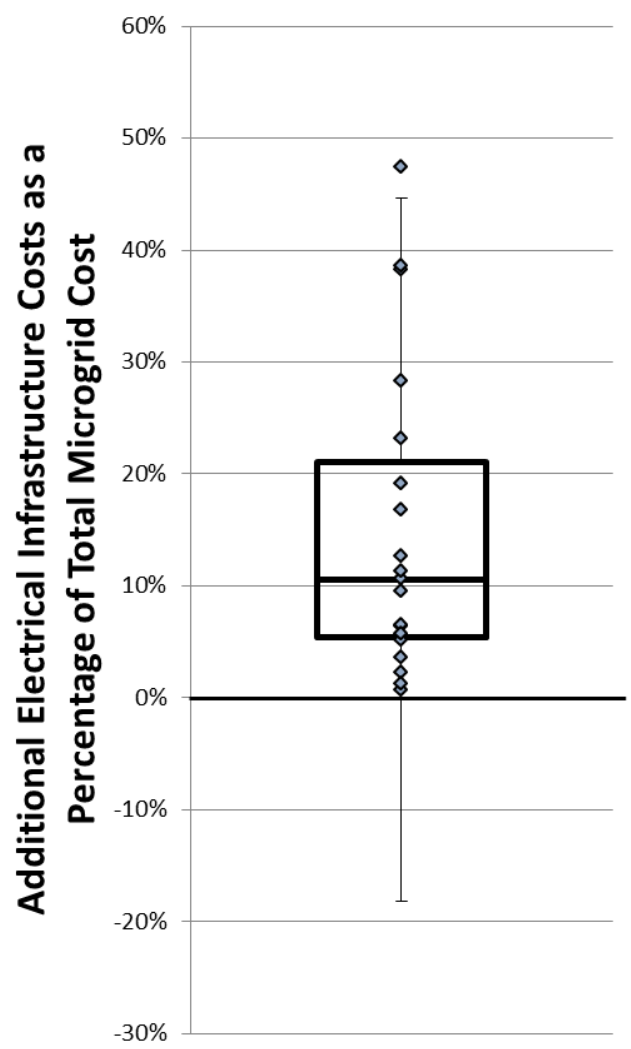

Figure 26. Additional electrical infrastructure costs as a percentage of total microgrid costs

Figure 27 shows additional electrical infrastructure costs per megawatt of capacity for three market segments. No projects in the campus/institutional segment had information about additional electrical infrastructure costs. Costs seem to generally follow a declining trajectory as capacity increases; however, the trend is not strong, particularly considering the small number of data samples. Community and utility market segments show the highest costs associated with this category, and this could be because such market segments tend to involve islanding at the medium-voltage level (when compared to smaller commercial microgrid projects), which involves higher investment in additional infrastructure such as medium-voltage switchgear and supervisory control and data acquisition systems. 


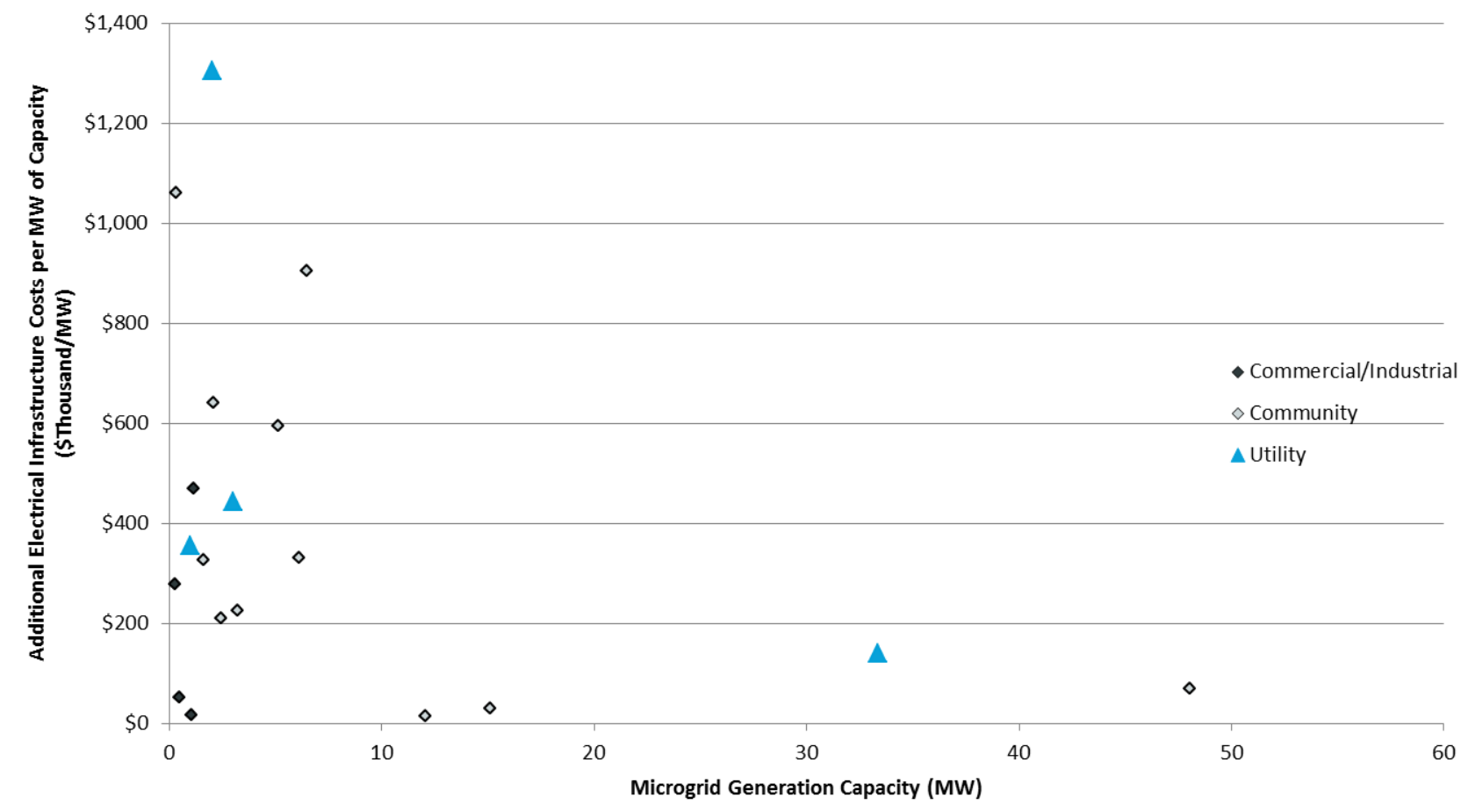

Figure 27. Additional electrical infrastructure costs per megawatt of capacity (\$thousand/MW)

\subsection{NY Prize Feasibility Study Database}

NY Prize is a competition administered by the New York State Energy Research \& Development Authority. The goal of the competition is to assist communities in their efforts to develop microgrids, to enhance the resiliency of the main electric grid, and to provide reliable power for essential services during a power outage. Winners of each stage of the competition receive funding targeted toward planning and feasibility studies (Stage 1), detailed microgrid design (Stage 2), and microgrid build-out (Stage 3). ${ }^{3}$

At present, we have collected data for 80 of the systems that were declared Stage 1 winners in 2015. ${ }^{4}$ We analyzed these data separately from the main NREL microgrid cost database because these are based only on feasibility studies and the projects are early in the planning process. Cost estimate accuracy for this stage of the competition is estimated to be $+/-30 \%$. In March 2017, 11 of the Stage 1 winners were selected for Stage 2 of the competition; these might be included in the NREL microgrid cost database in the future as the project plans and costs are refined. Appendix B contains a brief analysis of NY Prize Stage 1 and Stage 2 microgrid generation capacity and costs by category, mirroring the analysis performed for the NREL microgrid cost database.

The projects in the NY Prize are compared to the community projects in the microgrid database. Our analysis of the energy generation of the NY Prize systems indicates that they have slightly more new generation (compared to existing generation) as a whole than the community category systems in the NREL microgrid cost database; new generation makes up $42 \%-64 \%$ of the total

${ }^{3}$ See https://www.nyserda.ny.gov/All-Programs/Programs/NY-Prize.

${ }^{4}$ Three other systems were declared winners, but they did not provide detailed cost data. 
for the NY Prize projects (see Figure A-1) but only $29 \%$ for the community microgrid projects in the microgrid database (see Figure 12). Although community microgrid energy generation is dominated by diesel and natural gas in the microgrid database (see Figure 8 and Figure 13), the NY Prize systems have more CHP and other sources of energy, such as hydroelectric and wasteto-energy conversion (see Figure A-2 and Figure A-3). Renewable energy sources such as solar $\mathrm{PV}$ and wind make up less than $5 \%$ of generation for all of the microgrid systems.

Like the systems in the NREL microgrid database, the bulk of the cost of the NY Prize microgrids comes from conventional generation. Renewable generation, balance of systems, and additional infrastructure each contribute $10 \%-15 \%$, and controls and energy storage contribute less toward total costs. 


\section{Conclusions and Future Work}

Cost information for 80 microgrids was collected through an online survey, by directly contacting industry members and microgrid owners, and from publicly available information. The cost data reflect a wide range of microgrid design variability in the United States. The database reflects the regional distribution described by Navigant Research and GTM: (1) more than $50 \%$ of operational microgrids are located in states in the East Coast and West Coast, and (2) regional hot spots include California, the Northeast, and Alaska. In terms of DER mix, the microgrid study database reflects the market trend dominated by CHP and natural gas, followed by traditional diesel generation. It also shows that PV and storage are being installed in microgrids in the United States. The main characteristics of each market segment by DER type are summarized as follows:

- The campus/institutional segment is dominated by new CHP generation capacity.

- Communities are leveraging existing emergency diesel and natural gas generators into new microgrid projects.

- The commercial projects in the microgrid database show that the largest DER technology used is existing diesel generators, and the new technologies being installed in microgrids are energy storage, CHP, and solar PV.

- For utility microgrids, existing solar projects are in the form of DERs, which have the highest capacity, followed by new natural gas, diesel generators, and energy storage. Note that this group has only five entries in the database, and one of the projects integrates an existing, large PV project under a power purchase agreement.

- In remote microgrids, the focus is on reducing diesel fuel consumption by methods including increasing the percentage share of renewable energy and energy storage capacity. Existing wind, diesel, and new storage are the most prevalent forms of DERs.

Other conclusions drawn from the data classification and analysis of the microgrid database are listed as follows:

- Often, microgrid projects are built in phases and leverage existing DER projects built throughout time. The percentage of existing generation varies widely among market segments, ranging from $3 \%$ for campus/institutional microgrids to $68 \%$ for utility microgrids. The weighted average of existing generation per market segment of the projects represented in the database is $10 \%$.

- Regarding the type of existing DER assets that are integrated into microgrids, campus microgrids leverage primarily natural gas generators and renewable energy projects, whereas the commercial and community segments leverage legacy emergency diesel generators. The utility segment data were skewed by one project that has $26.5 \mathrm{MW}$ of solar capacity.

- To analyze total costs of microgrids, the projects in the microgrid database were classified according to (1) market segment and (2) microgrid complexity level. Complexity is described as a function of the number of DER assets, amount of renewable energy penetration, energy storage, control architecture, and enterprise-level capabilities. 
- By market segment, the main conclusions are:

o The analysis of total microgrid costs per megawatt shows that the community microgrid market has the lowest mean, at \$2.1 million/MW of DERs installed; followed by the utility and campus markets, which have mean costs of $\$ 2.6$ million/MW and \$3.3 million/MW, respectively. Finally, the commercial market has the highest average cost, at \$4 million/MW.

o The analysis of the normalized cost of projects as a function of the capacity of the projects seems to indicate that there might be some economy of scale in projects larger than $10 \mathrm{MW}$ of installed generation capacity. The commercial microgrid projects in the database are all less than $3 \mathrm{MW}$, with the exception of one larger project, and they drive the higher costs reported for this market segment

o Regarding the breakdown of component costs with respect to total system costs per megawatt, conventional and renewable generation represent the largest percentage in most segments. Conventional generation accounts for $76 \%$ of the total cost per megawatt in microgrids in the campus/institutional segment and $54 \%$ in the community segment. In commercial/industrial and utility microgrids, soft costs (43\% and 24\%, respectively) represent a significant portion of the total costs per megawatt. Finally, energy storage contributes significantly to the total cost of commercial and community microgrids, with percentages of $25 \%$ and $15 \%$ of the total costs per megawatt.

- By complexity level, the main conclusions are:

o Level 1 projects have the lowest mean, at \$2 million/MW (Table 4). The normalized costs in terms of IQR values and mean are very similar for levels 2 and 3, with average costs in the range from $\$ 3.5$ million/MW to $\$ 3.1$ million/MW. The IQR range and mean increase for Level 4, which has a mean of \$4.4 million/MW.

o Conventional generation costs represent the largest share of component costs in all levels, reaching $88 \%$ for levels 2 and 5 . Level 1 microgrids have a considerably higher portion of total cost per megawatt assigned to the controls and additional infrastructure components. This could be because microgrids at this level are represented by networked diesel generators, in which a larger portion of the project cost is commonly directed to retrofitting legacy generators (operating with an automatic transfer switch) to enable parallel operation. Level 3 projects show that renewable energy and storage costs become the most prominent contributor to the total costs of the projects. Finally, Level 4 microgrids show a considerable increase in soft costs.

- Microgrid controller costs reported in the microgrid database per megawatt range from $\$ 6,200 / \mathrm{MW}-\$ 470,000 / \mathrm{MW}$, excluding outliers, with a mean of $\$ 155,000 / \mathrm{MW}$.

- The soft cost category exhibits a high degree of variability, ranging from $1 \%-75 \%$. We believe this could be because some of the costs considered in this category might have been reported in other categories. For example, construction and engineering costs related to new generation plants might be reported as installed generation costs in some projects and as soft costs in others. 
A series of hypotheses are made from the non-DER cost components collected in the microgrid database:

- Controller cost as a percentage of total microgrid costs—both by market segment and complexity level—show a decline generally as microgrids grow in size, suggesting that the fixed component of controller costs might be significant.

- Soft costs are higher for smaller projects (less than $1 \mathrm{MW}$ ).

- Community and utility market segments show the highest costs associated with the additional infrastructure cost category, and this could be because such market segments tend to involve islanding at the medium-voltage level (when compared to smaller commercial microgrid projects), which involve more investments in additional infrastructure, such as medium-voltage switchgear and supervisory control and data acquisition systems.

Finally, in Phase II of this microgrid cost study we will analyze technical and cost drivers and barriers based on the input received form an industry workshop on microgrid costs and interviews with industry representatives. 


\section{References}

Abebe, A., J. Daniels, J.W. McKean, and J.A. Kapenga. 2001. Statistics and Data Analysis. Kalamazoo, MI: Western Michigan University.

http://www.stat.wmich.edu/s160/book/book.html.

Ardani, K., E. O’Shaughnessy, R. Fu, C. McClurg, J. Huneycutt, and R. Margolis. 2017.

Installed Cost Benchmarks and Deployment Barriers for Residential Solar Photovoltaics with Energy Storage: Q1 2016 (Technical Report NREL/TP-7A40-67474). Golden, CO: National Renewable Energy Laboratory. https://www.nrel.gov/docs/fy17osti/67474.pdf.

Bidram, A., and A. Davoudi. 2012. "Hierarchical Structure of Microgrids Control System.” IEEE Transactions on Smart Grid 3 (4). doi:10.1109/TSG.2012.2197425.

Bolinger, M., and J. Seel. 2016. Utility-Scale Solar 2015: An Empirical Analysis of Project Cost, Performance, and Pricing Trends in the United States (Technical Report LBNL-1006037). Berkeley, CA: Lawrence Berkeley National Laboratory.

Chung, D., C. Davidson, R. Fu, K. Ardani, and R. Margolis. 2015. U.S. Photovoltaic Prices and Cost Breakdowns: Q1 2015 Benchmarks for Residential, Commercial, and Utility-Scale Systems (Technical Report NREL/TP-6A20-64746). http://www.nrel.gov/docs/fy15osti/64746.pdf.

DOE. 2011. DOE Microgrid Workshop Report (Technical Report). Washington, D.C. https://energy.gov/sites/prod/files/Microgrid\%20Workshop\%20Report\%20August\%202011.pdf.

Feldman, D., G. Barbose, R. Margolis, M. Bolinger, D. Chung, R. Fu, J. Seel, C. Davidson, N. Darghouth, and R. Wiser. 2015. Photovoltaic System Pricing Trends: Historical, Recent, and Near-Term Projections-2015 Edition. Washington, D.C.: U.S. Department of Energy (DOE), Sunshot. http://www.nrel.gov/docs/fy15osti/64898.pdf.

Fu, R., D. Chung, T. Lowder, D. Feldman, K. Ardani, and R. Margolis. 2016. U.S. Solar Photovoltaic System Cost Benchmark: Q1 2016 (Technical Report NREL/TP-6A20-66532). Golden, CO: National Renewable Energy Laboratory. http://www.nrel.gov/docs/fy16osti/66532.pdf.

Hatziargyriou, N. 2014. Microgrids: Architectures and Control. Wiley. http://onlinelibrary.wiley.com/book/10.1002/9781118720677.

Wood, E. 2016. “What Does a Microgrid Cost?” Microgrid Knowledge. April 26, 2016. https://microgridknowledge.com/microgrid-cost/. 


\section{Appendix A}

The template used to collect microgrid project costs data is shown as follows. 


\section{Characterization}

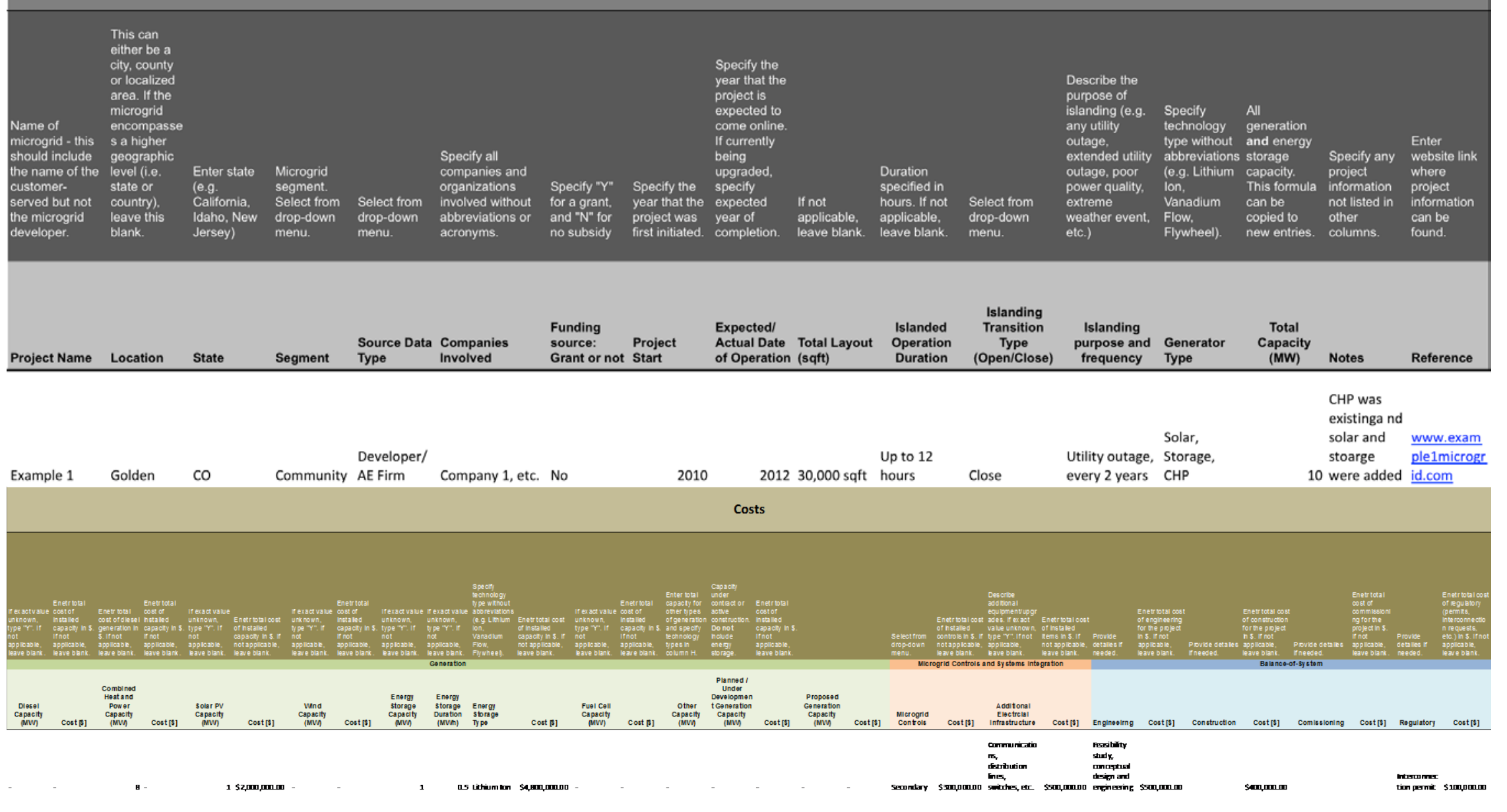


Dear Microgrid Market Participant:

The Office of Electricity of the U.S. Department of Energy (DOE), the National Renewable Energy Laboratory (NREL), and Navigant Research are developing a microgrid cost database. The project aims at identifying the costs of components, installation, system integration and soft costs (nonhardware) of U.S. commercial microgrids. This is your opportunity to help shape the standardization of reporting development costs across the microgrid industry. By gathering costs from real and under development microgrids, it is expected that the DOE will identify which components and/or development activities related to the microgrid revenue stream will require targeted R\&D support. In short, this is your opportunity to help guide the federal government's framework for aocelerating the deployment of microgrids in the U.S.

The cost data provided by the participants will be kept confidential. Each project entry, which will contain many data points similar to the Microgrid Deployment Tracker (capacity of different distributed generation and/or energy storage technologies), but will remain anonymous and will include actual cost data per category, whenever possible.

NREL/DOE are particularly interested in costs and performance attached to system level integration and non-hardware balance-of-system (BOS) costsoften referred to as "soft" costs, as well as in gaining more insight into the functionalities provided by different microgrid projects and how they affect the overall cost of the system.

Here are some examples of data fields to be filled out by survey participants: microgrid driver, islanded duration and transition type, and microgrid control types and costs.

In addition, we will be seeking data on the following cost categories: engineering, construction, commissioning and regulatory costs.

Please let us know if you are interested in participating by May 31st by clicking on the link below.

Start Survey

Some vendors, among them Schneider Electric and Encorp, have already agreed to participate. The more companies that contribute, the better the data and the more accurate industry-wide market forecasts can be. The results of this NREL study will be published at an aggregate level and the report will be publicly available. By participating in this survey, you will gain access to the data first and can help shape its presentation and interpretation into future DOE R\&D agendas for the development of the next generation microgrids. We thank you for your participation.

Sincerely,

Julieta Giraldez

NREL

Peter Asmus

Navigant Research 


\section{Appendix B: NY Prize Microgrid Energy Generation}

We collected information from 80 proposed Stage 1 NY Prize microgrid projects. (There were 83 State 1 winners, but 3 projects did not have detailed cost data.) We analyzed the 11 microgrids selected for Stage 2 separately because we think those microgrids are the most likely to be built and thus that information is significant. All of the NY Prize microgrids fall in the community market segment, so we compare NY Prize projects to only the community projects in the NREL cost database.

\section{New and Existing Generation}

The winners of the Stage 1 competition called for an average of 64\% new generation, which is slightly less than the average of $71 \%$ new generation for microgrids in the community segment in the NREL cost database. Those that were selected for Stage 2 funding leveraged a higher percentage of existing generation than the Stage 1 winners: 58\% versus 36\% (Figure A-1.).

\section{Stage 1}

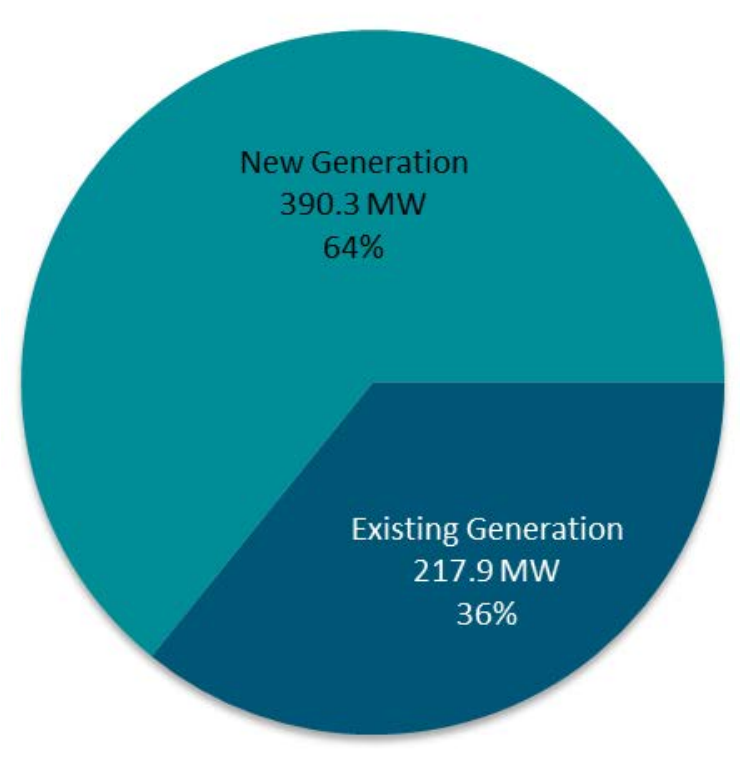

Stage 2

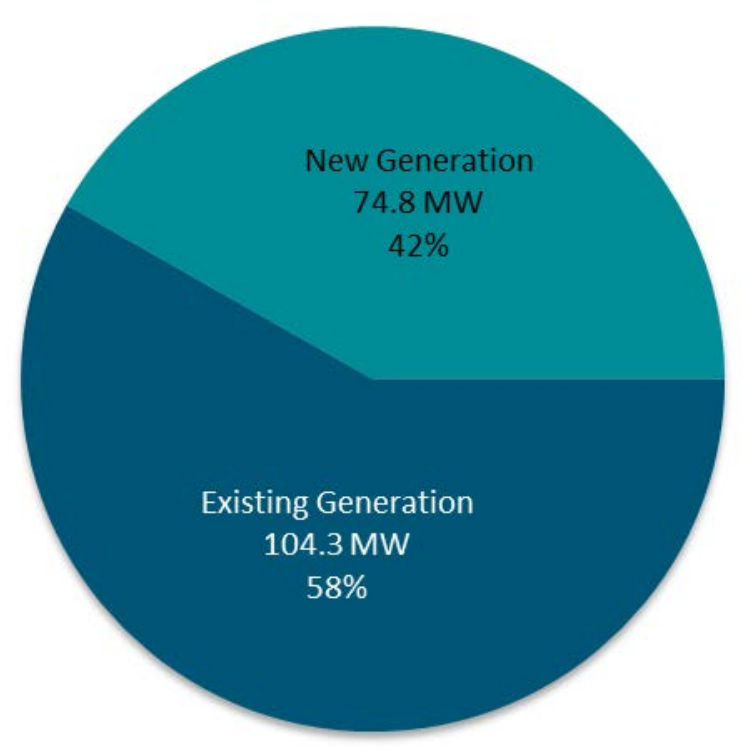

Figure A-1. New and existing generation for Stage 1 (left) and Stage 2 (right) of the NY Prize microgrids

\section{Existing Generation Fuel Types}

Similar to the community projects in the NREL cost database, winning projects of both stages of the NY Prize have a large diesel component, particularly for Stage 1 (Figure A-2.). In general, NY Prize winners do not leverage much existing renewable energy capacity, with 6\% solar PV capacity for Stage 1 and 1\% for Stage 2. A large component of existing capacity leveraged for new microgrid projects is the "Other" category; however, most of the capacity in this category comes from a single, 39.6-MW waste-to-energy project. Existing CHP is among the top three 
generation technologies in terms of capacity leveraged in both Stage 1 and Stage 2 projects. The natural gas share of 9\% in Stage 1 projects drops to almost 0\% in Stage 2.

\section{NY Prize Stage 1 Existing Generation}

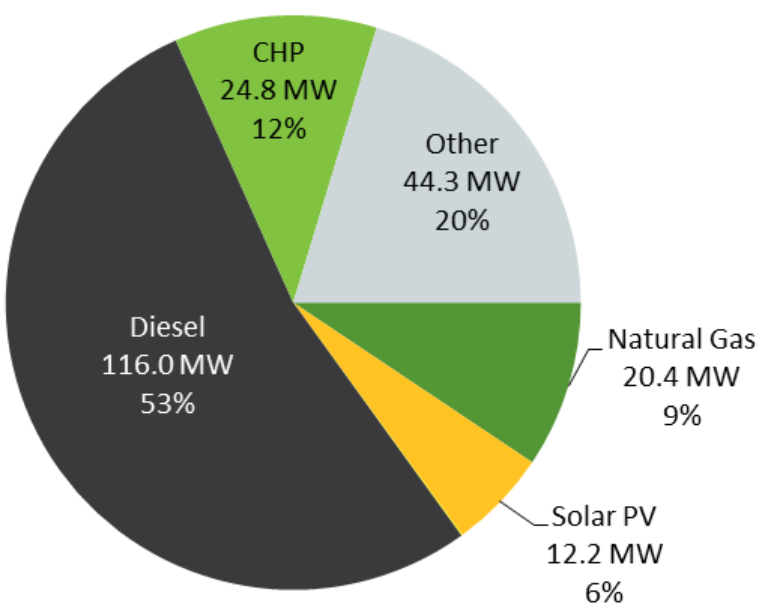

\section{NY Prize Stage 2 \\ Existing Generation}

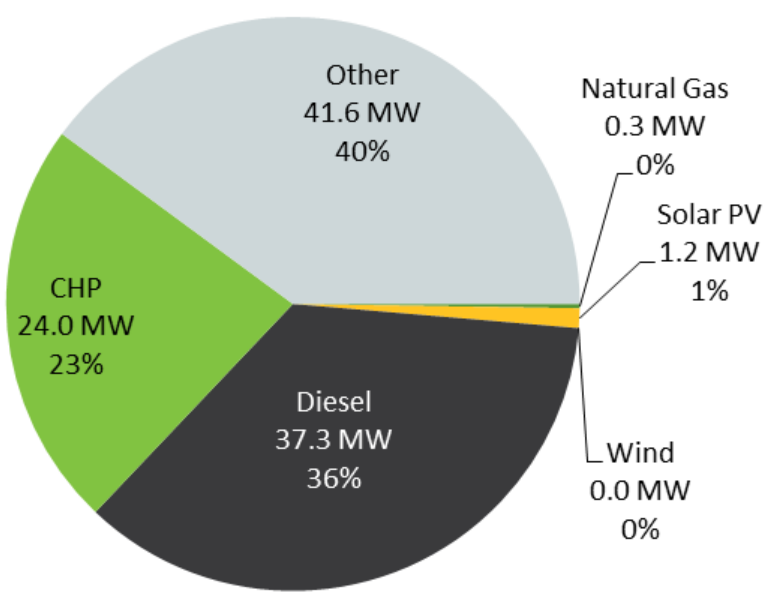

Figure A-2. Existing generation by type for the Stage 1(left) and Stage 2 (right) NY Prize microgrids

\section{New and Existing Energy Generation}

New CHP has the highest share of capacity among Stage 1 winners, followed by existing diesel, new natural gas, and new solar PV. Capacity in the "Other" category has the highest share among Stage 2 winners, primarily because of the aforementioned 39.6-MW project. Existing diesel, new natural gas, and new CHP are the other technologies with the biggest shares among Stage 2 winners (Figure A-3.). Regarding generation from renewable sources, PV and wind have shares smaller than $5 \%$ each in both stages. The main energy generation differences between the two databases are the "Other" category in the NY Prize and the fact that the main database has a much higher fraction of diesel generation, whereas the NY Prize systems rely more heavily on CHP. 


\section{Community - New and Existing Generation by Technology}

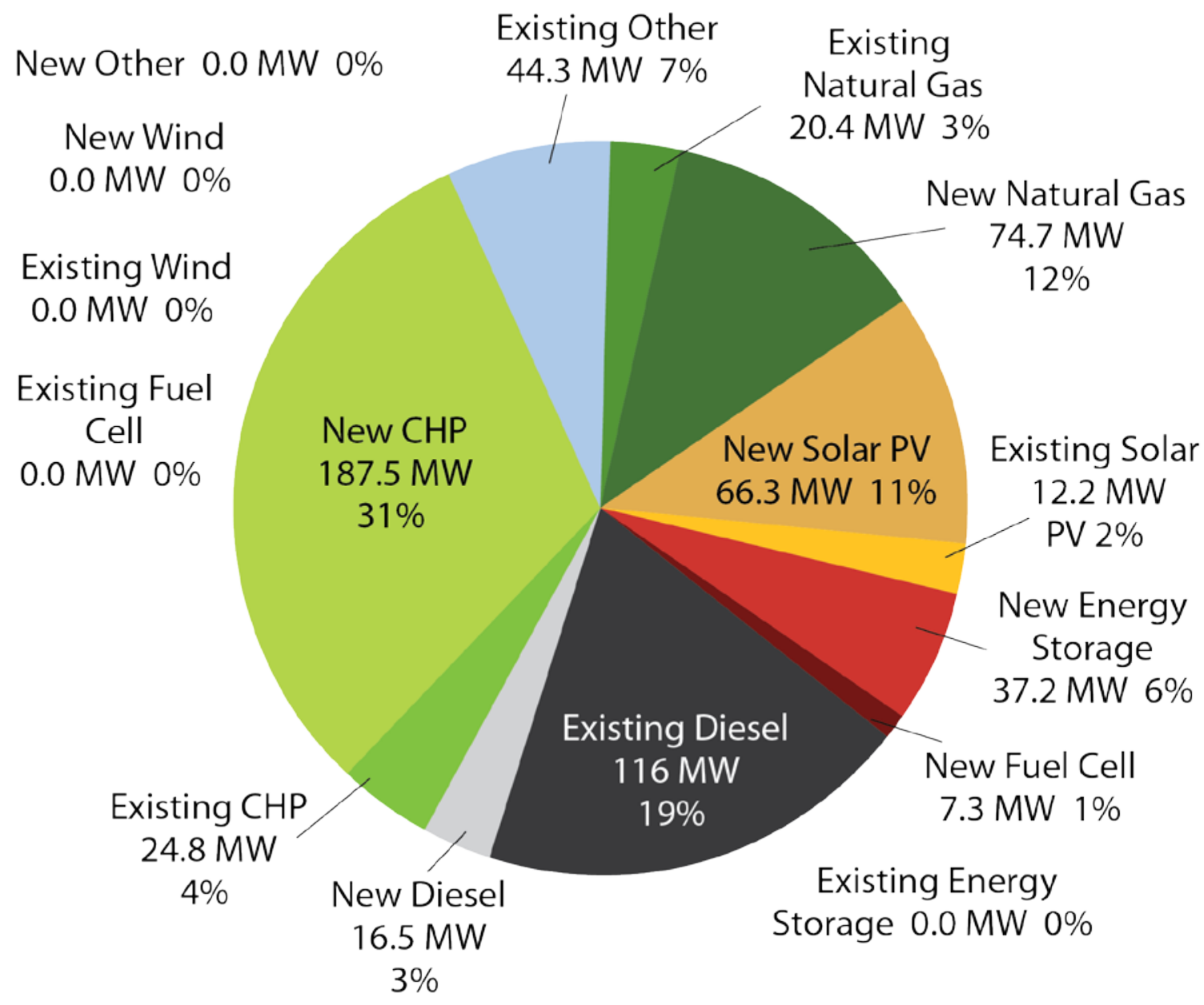




\section{Community - New and Existing Generation by Technology}

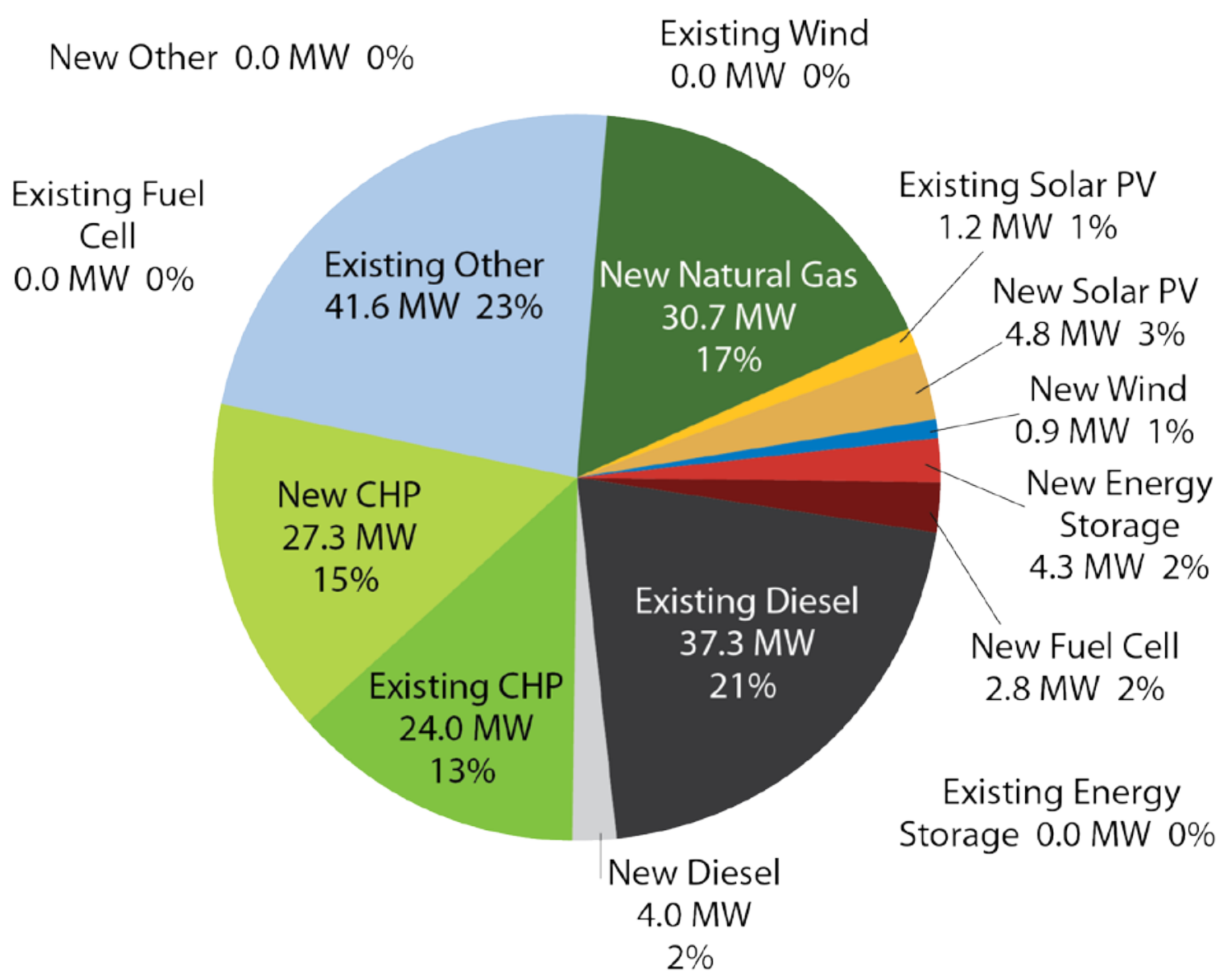

Figure A-3. New and existing generation for the Stage 1 (top) and Stage 2 (bottom) NY Prize microgrids

\section{Component Category Costs}

Looking at costs per megawatt by component, the cost distribution is very similar between Stage 1 and Stage 2 projects. This might be because the NY Prize application required applicants to accurately disaggregate costs. The main difference between both stages is that conventional generation costs go from 49\% in Stage 1 to 61\% in Stage 2, whereas energy storage decreases from $11 \%$ in Stage 1 to 3\% in Stage 2. Renewable generation accounts for approximately 10\% of the total cost, additional infrastructure accounts for $16 \%$, and soft costs account for $9 \%$. 

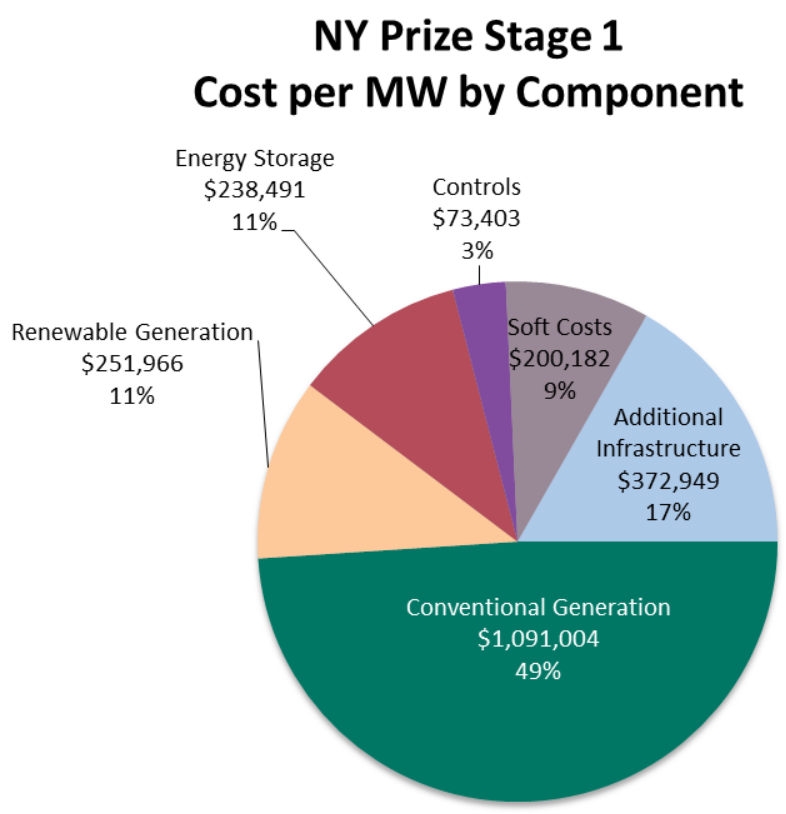

NY Prize Stage 2 Cost per MW by Component

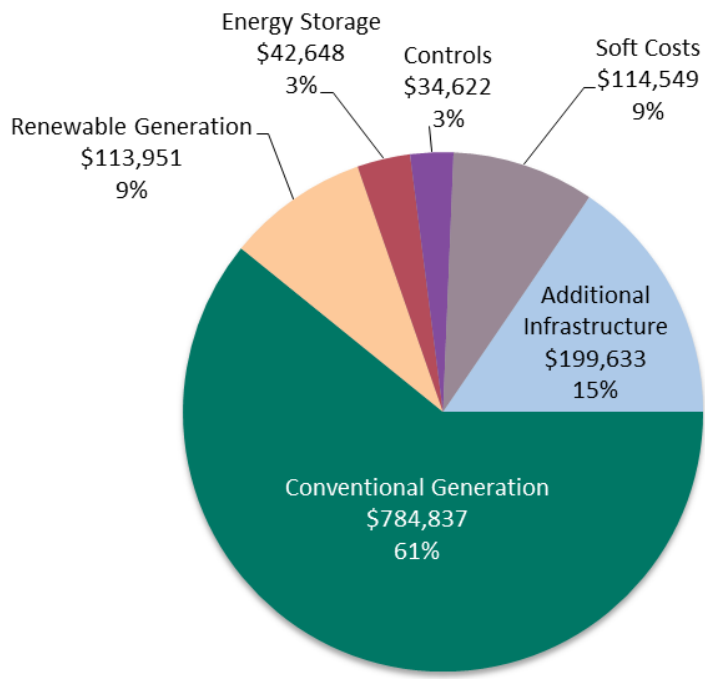

Figure A-4. Total cost breakdown per component category

\section{Controller Costs}

We analyzed the distribution of controller costs as a percentage of total microgrid costs for all of the Stage 1 systems that specifically included these data (46 out of 80 systems). Figure A-5. shows the 5\% median. The Q1-Q3 range goes from 2\%-9\% compared to a 7\% median and 4\%$11 \%$ range for the rest of the NREL microgrid database. The maximum value is $20 \%$, excluding a $37 \%$ outlier. The analysis shows that controller cost data as a percentage of total microgrid costs are relatively similar among the projects in our database and the NY Prize data despite the wide variety of system sizes, types, and uses.

Controller costs per megawatt range from $\$ 3,500 / \mathrm{MW}$ to nearly $\$ 600,000 / \mathrm{MW}$, excluding outliers, with a mean of $\$ 85,000 / \mathrm{MW}$. Note that these are estimated costs instead of the actual installed costs found in much of the NREL microgrid database, which might account for the wider spread in costs per megawatt and lower average cost for the NY Prize systems. 

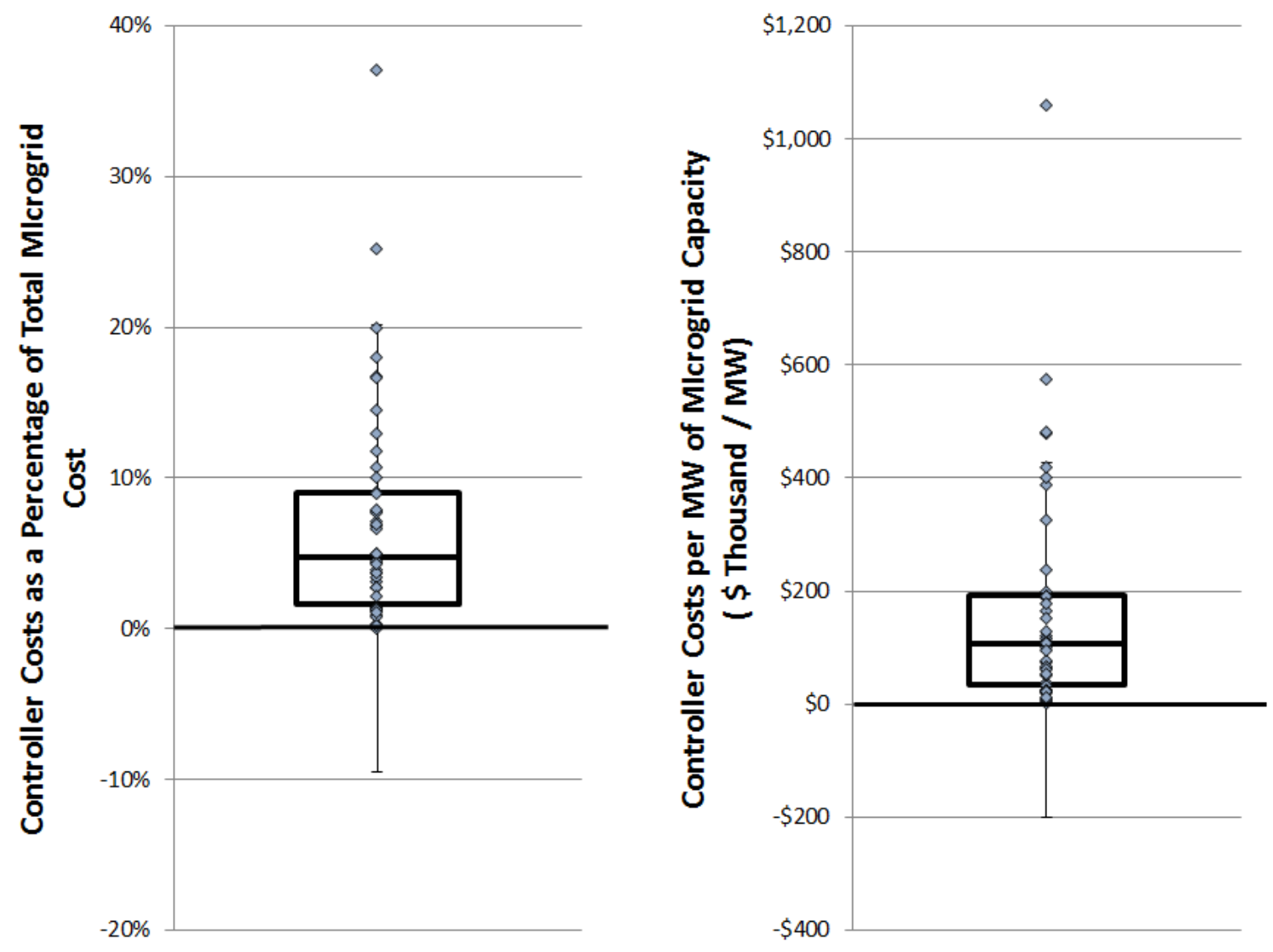

Figure A-5. Controller cost data as a percentage of total microgrid costs as dollars per megawatt of microgrid capacity (left) and per megawatt for the NY Prize Stage 1 feasibility studies (right)

Figure A-6. shows microgrid controller costs as a percentage of total project costs sorted by generation capacity in megawatts for the NY Prize Stage 1 feasibility studies. As with the NREL microgrid database systems, these microgrid controller costs show a generally downward trend as capacity increases for projects of $2 \mathrm{MW}$ or more (shown in light blue in the graph). 


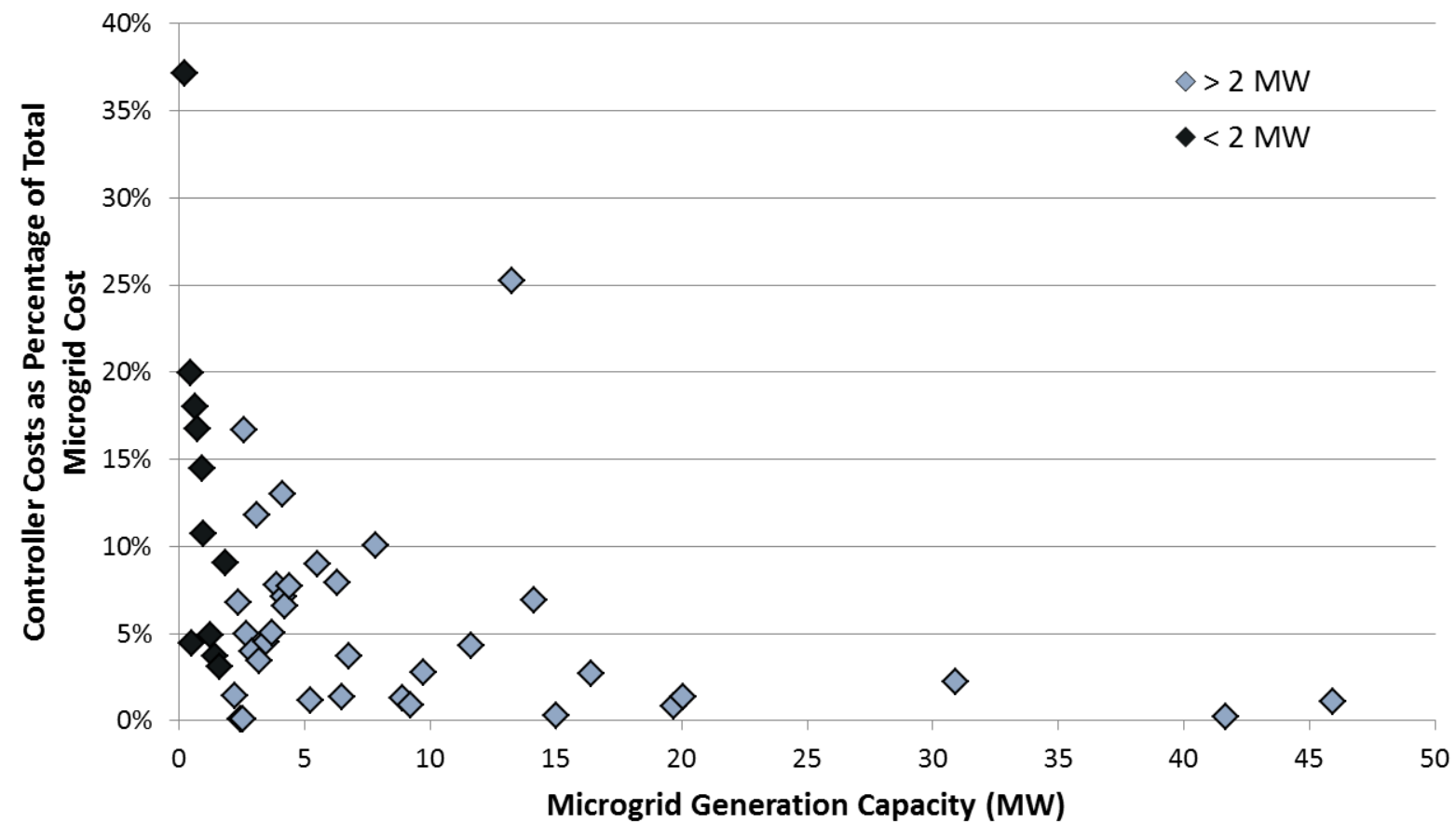

Figure A-6. Microgrid controller costs as a percentage of total project costs for the NY Prize Stage 1 feasibility studies

\section{Soft Costs}

As with the main NREL microgrid database, soft costs for the NY Prize data include engineering, construction, commissioning, and regulatory costs. Soft costs were calculated as the sum of these four cost subcategories, even for projects that did not include information about each of the four subcategories. Seventy-one projects had information about at least one cost subcategory within the soft cost category. Figure A-7. shows a box plot of soft costs as a percentage of total microgrid costs; all systems with soft cost data were included to show the wide variation in the NY Prize feasibility studies. Some systems’ total costs were made up entirely of soft costs. 


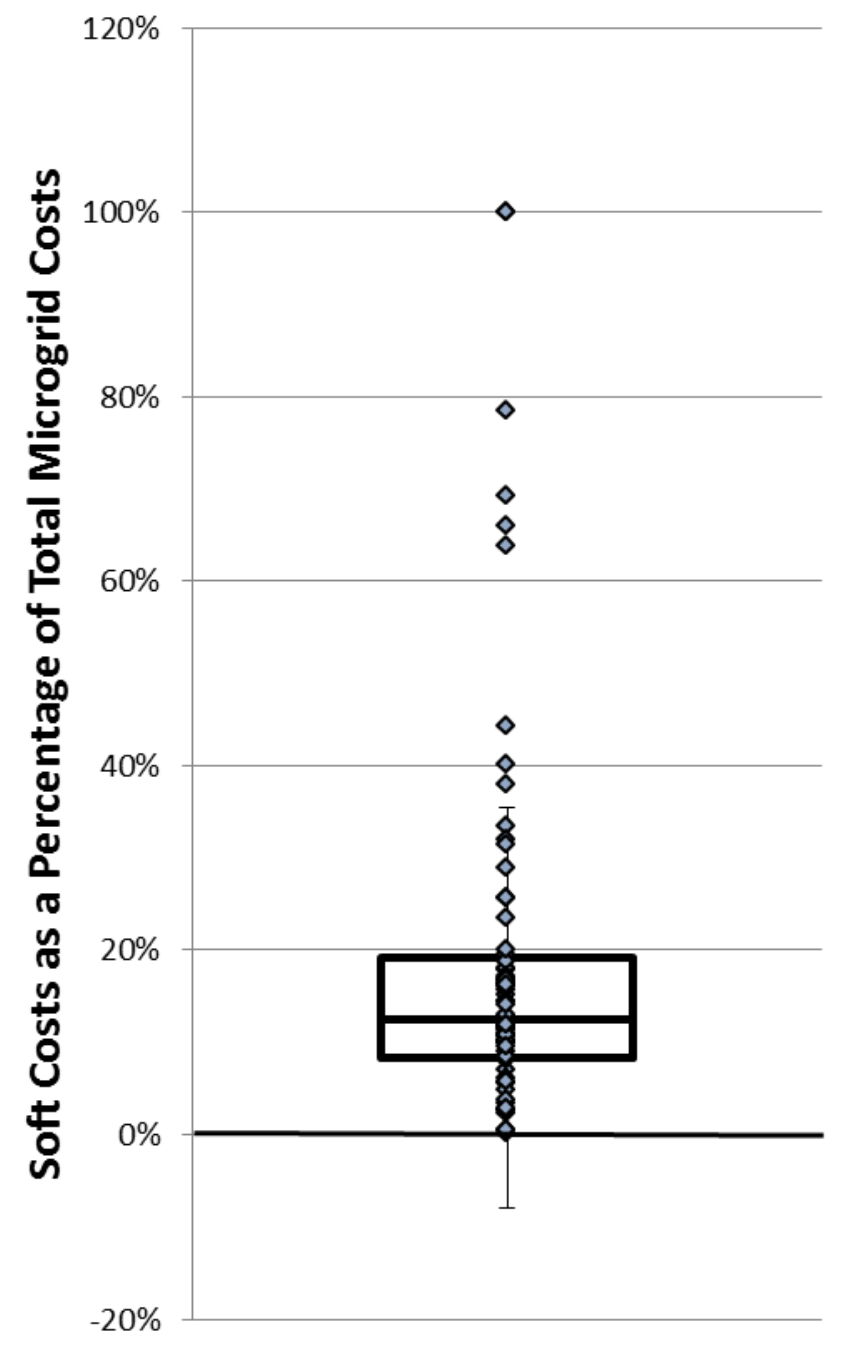

Figure A-7. Soft costs as a percentage of total microgrid costs for the NY Prize feasibility studies

Figure A-8. shows soft costs as a percentage of microgrid cost as a function of microgrid capacity. With the exception of the outliers identified in Figure A-7., soft costs generally follow a downward trend as microgrid capacity increases. The NY Prize data demonstrate the need for standardization in reporting microgrid costs and cost estimates and a better, more detailed understanding of both. 


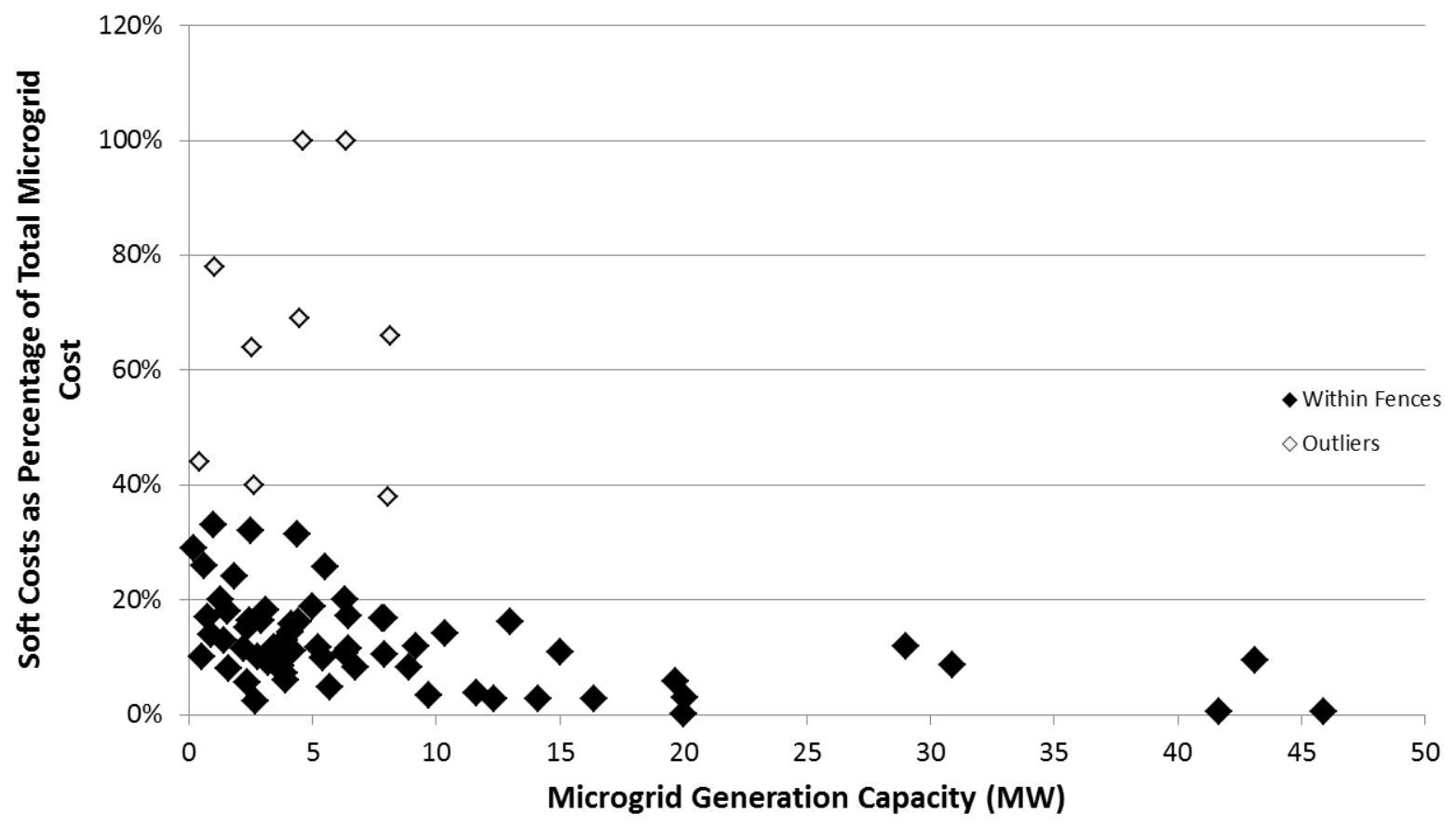

Figure A-8. Soft costs as a percentage of total microgrid cost compared to microgrid capacity for the NY Prize feasibility studies

\section{Additional Electric Infrastructure Costs}

Additional electric infrastructure costs include all the expenses on tangible assets, excluding generation equipment. These costs were estimated for 56 of the 80 systems in the NY Prize feasibility study database. Figure A-9. shows estimated additional electrical infrastructure costs as a percentage of total microgrid cost, which range from $1 \%-38 \%$, excluding a pair of outliers near the range from $65 \%-75 \%$. 


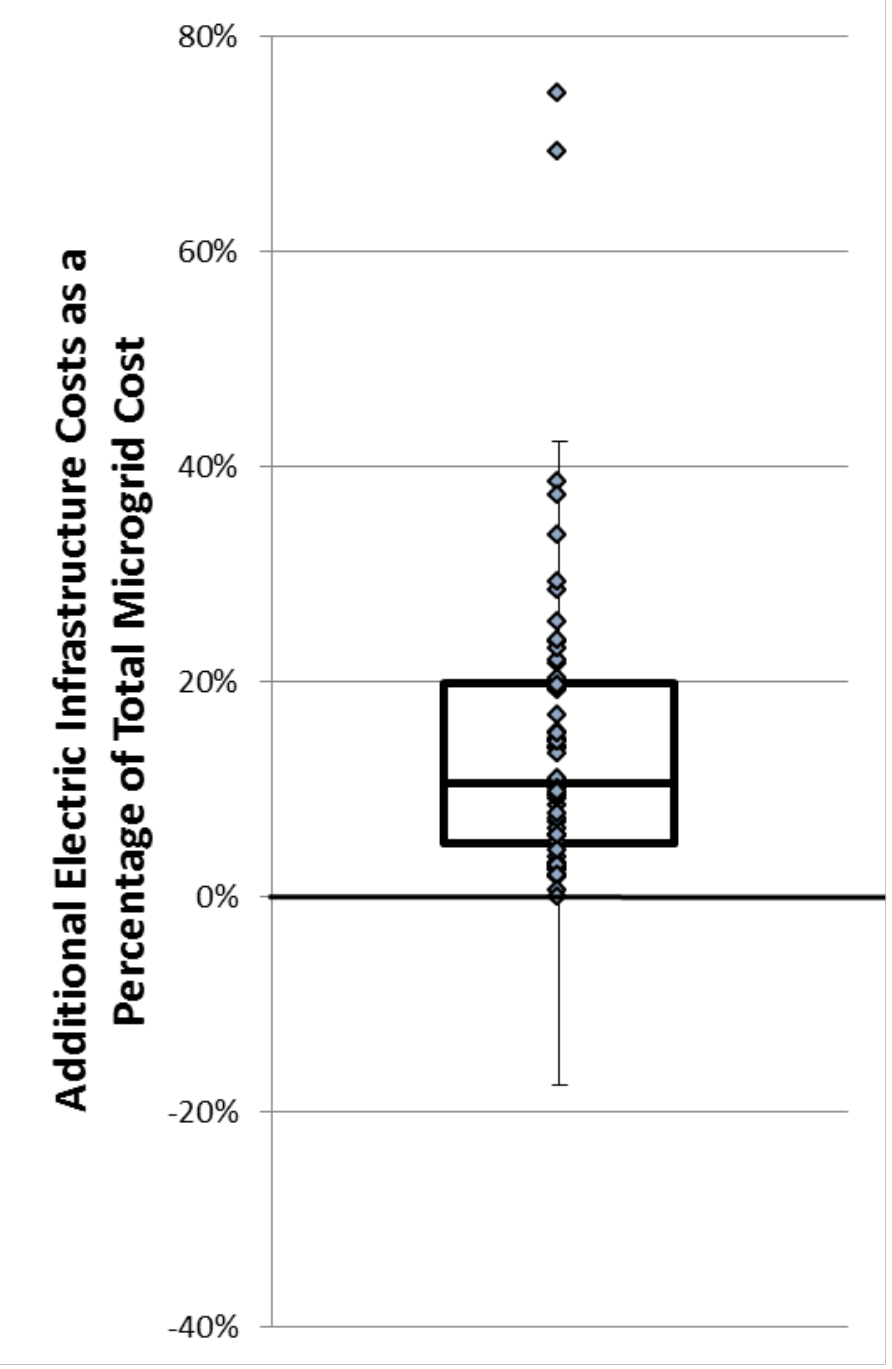

Figure A-9. Additional electric infrastructure costs as a percentage of total microgrid cost for the NY Prize feasibility study data

Figure A-10. shows additional electric infrastructure costs plotted against microgrid capacity. No apparent trend was gleaned from these data. 


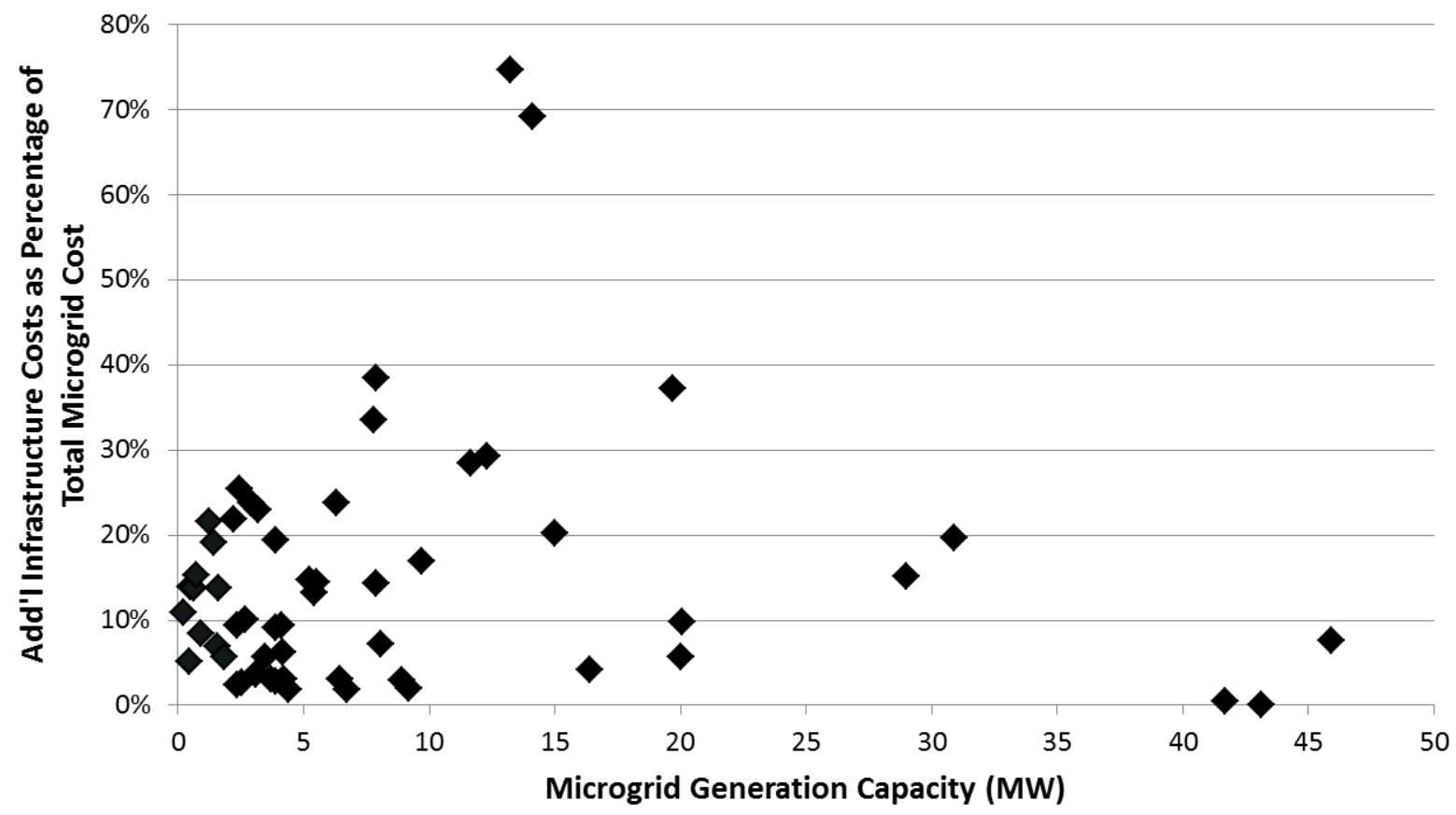

Figure A-10. Additional electric infrastructure costs as a percentage of total microgrid cost compared to microgrid capacity for the NY Prize feasibility studies 